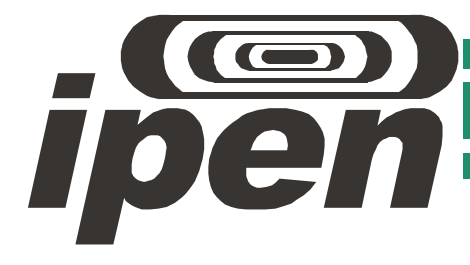

AUTARQUIA ASSOCIADA À UNIVERSIDADE DE SÃO PAULO

DESENVOLVIMENTO DE UM SIMULADOR ANTROPOMÓRFICO PARA SIMULAÇÃO E MEDIDAS DE DOSE E FLUXO DE NÊUTRONS NA INSTALAÇÃO PARA ESTUDOS EM BNCT

Rafael Oliveira Rondon Muniz

Dissertação apresentada como parte

dos requisitos para obtenção do Grau

de Mestre em Ciências na Área de Tecnologia Nuclear - Reatores

Orientador:

Prof. Dr. Paulo Rogério Pinto Coelho

São Paulo

$16 / 7 / 2010$ 
INSTITUTO DE PESQUISAS ENERGÉTICAS E NUCLEARES

Autarquia Associada à Universidade de São Paulo

DESENVOLVIMENTO DE UM SIMULADOR ANTROPOMÓRFICO PARA SIMULAÇÃO E MEDIDAS DE DOSE E FLUXO DE NÊUTRONS NA INSTALAÇÃO PARA ESTUDOS EM BNCT

Rafael Oliveira Rondon Muniz

Dissertação apresentada como parte dos requisitos para obtenção do Grau de Mestre em Ciências na Área de Tecnologia Nuclear - Reatores

Orientador:

Dr. Paulo Rogério Pinto Coelho

São Paulo 
Dedico este trabalho aos meus pais, Wanderley $e$ Cecília, com todo amor $e$ carinho. 


\section{Agradecimento}

Aos meus pais Wanderley e Cecília, pelo apoio sem o qual não conseguiria realizar este trabalho.

Ao meu orientador Dr. Paulo Rogério Pinto Coelho por toda dedicação em me orientar em todas as etapas deste trabalho, os meus sinceros agradecimentos.

À minha avó Palmira Gomes Muniz pelo apoio e incentivo.

À minha irmã Rafaela pelo apoio, meu muito obrigado.

A pesquisadora Graciete Simões de Andrade e Silva por toda ajuda, com a simulação da instalação e o programa DOT 3.5.

Ao Walmir Máximo Torres que me ajudou com o material necessário para a construção do Simulador Antropomórfico.

À Orlando Nogueira da Silva pela ajuda no projeto do Simulador Antropomórfico.

À Gabriel Angelo por toda ajuda no projeto e teste, do simulador antropomórfico na instalação.

Ao pesquisador Claudio Antonio Federico do Instituto de Estudos Avançados (IEAv), que concedeu a leitora de TL, sem a qual não seria possível o trabalho com os dosímetros termoluminescentes.

À Samuel Carracciolli Santos pela manutenção da leitora de TLDs.

Aos colegas de pós-graduação do Centro de Engenharia Nuclear em especial: Douglas Borges Domingos, Thiago Carlucci, Pedro Carlos Russo Rossi, Felipe Massicano, 
Luís Felipe Liambos Mura, Felipe Belonsi de Cintra, Gregório Soares de Souza, Talita Salles Coelho, Paula Cristina Guimarães Antunes, e Ariane Tada.

Ao Dr. Ulysses d'Utra Bitelli chefe do reator IPEN/MB-01, pela ajuda na utilização do laboratório de espectrometria gama.

À Elizabeth S. R. Somessari e a Carlos Gaia da Silveira do Centro de tecnologia das Radiações (CTR) do IPEN pelas irradiações dos TLDs na fonte panorâmica de ${ }^{60} \mathrm{Co}$.

Ao serviço de Proteção Radiológica e Equipe de Operação dos Reatores: IEA-R1 e IPEN/MB-01.

A todos os funcionários do Instituto de Pesquisas Energéticas e Nucleares (IPEN) que direta ou indiretamente ajudaram no desenvolvimento deste trabalho.

À Querina Felisardo de Oliveira por toda ajudada na revisão ortográfica.

Ao Conselho Nacional de Desenvolvimento Científico e Tecnológico (CNPq), pela bolsa de estudo. 


\title{
DESENVOLVIMENTO DE UM SIMULADOR ANTROPOMÓRFICO PARA SIMULAÇÃO E MEDIDAS DE DOSE E FLUXO DE NÊUTRONS NA INSTALAÇÃO PARA ESTUDOS EM BNCT
}

\author{
Rafael Oliveira Rondon Muniz
}

\begin{abstract}
Resumo
A instalação do IPEN para pesquisas em BNCT (Terapia por Captura de Nêutrons em Boro) utiliza o canal de irradiação número 3 do reator IEA-R1, no qual tem-se um campo misto de radiação - nêutrons e gama. As pesquisas em andamento necessitam que o campo de radiação, na posição de irradiação de amostra, tenha na composição os nêutrons térmicos maximizados e os componentes de nêutrons epitérmicos, rápidos e radiação gama minimizados. Este trabalho foi desenvolvido com o objetivo de avaliar se o campo de radiação atual na instalação é adequado aos trabalhos em BNCT. Para cumprir com este objetivo, uma metodologia para dosimetria de nêutrons térmicos e radiação gama em campos mistos de altas doses, que não era disponível no IPEN, foi implantada no Centro de Engenharia Nuclear do IPEN, utilizando dosímetros termoluminescentes - TLDs 400, 600 e 700. Para as medidas de fluxo de nêutrons térmicos e epitérmicos foram utilizados detetores de ativação de ouro aplicando a técnica de razão de cádmio. Um simulador antropomórfico cilíndrico composto de discos de acrílico foi desenvolvido e testado na instalação e para obter valores teóricos do fluxo de nêutrons e a dose ao longo do simulador antropomórfico foi utilizado o código computacional DOT 3.5. Na posição correspondente a aproximadamente metade do comprimento do cilindro do simulador antropomórfico, foram obtidos os seguintes valores: fluxo de nêutrons térmicos $(2,52 \pm$ $0,06) \cdot 10^{8} \mathrm{n} / \mathrm{cm}^{2} \mathrm{~s}$, epitérmicos $(6,17 \pm 0,26) \cdot 10^{7} \mathrm{n} / \mathrm{cm}^{2} \mathrm{~s}$, dose absorvida devido a nêutrons térmicos de $(4,2 \pm 1,8)$ Gy e devido a radiação gama $(10,1 \pm 1,3) \mathrm{Gy}$. Os valores obtidos mostram que os fluxos de nêutrons térmicos e epitérmicos são adequados para os estudos em BNCT, porém, a dose devido a radiação gama está elevada, indicando que a instalação deve ser aprimorada.
\end{abstract}




\title{
DEVELOPMENT OF AN ANTHROPOMORFIC SIMULATOR FOR SIMULATION AND MEASUREMENTS OF NEUTRON DOSE AND FLUX IN THE FACILITY FOR BNCT STUDIES
}

\author{
Rafael Oliveira Rondon Muniz
}

\begin{abstract}
IPEN facility for researches in BNCT (Boron Neutron Capture Therapy) uses IEA-R1 reactor's irradiation channel number 3 , where there is a mixed radiation field - neutrons and gamma. The researches in progress require the radiation fields, in the position of the irradiation of sample, to have in its composition maximized thermal neutrons component and minimized, fast and epithermal neutron flux and gamma radiation. This work was developed with the objective of evaluating whether the present radiation field in the facility is suitable for BNCT researches. In order to achieve this objective, a methodology for the dosimetry of thermal neutrons and gamma radiation in mixed fields of high doses, which was not available in IPEN, was implemented in the Center of Nuclear Engineering of IPEN, by using thermoluminescent dosimeters - TLDs 400, 600 and 700. For the measurements of thermal and epithermal neutron flux, activation detectors of gold were used applying the cadmium ratio technique. A cylindrical phantom composed by acrylic discs was developed and tested in the facility and the DOT 3.5. computational code was used in order to obtain theoretical values of neutron flux and the dose along phantom. In the position corresponding to about half the length of the cylinder of the phantom, the following values were obtained: thermal neutron flux $(2,52 \pm 0,06) \cdot 10^{8} \mathrm{n} / \mathrm{cm}^{2} \mathrm{~s}$, epithermal neutron flux $(6,17 \pm 0,26) \cdot 10^{7} \cdot 10^{6} \mathrm{n} / \mathrm{cm}^{2} \mathrm{~s}$, absorbed dose due to thermal neutrons $(4,2 \pm$ $1,8)$ Gy and $(10,1 \pm 1,3)$ Gy due to gamma radiation. The obtained values show that the fluxes of thermal and epithermal neutrons flux are appropriate for studies in BNCT, however, the dose due to gamma radiation is high, indicating that the facility should be improved.
\end{abstract}




\section{Sumário}

1.INTRODUÇÃO

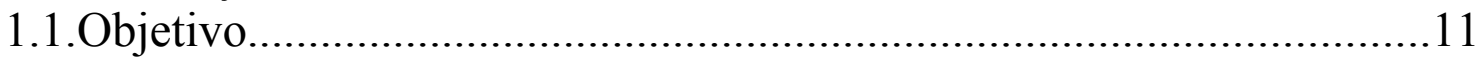

2.DESCRIÇÃO DA INSTALAÇÃO PARA PESQUISA EM BNCT..............13

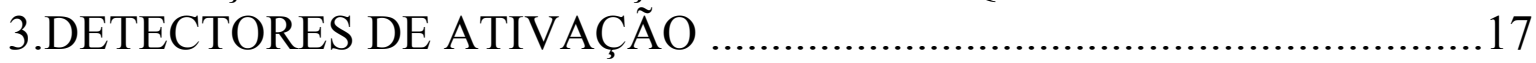

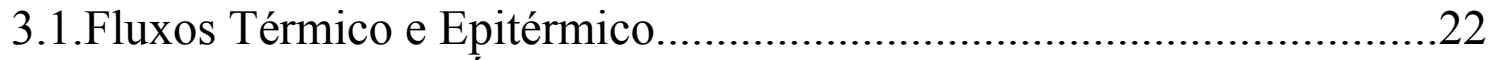

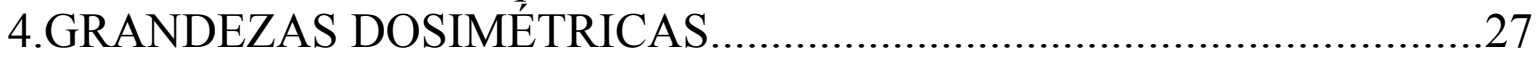

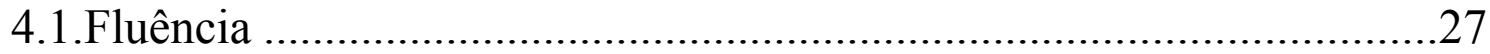

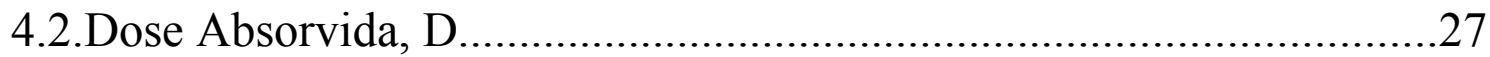

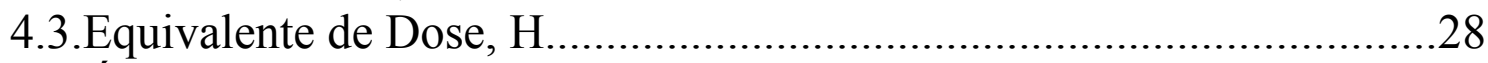

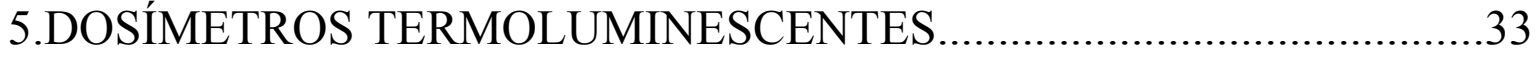

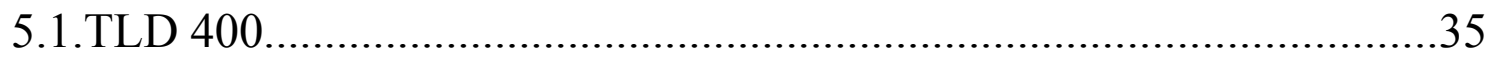

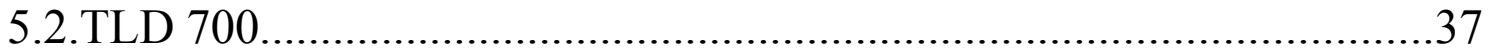

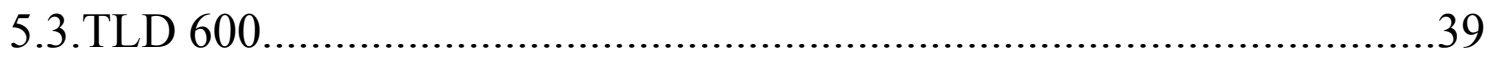

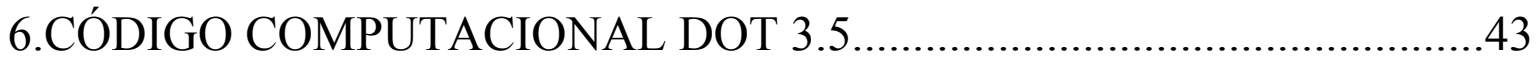

7.SIMULADOR ANTROPOMÓRFICO_....................................................44

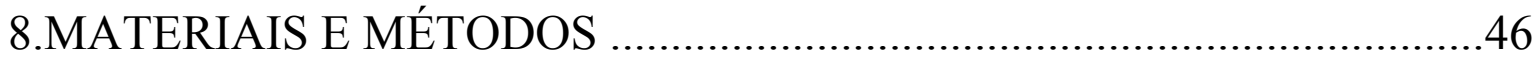

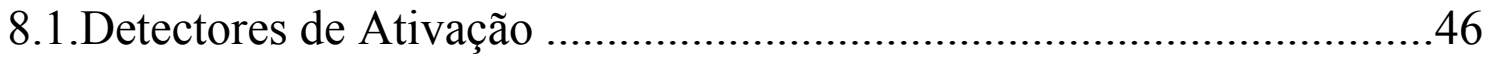

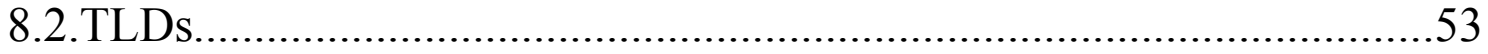

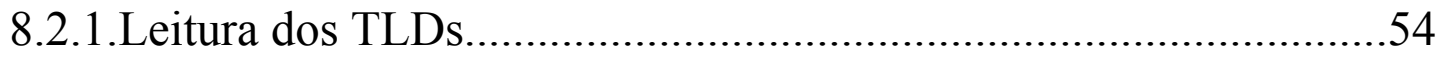

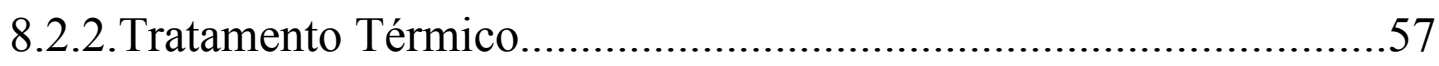

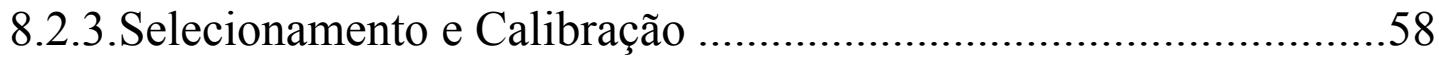

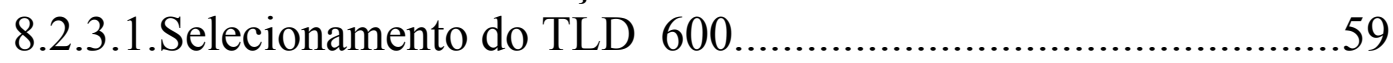

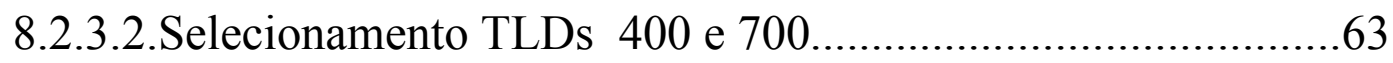

8.2.3.3.Relação de Resposta Gama para os TLDs 600 e 700...............64

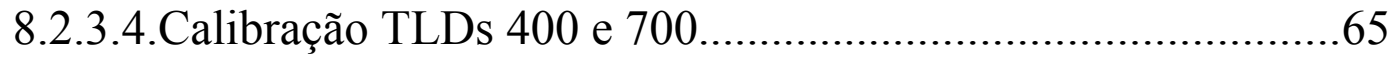

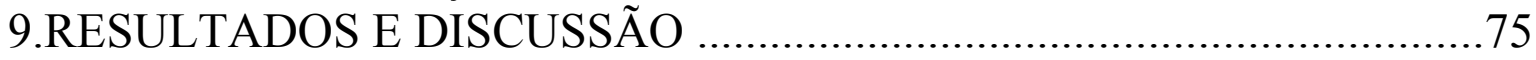

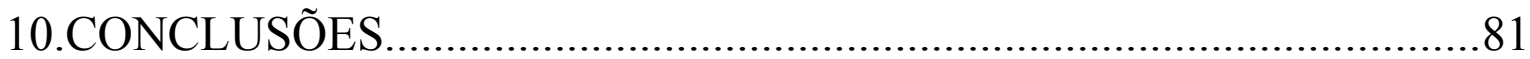

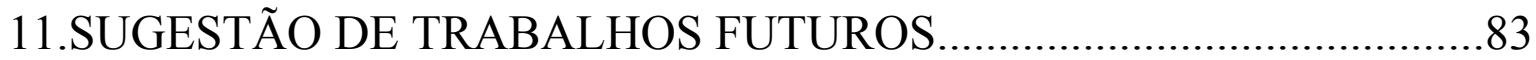

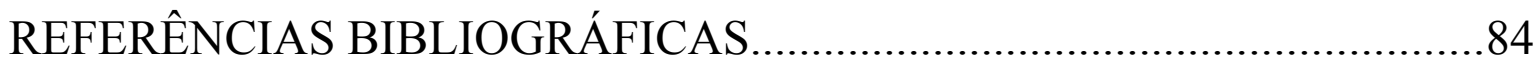




\section{Lista de Figuras}

Figura 1.1. Instalação para pesquisa em BNCT no Reator IEA-R1 ................10

Figura 2.1. Ilustração da vista superior da instalação.......................................13

Figura 2.2. Câmeras e monitor da instalação. .............................................14

Figura 2.3. Sistema para colocação e retirada de amostra. ...............................16

Figura 3.1. Atividade do detetor de ativação ao longo do tempo [7] ..............20

Figura 3.2. Seção de choque de captura radioativa do Ouro-197 [20]............23

Figura 3.3. Seção de choque de absorção total do Cd para nêutrons [20].......24

Figura 5.1. Ilustração do fenômeno termoluminescente. ..................................34

Figura 5.2. Curva de emissão de luz em função da temperatura [14] ...........35

Figura 5.3. Curva TL do TLD 400 [15].........................................................

Figura 5.4. Linearidade dos picos 4, 5 e 6 até 100 Gy do TLD 400 [16]..........36

Figura 5.5. Dependência energética do TLD 400 ............................................

Figura 5.6. Resposta TL para fonte de Cobalto-60........................................38

Figura 5.7. Seção de choque total de absorção do Lítio - 6 [20] .....................40

Figura 5.8. Curva TL do TLD $600 \mathrm{com}$ as duas regiões dosimétricas [18]....41

Figura 7.1. Simulador antropomórfico......................................................4

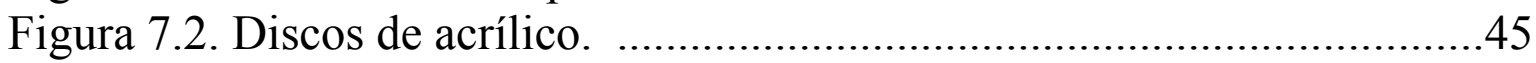

Figura 7.3. Garra com as molas de reforço para segurar o simulador

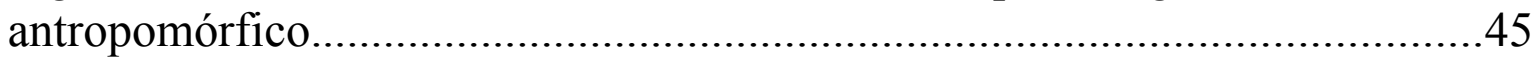

Figura 8.1. Folhas de Ouro e cobertura de Cádmio..........................................46

Figura 8.2. Laboratório de espectrometria gama. ..........................................47

Figura 8.3. Diagrama da eletrônica utilizada para a espectrometria gama......47

Figura 8.4. Tela do programa Maestro para a folha de Ouro irradiada...........49

Figura 8.5. Eficiência absoluta em função da energia do fóton para a $3^{\mathrm{a}}$

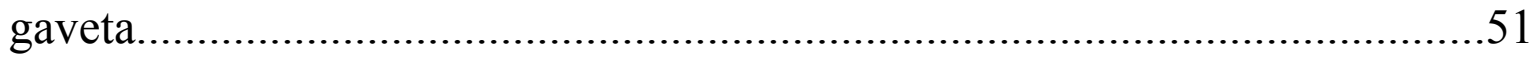

Figura 8.6. Balança Mettler H20..................................................................53

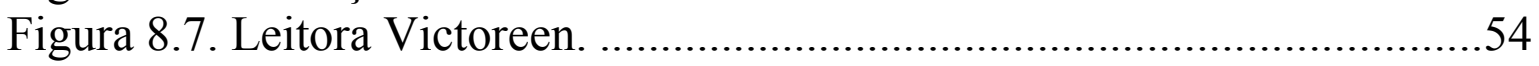

Figura 8.8. Curva TL do TLD 400 - carga por canal....................................56

Figura 8.9. Relação entre as repostas TL do TLD 600 e 700 irradiados na

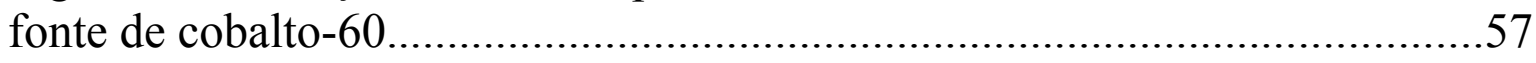

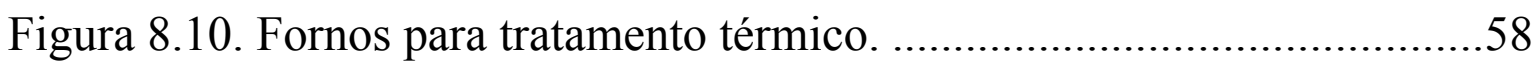

Figura 8.11. Diagrama de reutilização dos TLDs.........................................58

Figura 8.12. Espectro de emissão de nêutrons da fonte AmBe [33]..............60

Figura 8.13. Arranjo utilizado para calibração dos TLDs 600.........................61

Figura 8.14. Resposta média dos TLDs 600 Selecionados..............................62

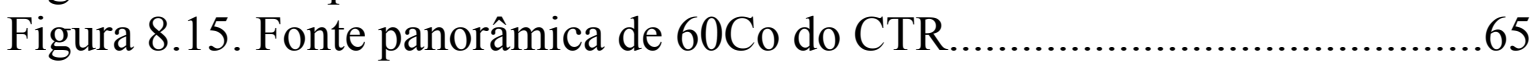

Figura 8.16. Curva de calibração para os TLDS 400.....................................66

Figura 8.17. Curva de calibração dos TLDs 700 com ajuste linear................67

Figura 8.18. Curva de calibração dos TLDs 700 com ajuste polinomial........68 
Figura 8.19. Resposta dos TLDs 600 em função da dose absorvida devido a nêutrons térmicos.

Figura 8.20. Curva TL de um dos TLDs 600 irradiados durante 90 minutos. 72 Figura 8.21. Curva TL dos TLDs 600 irradiados por 30, 90 e 180 minutos... 73 Figura 8.22. Curva de calibração normalizada dos TLDs 600 .74 Figura 9.1. Fluxo térmico medido e calculado ao longo do simulador

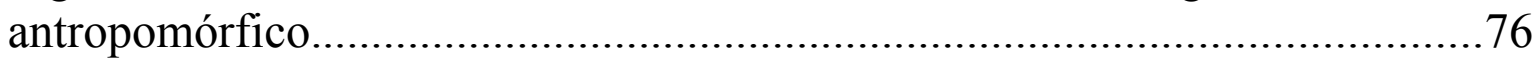
Figura 9.2. Fluxo epitérmico medido e calculado ao longo do simulador

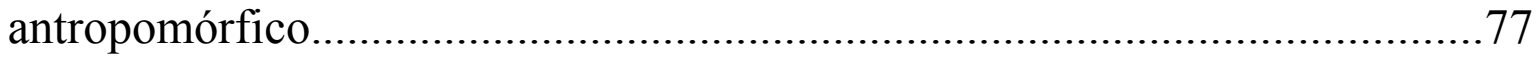
Figura 9.3. Dose absorvida devido aos nêutrons térmicos ao longo do

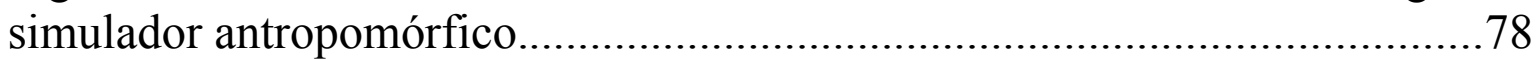
Figura 9.4. Dose absorvida devido à radiação gama ao longo do simulador antropomórfico. 


\section{Índice de tabelas}

Tabela 4.1 - Fator de qualidade para alguns tipos de radiação.........................29

Tabela 4.2 - Fator de qualidade para nêutrons.................................................30

Tabela 4.3 - Coeficiente de conversão da fluência de nêutrons para equivalente de dose ambiental.........................................................................31

Tabela 5.1 - Características básicas dos TLDs................................................33

Tabela 5.2 - Sensibilidade dos TLDs 600 e 700 para nêutrons térmicos.........38

Tabela 8.1 - Energias dos fótons emitidos pela fonte de Európio- $152 \ldots \ldots \ldots \ldots . . .50$

Tabela 8.2 - Valores dos parâmetros do ajuste de eficiência. .........................52

Tabela 8.3 - Eficiência ( $)$ global absoluta do HPGe em função da energia de cada fotópico emitido pela fonte de Európio - 152. ……………….............52

Tabela 8.4 - Parâmetros utilizados na leitora de TLDs...................................55

Tabela 8.5 - Principais energias e intensidades das partículas Alfa emitida

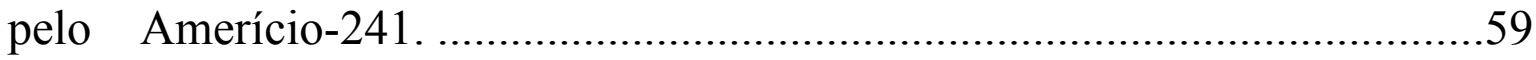

Tabela 8.6 - Principais energias dos fótons emitidos pelo Amerício-241.......59

Tabela 8.7 - Fator individual de cada TLD..................................................63

Tabela 8.8 - Fator gama para cada dose aplicada.........................................64

Tabela 8.9 - Valores dos parâmetros da calibração dos TLDs 400. ................66

Tabela 8.10 - Valores dos parâmetros da calibração linear dos TLDs 700.....67

Tabela 8.11 - Valores dos parâmetros da calibração polinomial dos TLDs 700.

Tabela 8.12 - Dose absorvida devido a nêutrons térmicos, utilizando as folhas

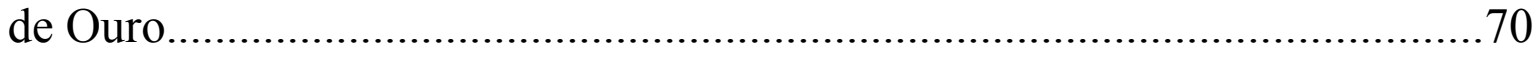

Tabela 8.13 - Valores dos parâmetros da calibração normalizada dos TLDs

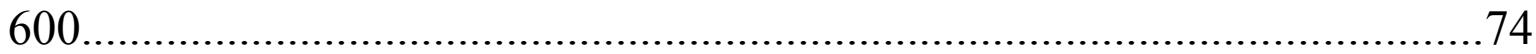




\section{INTRODUÇÃO}

O câncer é uma doença que atinge milhões de pessoas pelo mundo. As pesquisas para o tratamento do câncer se desenvolvem de várias formas, que buscam minimizar os danos nas células sadias e maximizar a destruição de células cancerígenas. As técnicas de combate ao câncer são aplicadas separadamente ou em conjunto dependendo do desenvolvimento do câncer e do órgão atingido. As mais conhecidas são a cirurgia, a radioterapia e a quimioterapia.

Uma técnica que busca aplicar ao máximo a ideia de selecionar as células cancerígenas que serão destruídas e minimizar a destruição das células sadias é a Boron Neutron Capture Therapy (BNCT) que significa Terapia por Captura de Nêutrons por Boro $[1]$.

O conceito de Terapia por Captura de Nêutrons (NCT) foi proposto pela primeira vez logo após a descoberta do nêutron por Chadwick, e baseia-se na alta seção de choque do ${ }^{10} \mathrm{~B}$ para nêutrons térmicos descoberto por Goldhaber em 1934 [2].

A técnica de BNCT consiste resumidamente em injetar no paciente um composto especial contendo boro-10 que é preferencialmente absorvido pelas células cancerígenas. Em seguida irradia-se com nêutrons térmicos (a classificação de nêutrons em térmico, epitérmico e rápido baseia-se na energia cinética deles), o local do tumor, induzindo-se reações dos nêutrons com o boro $-{ }^{10} \mathrm{~B}(\mathrm{n}, \alpha){ }^{7} \mathrm{Li}$, produzindo partículas alfa e íons de ${ }^{7} \mathrm{Li}$, liberando energia cinética das partículas e íons:

$$
\begin{gathered}
{ }_{0}^{1} n+{ }_{5}^{10} B \rightarrow{ }_{3}^{7} L i^{*}+{ }_{2}^{4} \alpha \quad \mathrm{Q}=2,310 \mathrm{MeV}\left({ }^{*} \text { lítio no estado excitado) em } 94 \%\right. \text { das reações. } \\
{ }_{0}^{1} n+{ }_{5}^{10} B \rightarrow{ }_{3}^{7} L i+{ }_{2}^{4} \alpha \quad \mathrm{Q}=2,792 \mathrm{MeV} \text { (lítio no estado fundamental) em } 6 \% \text { das reações. }
\end{gathered}
$$

Estas partículas tem um alcance médio de 12 a $13 \mu \mathrm{m}$ (soma das distâncias percorrida por cada partícula), que é pequeno comparado com a dimensão da célula, e portanto destroem seletivamente as células cancerígenas. 
Em meados de 1936 Gordon Locher propôs os princípios de BNCT [2]. Logo após a proposição da técnica de BNCT para o tratamento de tumores, surgiu o interesse no desenvolvimento da aplicação de BNCT para tratamento do tumor cerebral - glioblastoma multiforme (GBM). Foi postulado que reduzindo a barreira sanguínea do cérebro nas proximidades do tumor aumentaria a seletividade e a concentração de boro no tumor comparado com o cérebro no estado normal. Inicialmente o composto usado para transportar o boro foi sódio tetraborato (borax). Provavelmente o interesse imediato para aplicar BNCT em tumores cerebrais seja o fato desses tumores serem de difícil tratamento pelas técnicas convencionais e portanto, mesmo que a técnica de BNCT tivesse o mínimo de eficácia já seria superior a ineficácia das terapias convencionais.

Com isso, os primeiros testes clínicos foram realizados no Hospital Geral de Massachusetts (MGH) e no Brookhaven National Laboratory (BNL) usando nêutrons térmicos. Estes teste iniciais foram entre 1959 a 1961 e não mostraram nenhuma melhoria na sobrevida dos pacientes ou evidência de eficácia terapêutica [2]. Os resultados iniciais tinham origem em basicamente dois problemas: o composto Borax não tinha uma boa seletividade, e o feixe usado não era tão penetrante - e com isso não atingia o tumor e depositava energia na região sadia.

Desenvolver compostos transportadores de boro mais seletivos e melhorar a concentração de boro são desafios para a melhoria na aplicação da técnica de BNCT. O desenvolvimento nos compostos transportadores de boro-10 que se mostraram mais promissores para o tratamento de tumores cerebrais foram o $\mathrm{BSH}$ e boro-fenilalanina (BPA) que melhoraram a concentração de boro-10 no tecido [2].

Além dos tratamentos de BNCT discutidos, em meados de 1989 Mishima [2] no Japão empregou BPA para o tratamento de câncer de pele (melanoma). Ele relatou o regressão do tumor em resposta ao tratamento de BNCT e reações normais na pele superficial e subcutânea.

Mais recentemente, a atenção se voltou para o uso de nêutrons epitérmicos (com energia entre $0,5 \mathrm{eV}$ e $10 \mathrm{keV}$ ) mais penetrantes em um esforço para reduzir os danos 
na superfície do crânio, mais precisamente no couro cabeludo, sem ter que expor o cérebro, através de cirurgia, ao feixe de nêutrons.

A terapia por BNCT é complexa e a interdisciplinaridade e interação entre muitos profissionais é indispensável. A pesquisa na área de BNCT para tumores cancerígenos tem apresentado grande ímpeto nos últimos anos devido aos resultados promissores obtidos. Já somam mais de 700 pacientes submetidos a essa terapia em todo o mundo [3]. Este panorama internacional tem motivado os pesquisadores do IPENCNEN/SP Instituto de Pesquisas Energéticas e Nucleares a envidar esforços neste campo de pesquisa.

Foi construída uma instalação junto ao reator IEA-R1, Figura 1.1, do IPENCNEN/SP, para a realização de pesquisas neste campo [4]. A construção desta instalação visa realizar pesquisas na área de Física das Radiações e Radiobiologia; permite caracterizar campos de radiação (nêutrons e gamas) adequados para a aplicação da técnica de BNCT, desenvolver estudos de filtros para aumentar a eficiência da técnica, estudos de níveis de dose utilizando "phantoms" e estudos biológicos "in vitro" e "in vivo".

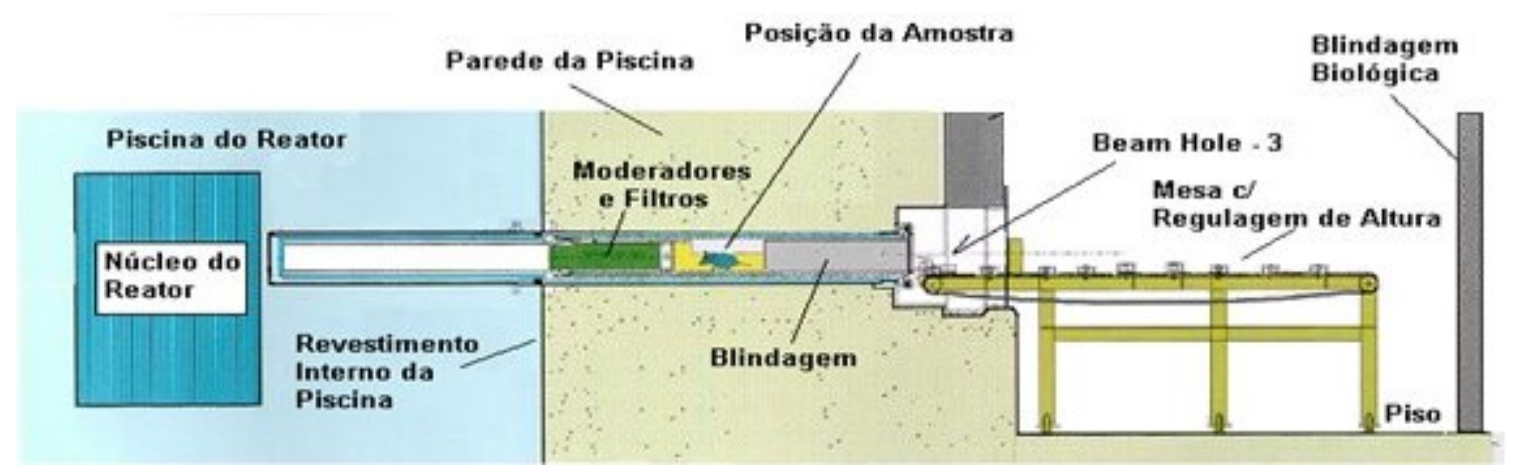

Figura 1.1. Instalação para pesquisa em BNCT no Reator IEA-R1.

$\mathrm{Na}$ técnica de BNCT a reação nuclear básica ocorre com o isótopo ${ }^{10} \mathrm{~B}$ que possui uma alta seção de choque para nêutrons térmicos $(3840 \mathrm{~b}$, b é barns a unidade usual para seção de choque e é $10^{-24} \mathrm{~cm}^{2}$ ). O fluxo de nêutrons térmicos no tumor deve ser intenso, maior ou igual a $5.10^{8} \mathrm{n} / \mathrm{cm}^{2} \mathrm{~s}$, para permitir que os tratamentos completos sejam 
realizados em torno de uma hora. A dose deve ser minimizada nos tecidos sadios próximos ao tumor cancerígeno, e consequentemente, a radiação gama e os fluxos de nêutrons epitérmicos e rápidos devem ser minimizados; ou usando o feixe epitérmico o fluxo de nêutrons epitérmicos tem que ser maximizado e o de térmicos e rápidos minimizado.

A dosimetria de BNCT requer uma análise cuidadosa de diferentes componentes do campo de radiação.

Com o objetivo de avaliar a adequação do campo de radiação às pequisas em BNCT, na instalação, realizou-se irradiações de detectores de ativação (tipo folha). Os detectores ficam ativados tornando-se fontes radioativas emissoras de radiação gama. Após a irradiação, as folhas são analisadas por espectrometria gama, permitindo determinar os fluxos de nêutrons térmicos e epitérmicos.

A dose absorvida devido à radiação gama é determinada utilizando dosímetros termoluminescentes (TLDs).

É necessário a utilização destes detetores (Ativação e TLDs) na instalação devido ao fato que estes detectores são compactos e, portanto, causam pequena perturbação no campo de radiação que se deseja mensurar. Outro ponto importante, é que estes detectores não necessitam de eletrônica no local da medição, como outros tipos de detectores (câmara de ionização, detector proporcional, etc). Esta é uma grande vantagem para a aplicação na instalação devido aos problemas que seriam causados se fosse necessário a colocação de cabeamento do exterior do BH-3 (Beam Hole número 3) até a posição de irradiação de amostra no interior do BH-3.

\subsection{Objetivo}

A instalação do IPEN para pesquisas em BNCT utiliza o canal de irradiação número 3 do reator IEA-R1, na qual se tem um campo misto de radiação - nêutrons e gama. Nos estudos de BNCT (em andamento na instalação), é essencial que o campo de radiação, na posição de irradiação de amostra, seja maximizado na sua componente de nêutrons térmicos e reduzido nas de nêutrons epitérmicos e rápidos e na de radiação gama. 
Este trabalho foi proposto com o objetivo de avaliar se o campo de radiação é adequado aos trabalhos em BNCT. Para tanto três metas foram estabelecidas:

$1^{\circ}$ ) implantar, no Centro de Engenharia Nuclear do IPEN, uma metodologia para dosimetria de nêutrons térmicos e radiação gama em campos mistos de altas doses, utilizando dosímetros termoluminescentes, tendo em vista que esta metodologia não é disponível no IPEN para estas condições;

$2^{\circ}$ ) realizar medidas de fluxo de nêutrons térmicos e epitérmicos com detetores de ativação através da técnica de razão de cádmio e;

$3^{\circ}$ ) desenvolver e testar um simulador antropomórfico para a instalação de BNCT.

O desenvolvimento deste trabalho permitirá ao grupo de estudos sobre BNCT do IPEN avaliar se o campo de radiação na posição de irradiação de amostras é adequado às necessidades do estudo em BNCT e planejar as alterações necessárias para melhor adequação da instalação. 


\section{DESCRIÇÃO DA INSTALAÇÃO PARA PESQUISA EM BNCT}

A instalação do IPEN para pesquisas em BNCT utiliza o canal de irradiação número 3 (Beam Hole número 3, BH-3) do reator IEA-R1 com comprimento de 261,5cm e diâmetro interno útil de $12,8 \mathrm{~cm}$. Os nêutrons e a radiação gama que escapam do núcleo do reator e entram no BH-3 (Figura 1.1) passam pelos filtros e moderadores que reduzem a energia dos nêutrons epitérmicos e rápidos, além de reduzir a radiação gama que incidem na posição de irradiação de amostra. Na sequência, tem-se a blindagem de chumbo que possui alta eficiência para reduzir a intensidade do feixe de raios gama que sai do BH-3.

A instalação foi projetada para possibilitar a colocação e retirada de amostras do canal de irradiação com o reator em operação. Para tanto, se fez necessário uma blindagem externa (biológica) ao $\mathrm{BH}-3$, (Figura 2.1).

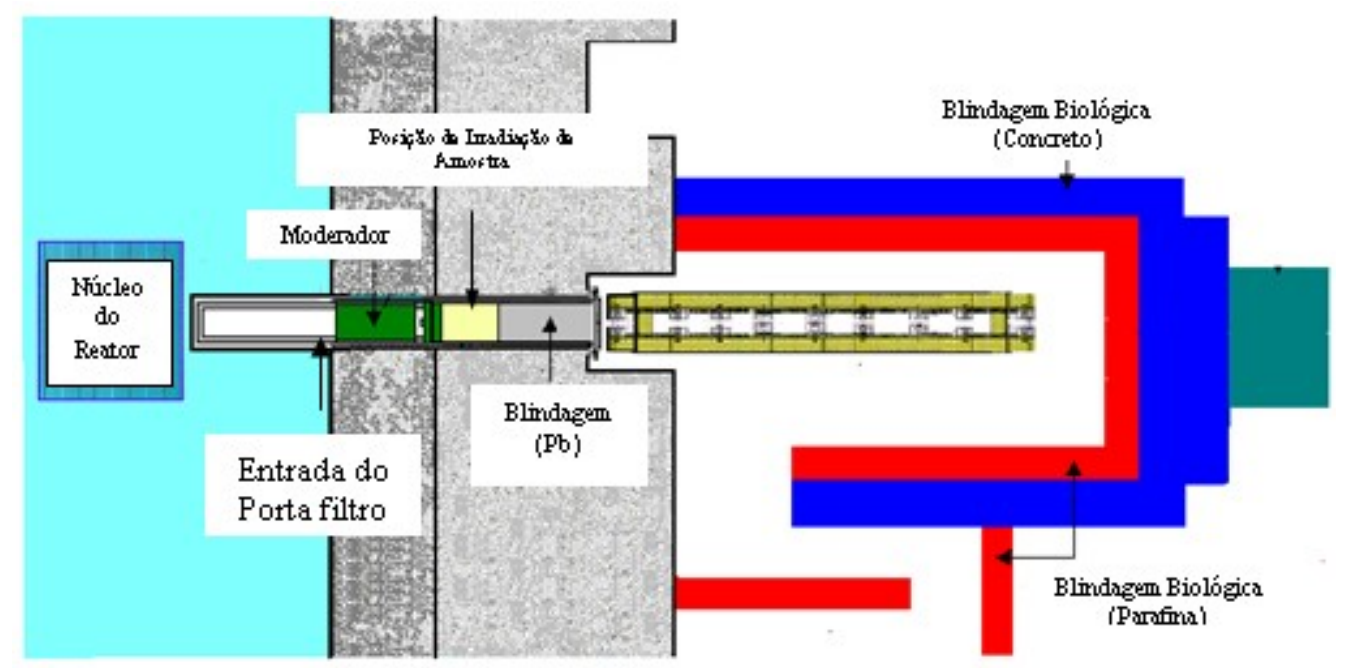

Figura 2.1. Ilustração da vista superior da instalação.

Durante a operação do reator, os níveis de dose são altos na área delimitada pela blindagem biológica (interior da instalação), não sendo possível entrar nesta área quando o reator está em operação, portanto, todo sistema para colocar e retirar amostra e operado do lado de fora da instalação. 
No interior da instalação foram fixadas câmeras de vídeo para acompanhar a colocação e retirada de amostras. As imagens são visualizadas através de um monitor localizado fora da instalação (Figura 2.2).

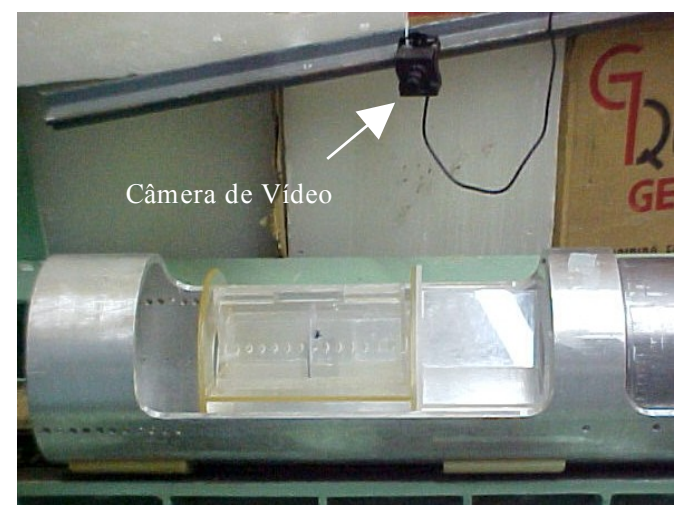

(a)

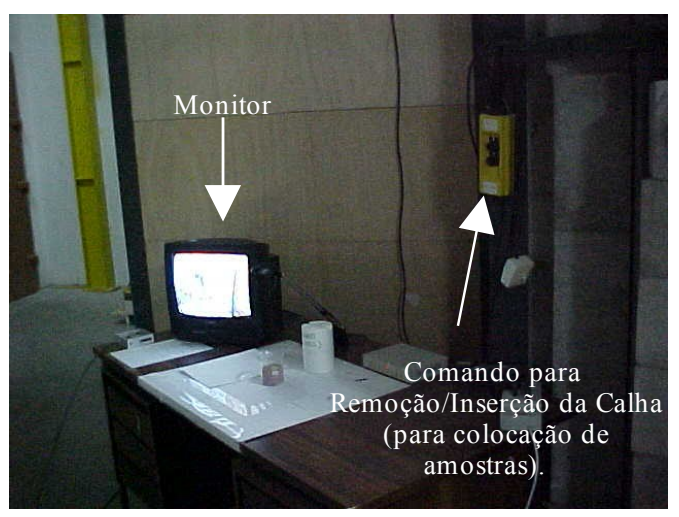

(b)

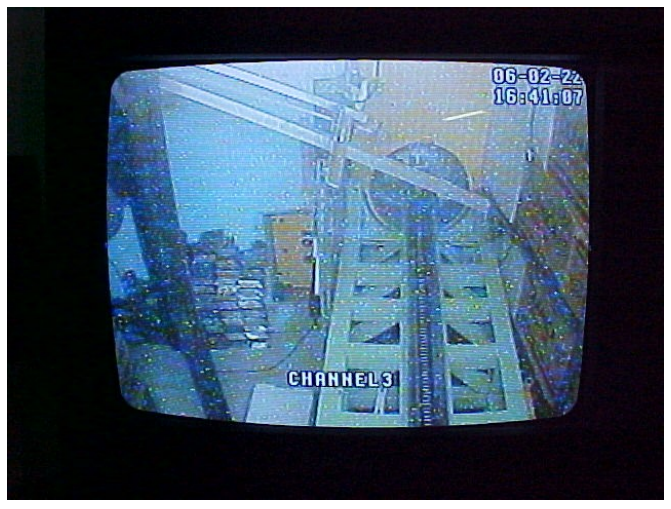

(c)

Figura 2.2. Câmeras e monitor da instalação.

(a) câmera dentro da instalação para a visualização da inserção/retirada de amostra. (b) mesa com o monitor que projeta as imagens das câmeras dentro da instalação. (c) imagem da câmera que mostra o interior da instalação.

Para colocar e retirar amostras na posição de irradiação, com o reator em operação, utiliza-se um conjunto de dois sistemas: o primeiro sistema tem controle remoto manual e é constituído de uma garra presa a um carrinho, cabo de aço e um trilho, o segundo sistema é motorizado com comando remoto, para remoção e inserção da calha no BH-3. A operação do conjunto consiste nas seguintes etapas, todas realizadas por comando externo à instalação, Figura 2.2 e 2.3 : 
a) coloca-se a amostra no suporte de amostra;

b) prende-se o suporte na garra, quando esta se encontra fora da instalação (Figura $2.3(\mathrm{a})$ );

c) aciona-se o comando para remoção da calha do interior do BH-3;

d) desce-se o carrinho com a garra pelo trilho até a calha (Figura 2.3 (b));

e) ao chegar à calha, o suporte com a amostra é liberado da garra (Figura 2.3 (c));

f) puxa-se o carrinho para fora da instalação e

g) insere-se a calha no BH-3.

Para retirar a amostra faz-se a operação inversa - etapas c, d, e (pegando a amostra), f e g. O carrinho é empurrado no trilho utilizando-se o cabo de aço de controle da garra. 


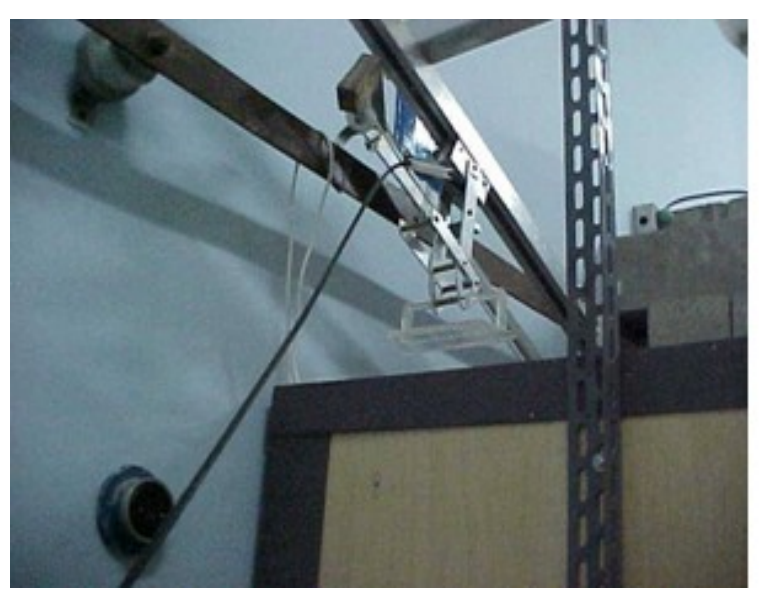

(a)

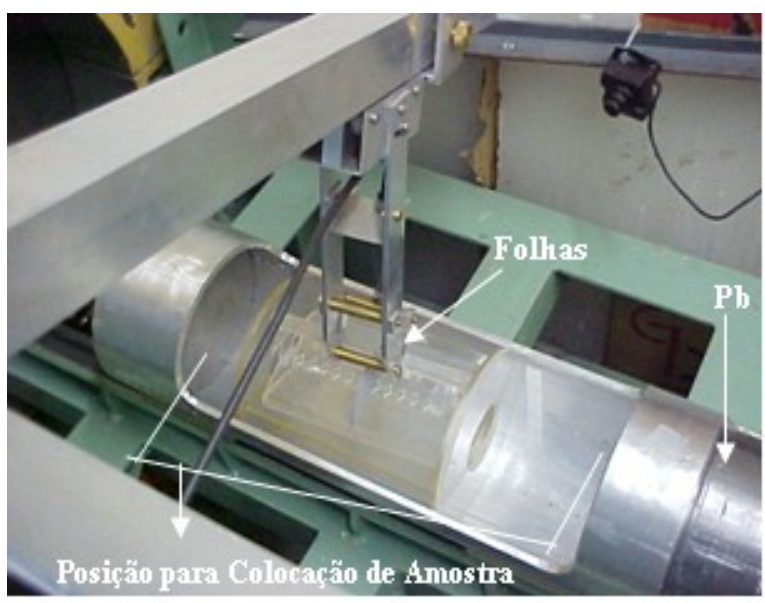

(c)

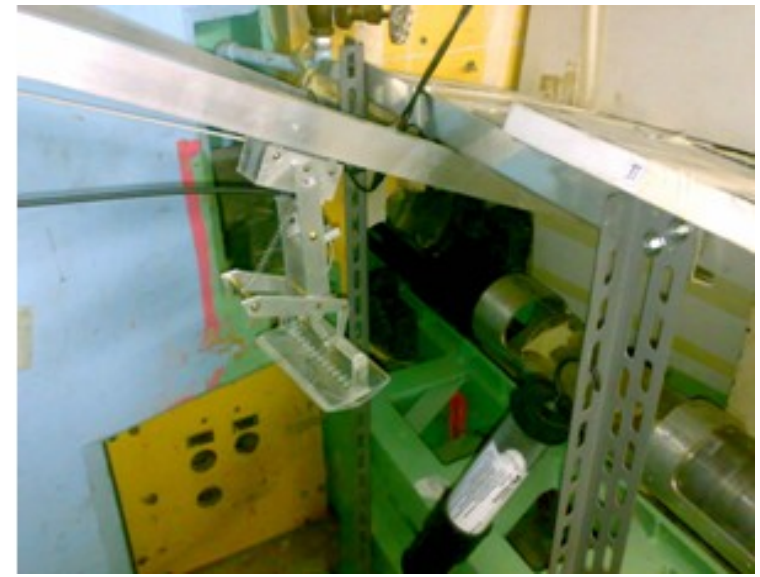

(b)

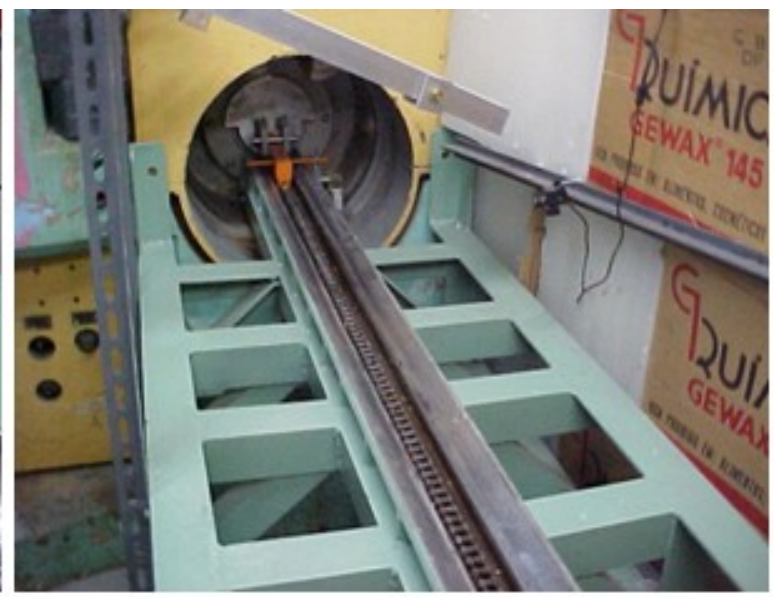

(d)

Figura 2.3. Sistema para colocação e retirada de amostra.

(a) Amostra presa à garra fora da instalação. (b) Garra com a amostra descendo pelo trilho. (c) Amostra na calha para inserção no BH-3. (d) calha inserida no BH-3 para irradiação. 


\section{DETECTORES DE ATIVAÇÃO}

O nêutron é uma partícula que não possui carga elétrica e por isso sua forma de detecção é indireta. Uma forma de detectar nêutrons é através da indução de radioatividade em materiais, ou seja, o nêutron interage com certos materiais, fazendo com que estes fiquem radioativos. Esta técnica é conhecida como análise por ativação [5], e com ela obtém-se informações sobre o campo neutrônico (fluxos de nêutrons) em que os materiais foram expostos.

Neste trabalho utilizaram-se detectores de ativação na forma de folhas (Ouro com $1 \mathrm{~mm}$ de espessura), chamadas de folhas de ativação, com alto grau de pureza. As medidas dos fluxos de nêutrons, pelo método de ativação, são feitas através da contagem da radioatividade induzida nos detetores de ativação utilizando-se espectrometria gama.

A técnica de análise por ativação é bem estabelecida na literatura, além de amplamente aplicada no IPEN [6]. A seguir são apresentadas, resumidamente, as deduções necessárias para obter informações sobre o fluxo de nêutrons como descrito na referência [7].

Submetendo o detector de ativação a um campo neutrônico teremos a taxa de produção dos átomos radioativos $\frac{d n}{d t}$ dada por:

$$
\frac{d n}{d t}=N \sigma_{a c t}^{-} \phi-n \bar{\sigma}_{a} \phi-n \lambda
$$

em que:

$n(t)$ é o numero de átomos radioativos existentes no tempo t;

$N$ é o número inicial de átomos não radioativos;

$\sigma_{a c t}^{-}$é a seção de choque de ativação média; 
$\overline{\sigma_{a}} \quad$ é a seção de choque de absorção média e

$\lambda \quad$ é a constante de decaimento do átomo radioativo formado.

O fluxo total de nêutrons é dado pela integral do fluxo em cada energia $\psi(E) \quad$ :

$$
\phi={ }_{0}^{\infty} \int(E) d E
$$

em que:

$\sigma(E)$ é a seção de choque em função da energia.

A seção de choque média é calculada através de:

$$
\bar{\sigma}=\frac{\int_{0}^{\infty} \sigma(E) \psi(E) d E}{\int_{0}^{\infty} \psi(E) d E} .
$$

A taxa de consumo dos átomos $\frac{d N}{d t}$ é dado por:

$$
\frac{d N}{d t}=-N \overline{\sigma_{T}} \phi
$$

onde:

$\overline{\sigma_{T}}$ é a seção de choque total.

A solução da equação 3.4 é:

$$
N=N_{0} \mathrm{e}^{-\phi \overline{\sigma_{T}}},
$$


em que:

$N_{0} \quad$ é o número inicial de átomos.

Substituindo a equação 3.5 na equação 3.1 obtêm-se:

$$
\frac{d n}{d t}+n\left(\bar{\sigma}_{a} \phi+\lambda\right)=\phi \sigma_{a c t}^{-} N_{0} \mathrm{e}^{\left(-\phi \overline{\sigma_{T}}\right) t}
$$

Resolvendo a equação 3.6 pela técnica do fator integrante ( $\left.\mathrm{e}^{\left(\lambda+\phi \sigma_{a}\right) t}\right)$ tem-se:

$$
\frac{d}{d t}\left[n \mathrm{e}^{\left(\phi \overline{\sigma_{a}}+\lambda\right) t}\right]=\sigma_{a c t}^{-} \phi N_{0} \mathrm{e}^{-\left[-\left(\bar{\sigma}_{a} \phi+\lambda\right)+\bar{\sigma}_{T} \phi\right] t} .
$$

Integrando a equação 3.7 considerando $\quad \overline{\sigma_{a}} \phi \ll \lambda$ e $\quad \overline{\sigma_{T}} \phi \ll \lambda$ tem-se:

$$
n=\frac{\sigma_{a c t} \phi N_{0}}{\lambda}\left(1-\mathrm{e}^{-\lambda t}\right)=\frac{\sigma_{a c t} \phi V d}{\lambda}\left(1-\mathrm{e}^{-\lambda t}\right)
$$

onde:

$$
\begin{array}{ll}
d & \text { densidade de átomos do material; } \\
V & \text { volume do material irradiado; } \\
A_{0}=n \lambda & \text { atividade ao final da irradiação e } \\
\sum_{a c t}=N \sigma_{a c t}^{-} & \text {seção de choque média macroscópica de ativação. }
\end{array}
$$

Portanto, a atividade ao final da irradiação é dada por:

$$
A_{0}=\Sigma_{a c t} \phi V\left(1-\mathrm{e}^{-\lambda t}\right)
$$

Com o cálculo da atividade ao fim da irradiação é obtida a atividade de saturação ( $A_{\infty}$ ), que é a atividade máxima que o detetor atingiria se fosse irradiado por 
um tempo infinito. A atividade de saturação é numericamente igual à taxa de reação a que o detector esteve exposto e é dada por:

$$
A_{0}=A_{\infty}\left(1-\mathrm{e}^{-\lambda t}\right)
$$

Como $A_{\infty}=\Sigma_{a c t} \phi V$, substituindo na equação 3.10 obtêm-se o fluxo expresso por:

$$
\phi=\frac{A_{\infty}}{\sum_{a c t} V} .
$$

A Figura 3.1 mostra os principais momentos do processo: atividade da folha ao final da irradiação (A), atividade de saturação $\left(A_{\infty}\right)$ e os intervalos entre: t0 e t1 (o tempo de espera) e entre $\mathrm{t} 1 \mathrm{e} \mathrm{t} 2$ (o tempo de contagem da folha).

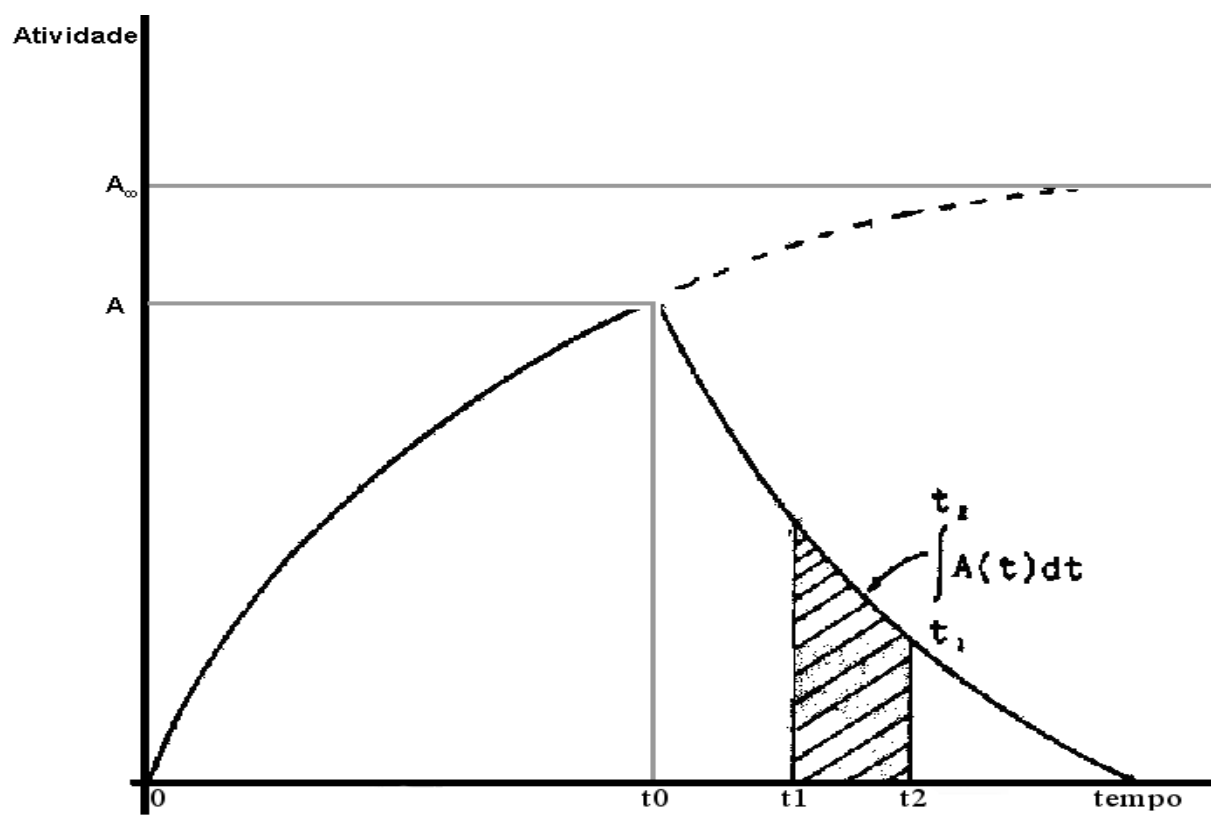

Figura 3.1. Atividade do detetor de ativação ao longo do tempo [7].

A contagem acumulada entre os instantes t 1 e t2 é dada por: 


$$
C=\varepsilon I \int_{t_{1}}^{t_{2}} A e^{-\lambda t} d t+B G
$$

Resolvendo a equação 3.12 teremos a atividade da folha ao final da irradiação como sendo:

$$
A=\frac{\lambda C_{0} e^{\lambda t_{e}}}{\varepsilon I\left(1-e^{-\lambda t_{c}}\right)},
$$

onde:

$\lambda, \quad$ constante de decaimento do radioisótopo formado;

$C_{0}$, é a contagem líquida (descontado o BG) obtida na espectrometria gama;

$t_{e}$, tempo de espera, ou seja, o tempo decorrido entre o final da irradiação $\left(\mathrm{t}_{0}\right)$ e o início da contagem $\left(\mathrm{t}_{1}\right)$;

$\varepsilon, \quad$ eficiência global do sistema de detecção por espectrometria $\gamma$;

I , probabilidade de emissão gama do isótopo formado;

$t_{c}, \quad$ tempo de contagem $\left(\mathrm{t}_{2}-\mathrm{t}_{1}\right)$ na espectrometria gama.

Através da atividade ao final da irradiação obtêm-se a atividade de saturação. A relação entre atividade ao final da irradiação e atividade de saturação é dada por:

$$
A_{\infty}=\frac{A}{1-e^{-\lambda t_{i}}},
$$

em que:

$t_{i}, \quad$ tempo de irradiação.

A razão entre a atividade de saturação e o número de núcleos alvos do detector é utilizada para obter os fluxos de nêutrons e será mostrado a seguir. O número de núcleos alvos em um detetor é calculado por: 


$$
N_{a l v}=\frac{N a \cdot m \cdot f}{a}
$$

onde:

$N_{a l v,} \quad$ número de núcleos alvo;

$\mathrm{Na}, \quad$ Número de Avogadro;

m, massa da folha de ativação;

$f$ fração isotópica;

a, peso atômico do núcleo alvo.

\subsection{Fluxos Térmico e Epitérmico}

A classificação de nêutrons em térmico, epitérmico e rápido baseia-se na energia cinética deles. Os intervalos de energia de cada região dependem da técnica de medida utilizada. Neste trabalho a classificação usada para cada região foi: nêutrons térmicos até $0,5 \mathrm{eV}$, nêutrons epitérmicos entre $0,5 \mathrm{eV}$ e $10 \mathrm{keV}$ e nêutrons rápidos acima de $10 \mathrm{keV}$. Para determinar o fluxo térmico e epitérmico neste trabalho foi utilizada a técnica de razão de cádmio que consiste em irradiar, em idênticas condições, uma folha de ouro coberta com cádmio e outra sem cobertura de cádmio (folha nua); o ouro possui alta seção de choque de captura radioativa, tanto na região térmica como na região epitérmica (Figura $3.2)$. 


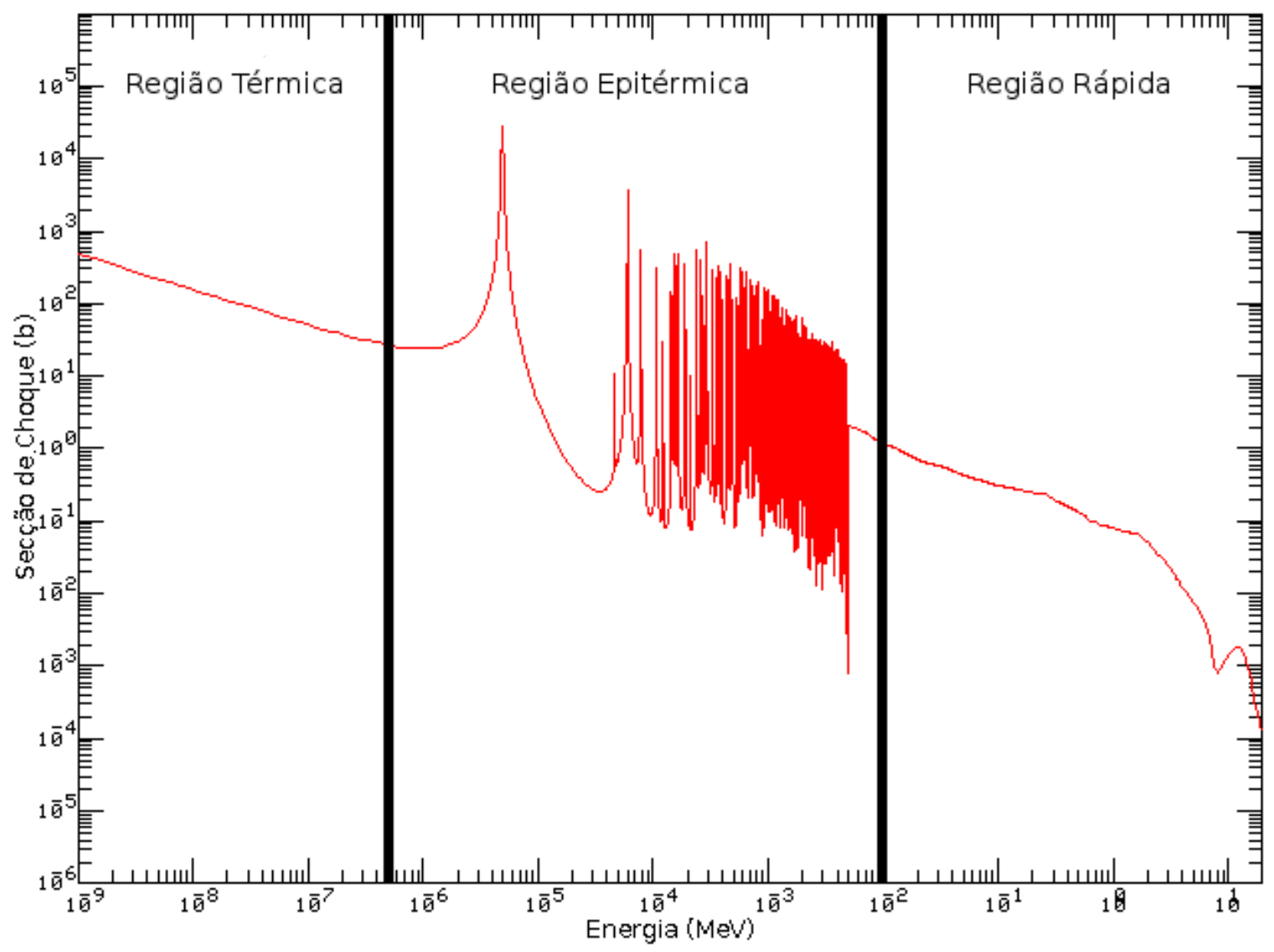

Figura 3.2. Seção de choque de captura radioativa do Ouro-197 [20].

O cádmio atua como um filtro absorvendo os nêutrons térmicos (nêutrons de até $0,5 \mathrm{eV}$ ) devido à sua alta seção de choque de absorção na região térmica (Figura 3.3), então a folha de ouro com cobertura de cádmio preferencialmente sofrerá reações devido aos nêutrons epitérmicos. Fazendo-se a razão entre as atividades induzidas nas folhas de ouro, com e sem cobertura de Cádmio, obtêm-se os fluxos térmico e epitérmico. 


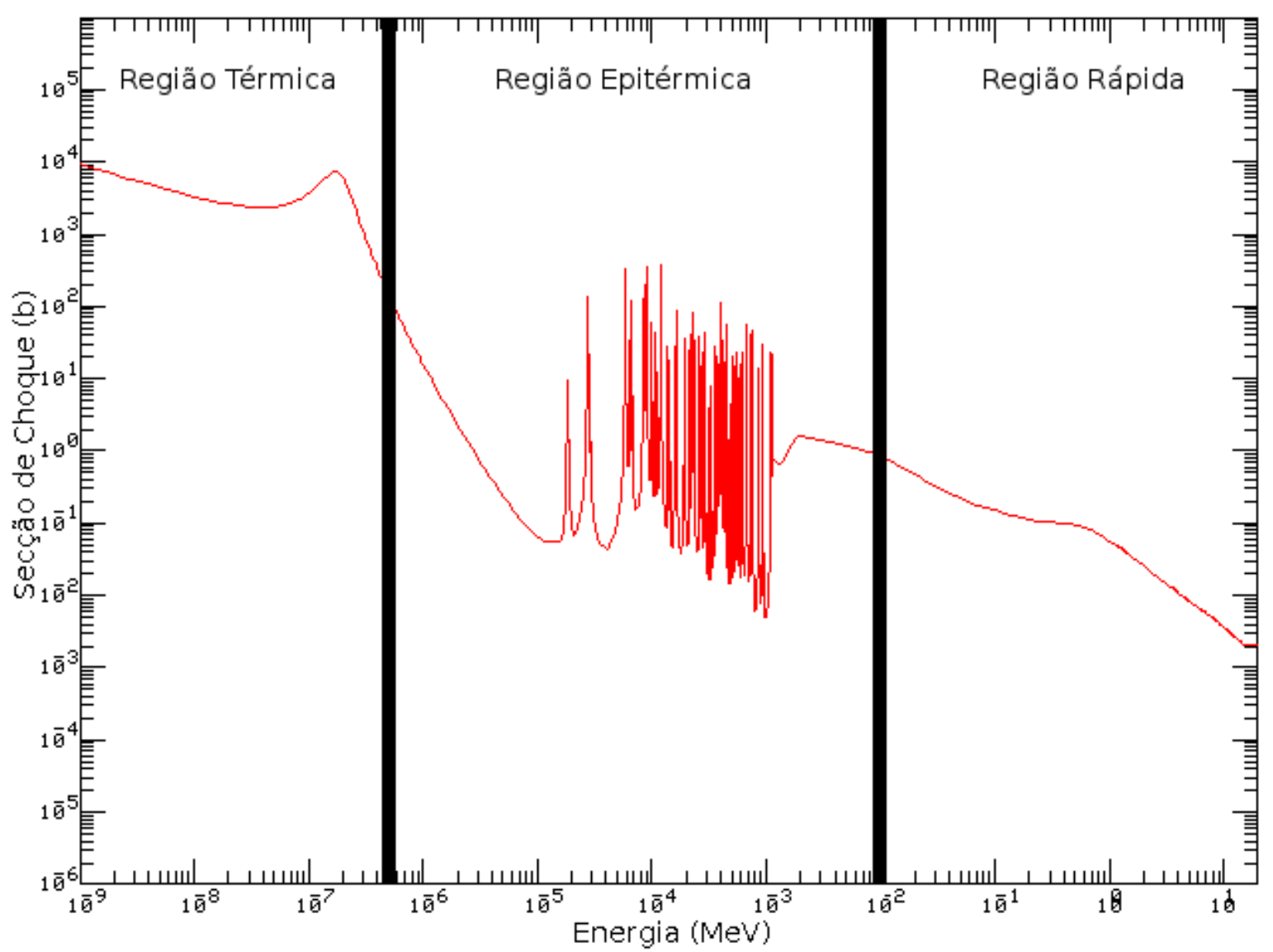

Figura 3.3. Seção de choque de absorção total do Cd para nêutrons [20].

A atividade de saturação da folha sem cobertura de cádmio é devido aos nêutrons térmicos e epitérmicos e é dada por:

$$
A_{\infty}=A_{\infty \text { térmico }}+A_{\infty \text { epitérmico }} .
$$

A razão de cádmio $\left(R_{C d}\right)$ é a razão entre a atividade de saturação da folha nua e a com cobertura de cádmio, assim:

$$
R_{c d}=\frac{A_{\infty \text { nua }}}{A_{\infty C d}}
$$

Devido ao fato do cádmio não ser um filtro ideal, pois também apresenta uma seção de choque para nêutrons epitérmicos, faz com que o cádmio (com $0,5 \mathrm{~mm}$ de espessura) absorva aproximadamente 10\% dos nêutrons epitérmicos [7]. Sendo assim, a 
atividade de saturação da folha coberta com cádmio deve ser corrigida pelo fator de cádmio $\left(\mathrm{F}_{\mathrm{Cd}}\right)$, para se obter a atividade de saturação devido aos nêutrons epitérmicos. Essa correção é dada por:

$$
A_{\infty \text { epitérmico }}=A_{\infty C d} F_{C d}
$$

Utilizando as equações 3.16, 3.17 e 3.18 tem-se a atividade de saturação devido aos nêutrons térmicos e epitérmicos, dadas por:

$$
\begin{gathered}
A_{\infty \text { térmico }}=A_{\infty \text { пиа }}\left(1-\frac{F_{C d}}{R_{C D}}\right) \mathrm{e} \\
A_{\infty \text { epitérmico }}=A_{\infty \text { пиа }} \frac{F_{C d}}{R_{c d}} .
\end{gathered}
$$

Substituindo a equação 3.19 na equação 3.11 obtêm-se o fluxo térmico, dado por:

$$
\phi_{\text {térmico }}=\frac{\left(\frac{A_{\infty \text { nua }}}{N_{\text {alv. }}}\right)\left(1-\frac{F_{C d}}{R_{C d}}\right)}{\sigma_{\text {act }}^{-} K_{\text {térmico }}},
$$

em que:

$$
\begin{aligned}
& \sigma_{a c t}^{-} \quad \text { é a seção de choque microscópica média do ouro na região de absorção do } \\
& \text { Cádmio, e } \\
& \quad \text { e a perturbação que a folha causa no fluxo térmico devido a alta seção de } \\
& \text { choque do ouro. }
\end{aligned}
$$

Na região epitérmica o fluxo varia com o inverso da energia do nêutron, como a região epitérmica cobre uma faixa de energia de algumas décadas é conveniente introduzir a variável letargia $(\mu)$ em que: 


$$
\mu=\ln \frac{E_{0}}{E} \text {, }
$$

onde:

$E_{0} \quad$ energia máxima do nêutron na região, neste trabalho $10 \mathrm{keV}$ e

E energia inferior do nêutron na região, neste caso, a energia de corte do Cádmio.

O fluxo epitérmico é obtido substituindo-se a equação 3.20 na equação $3.11 \mathrm{e}$ considerando a letargia obtendo-se:

$$
\phi_{\text {epitérmico }}=\frac{\left(\frac{A_{\infty \text { nua }}}{N_{\text {alv }}}\right) F_{C d}}{I_{R} R_{C d} K_{\text {epitérmico }}} \mu,
$$

onde:

$I_{R} \quad$ é a integral de ressonância do ouro para nêutrons epitérmicos, e

$K_{\text {epitérmico }}$ é o fator devido a perturbação que o ouro causa no fluxo epitérmico devido a alta seção de choque do ouro. 


\section{GRANDEZAS DOSIMÉTRICAS}

As grandezas físicas Fluência e Dose Absorvida estão associadas à quantidade de radiação que um material foi submetido ou absorveu.

A International Commission on Radiological Protection (ICRP) e a International Commission on Radiation Units and Measurements (ICRU) são as instituições internacionais que dão as definições e unidades das grandezas dosimétricas.

Uma descrição das grandeza utilizadas neste trabalho, conforme apresentada por Tauhata [8], é apresentada a seguir para facilitar a compreensão da metodologia utilizada neste trabalho.

\subsection{Fluência $\Phi$}

A fluência $\Phi$ de partículas é a taxa $\mathrm{dN} / \mathrm{da}$, onde $\mathrm{dN}$ é o número de partículas incidentes sobre uma esfera de seção de área da, medida em unidade de $\mathrm{m}^{2}$.

$$
\phi=\frac{d N}{d a} \quad\left(m^{-2}\right)
$$

$\mathrm{O}$ número de partículas $\mathrm{N}$ pode corresponder ás partículas emitidas, transferidas ou recebidas.

Esta grandeza é muito utilizada na medição de nêutrons. Uma das formas de determinar a fluência de nêutrons por exemplo é medir o fluxo e integrar no tempo.

\subsection{Dose Absorvida, $D$}

Outro efeito da interação da radiação com a matéria é a transferência de energia. Esta nem sempre é toda absorvida, devido à variedade de modos de interação da radiação e à natureza do material. Assim, por exemplo, uma quantidade da energia 
transferida pode ser captada no processo de excitação dos átomos, ou perdida por radiação de freamento (Bremsstrahlung), cujos fótons podem escapar do material.

A relação entre a energia absorvida e a massa do volume de material atingido é a base da definição da grandeza Dose Absorvida. Entretanto, para especificar melhor as variações espaciais e evitar a variação da quantidade de energia absorvida em diferentes pontos do volume do material, a Dose Absorvida é definida como uma função num ponto $\mathrm{P}$, de interesse, ou seja,

$$
D=\frac{d \bar{\varepsilon}}{d m} \quad\left(\mathrm{Jkg}^{-1}=\text { Gray }\right)
$$

onde:

$d \varepsilon$ é a energia média depositada pela radiação no ponto $\mathrm{P}$ de interesse, num meio de massa dm.

\subsection{Equivalente de Dose, $\mathrm{H}$}

$\mathrm{O}$ equivalente de dose determina uma equivalência entre doses de diferentes radiações para produzir o mesmo efeito biológico.

O Equivalente de Dose H, é obtido multiplicando-se a Dose Absorvida, D, pelo fator de qualidade, Q, ou seja:

$$
H=D \cdot Q \quad\left(\mathrm{Jg}^{-1}=\text { sievert }\right)
$$

O fator de qualidade Q é adimensional e constitui um fator de peso proveniente da simplificação dos valores da Eficiência Biológica Relativa (RBE) dos diferentes tipos de radiação na indução de determinado tipo de efeito biológico. Na equivalência, as diferenças entre as radiações foram expressas pelos diferentes valores do LET (Linear Energy Transfer) que é a Transferência linear de energia, ou seja, o valor de Q foi obtido em função do LET. 
A Tabela 4.1 traz os fatores de qualidade para os diversos tipos de radiação menos para nêutrons que será detalhado a seguir.

Tabela 4.1 - Fator de qualidade para alguns tipos de radiação.

\begin{tabular}{lc}
\hline \multicolumn{1}{c}{ Tipo de Radiação } & Q \\
\hline Raios X, Radiação $\gamma$ e elétrons & 1 \\
$\begin{array}{l}\text { Prótons e partículas com uma (1) unidade } \\
\text { de carga e com massa de repouso maior que } \\
\text { uma unidade de massa atômica e de energia } \\
\text { desconhecida }\end{array}$ & 10 \\
$\begin{array}{l}\text { Radiação } \alpha \text { e demais partículas com carga } \\
\text { superior a uma (1) unidade de carga }\end{array}$ & 20 \\
\hline
\end{tabular}

Fonte - Tauhata et al, 2003.

O ICRU 66 traz a determinação das quantidades operacionais de equivalente de dose para nêutrons [9].

As fontes de nêutrons utilizadas em diversas aplicações, como as fontes de Amerício - Berílio, emitem nêutrons com uma distribuição energética que vai de alguns quiloelétron-volt $(\mathrm{keV})$ até megaelétron-volt $(\mathrm{MeV})$. A Tabela 4.2 mostra o fator de qualidade médio para uma distribuição de energia de nêutrons [10]. 
Tabela 4.2 - Fator de qualidade para nêutrons.

\begin{tabular}{cc}
\hline Energia $(\mathbf{M e V})$ & $\bar{Q}$ \\
\hline $2,5.10^{-8}$ & 2 \\
$1.10^{-7}$ & 2 \\
$1.10^{-6}$ & 2 \\
$1.10^{-5}$ & 2 \\
$1.10^{-4}$ & 2 \\
$1.10^{-3}$ & 2 \\
$1.10^{-2}$ & 2,5 \\
$1.10^{-1}$ & 7,5 \\
$5.10^{-1}$ & 11 \\
1 & 11 \\
2,5 & 9 \\
5 & 8 \\
7 & 7 \\
10 & 6,5 \\
14 & 7,5 \\
20 & 8 \\
\hline Fonte - ANSI/ANS 1997. &
\end{tabular}

A grandeza operacional equivalente de dose ambiental, é uma forma global de se obter o equivalente de dose, sem levar em consideração o ângulo de incidência da partícula e o órgão irradiado.

A Tabela 4.3 mostra os valores do coeficiente de conversão $\left(h_{\Phi}\right)$ para, a partir da fluência, se obter o equivalente de dose ambiental dos nêutrons. 
Tabela 4.3 - Coeficiente de conversão da fluência de nêutrons para equivalente de dose ambiental.

\begin{tabular}{|c|c|}
\hline Energia (MeV) & $h_{\Phi} \quad(\mathrm{pSv} / \mathrm{h})$ \\
\hline $1,00.10^{-9}$ & 6,60 \\
\hline $2,53 \cdot 10^{-8}$ & 10,60 \\
\hline $1,00.10^{-7}$ & 12,90 \\
\hline $2,00 \cdot 10^{-7}$ & 13,50 \\
\hline $5,00.10^{-7}$ & 13,60 \\
\hline $1,00.10^{-6}$ & 13,30 \\
\hline $2,00.10^{-6}$ & 12,90 \\
\hline $5,00.10^{-6}$ & 12,00 \\
\hline $1,00.10^{-5}$ & 11,30 \\
\hline $5,00.10^{-5}$ & 9,90 \\
\hline $1,00.10^{-4}$ & 9,40 \\
\hline $5,00.10^{-4}$ & 8,30 \\
\hline $1,00.10^{-3}$ & 7,90 \\
\hline $5,00.10^{-3}$ & 8,00 \\
\hline $1,00.10^{-2}$ & 10,50 \\
\hline $2,00.10^{-2}$ & 16,60 \\
\hline $3,00.10^{-2}$ & 23,70 \\
\hline $5,00.10^{-2}$ & 41,10 \\
\hline $7,00.10^{-2}$ & 60,00 \\
\hline $1,00.10^{-1}$ & 88,00 \\
\hline $2,00.10^{-1}$ & 170 \\
\hline $3,00.10^{-1}$ & 233 \\
\hline $5,00.10^{-1}$ & 322 \\
\hline $7,00.10^{-1}$ & 375 \\
\hline $9,00.10^{-1}$ & 400 \\
\hline $1,00.10^{0}$ & 416 \\
\hline $2,00.10^{0}$ & 420 \\
\hline $3,00.10^{0}$ & 412 \\
\hline $4,00.10^{0}$ & 408 \\
\hline $5,00.10^{0}$ & 405 \\
\hline $6,00.10^{0}$ & 400 \\
\hline $7,00.10^{0}$ & 405 \\
\hline $8,00.10^{0}$ & 409 \\
\hline $9,00.10^{0}$ & 420 \\
\hline $1,00.10^{1}$ & 440 \\
\hline
\end{tabular}


Para obter o equivalente de dose ambiental multiplica-se a fluência pelo coeficiente de conversão dado na tabela Tabela 4.3:

$$
H^{*}=\Phi . h_{\Phi}
$$




\section{DOSÍMETROS TERMOLUMINESCENTES.}

Os dosímetros termoluminescentes (TLDs) foram utilizados para determinar a dose absorvida devido à radiação gama e para o estudo da dose devido a nêutrons térmicos.

Foram utilizados TLDs comerciais fabricados pela Thermoelectric, com $0,32 \times 0,32 \times 0,89 \mathrm{~cm}^{3}$ de dimensão. Na Tabela 5.1 estão as informações básicas dos TLDs usados neste trabalho.

Tabela 5.1 - Características básicas dos TLDs.

\begin{tabular}{|c|c|c|c|c|c|c|c|}
\hline Tipo & Materiais & $\stackrel{*}{*}$ & $\begin{array}{l}\text { Espectro de } \\
\text { emissão TL }\end{array}$ & $\begin{array}{c}\text { Sensibilidade } \\
\text { para } \\
{ }^{60} \mathrm{Co} \mathrm{com} \\
\text { relação } \\
\text { ao LiF }\end{array}$ & $\begin{array}{l}\text { Resposta de } \\
\text { energia } \\
30 \mathrm{keV} /{ }^{60} \mathrm{Co}\end{array}$ & $\begin{array}{l}\text { Intervalo } \\
\text { de uso }\end{array}$ & Esmaecimento \\
\hline TLD-600 & $\begin{array}{l}\mathrm{LiF}: \mathrm{Mg}, \mathrm{Ti} \\
\text { (isótopo }{ }^{6} \mathrm{Li} \text { ) }\end{array}$ & 8.2 & $\begin{array}{l}3500-6000 \mathrm{~A} \\
(4000 \max )\end{array}$ & 1.0 & 1.25 & $\begin{array}{l}1 \mathrm{O} \mu \mathrm{Gy}- \\
10 \mathrm{~Gy}\end{array}$ & $\begin{array}{c}5 \% / \text { ano a } 20^{\circ} \mathrm{C} \\
\text { (corrigido) }\end{array}$ \\
\hline TLD 700 & $\begin{array}{l}\mathrm{LiF}: \mathrm{Mg}, \mathrm{Ti} \\
\text { (isótopo }{ }^{7} \mathrm{Li} \text { ) }\end{array}$ & 8.2 & $\begin{array}{l}3500-6000 \mathrm{~A} \\
(4000 \max )\end{array}$ & 1.0 & 1.25 & $\begin{array}{l}10 \mu \mathrm{Gy}- \\
10 \mathrm{~Gy}\end{array}$ & $\begin{array}{c}5 \% / \text { ano a } 20^{\circ} \mathrm{C} \\
\text { (corrigido) }\end{array}$ \\
\hline TLD400 & $\mathrm{CaF}_{2}: \mathrm{Mn}$ & 16.3 & $\begin{array}{l}4400-6000 \mathrm{~A} \\
(5000 \text { max })\end{array}$ & 10 & $\sim 13$ & $\begin{array}{l}0.1 \mu \mathrm{Gy}- \\
100 \mathrm{~Gy}\end{array}$ & $\begin{array}{l}8 \% \text { nas } 1^{\text {as }} 24 \mathrm{~h} \\
12 \% \text { em } 3 \text { meses }\end{array}$ \\
\hline
\end{tabular}

Fonte - Thermo Electron Corporation $<$ www.thermo.com/rmp $>$

* Número atômico efetivo

Os dosímetros termoluminescentes são detetores sólidos em que na sua rede cristalina é adicionado impurezas que geram regiões de armadilhamento de elétrons entre a banda de valência e a banda de condução (níveis de energia). Ao se expor o TLD à radiação ionizante, tem-se a probabilidade da radiação fazer com que um elétron da banda de valência passe para a banda de condução. O elétron ao retornar para a banda de valência tem a probabilidade de ficar "armadilhado". Ao estimular o TLD termicamente, através de aquecimento adequado, os elétrons "armadilhados" são liberados das armadilhas e vão para a banda de condução e logo após retornam para a banda de valência ou são rearmadilhados. 
Neste processo emitem fótons, pois vão de um nível energético maior para um nível de energia menor. Este processo é ilustrado pela Figura 5.1 [12].
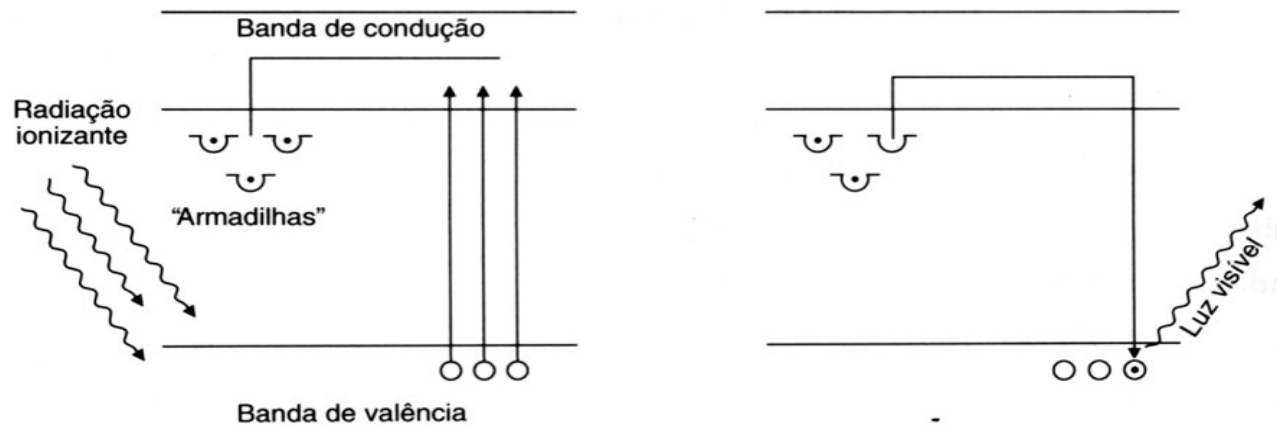

Figura 5.1. Ilustração do fenômeno termoluminescente.

Lado esquerdo - devido à radiação ionizante os elétrons saem da banda de valência e vão para a banda de condução. Ao retornarem da banda de condução ficam armadilhados. Lado direito - quando o TLD é aquecido os elétrons saem das armadilhas, vão para a banda de condução, e retornam para a banda de valência emitindo fóton [13].

A quantidade de fótons emitidos pelo TLD é proporcional a dose de radiação a que o dosímetro foi exposto.

Na leitora de TLD o dosímetro termoluminescente é aquecido a uma taxa constante $\left({ }^{\circ} \mathrm{C} / \mathrm{s}\right)$, e conforme a temperatura vai aumentando, aumenta a probabilidade de desarmadilhamento dos elétrons e portanto também aumenta a emissão de luz pelo TLD até atingir um ponto máximo (máxima probabilidade de desarmadilhamento) e então a quantidade de luz diminui formando um pico de emissão (Figura 5.2). O estudo da formação do pico, da emissão de luz, da característica do material termoluminescente é descrito pela teoria dos modelos cinéticos [14]. 


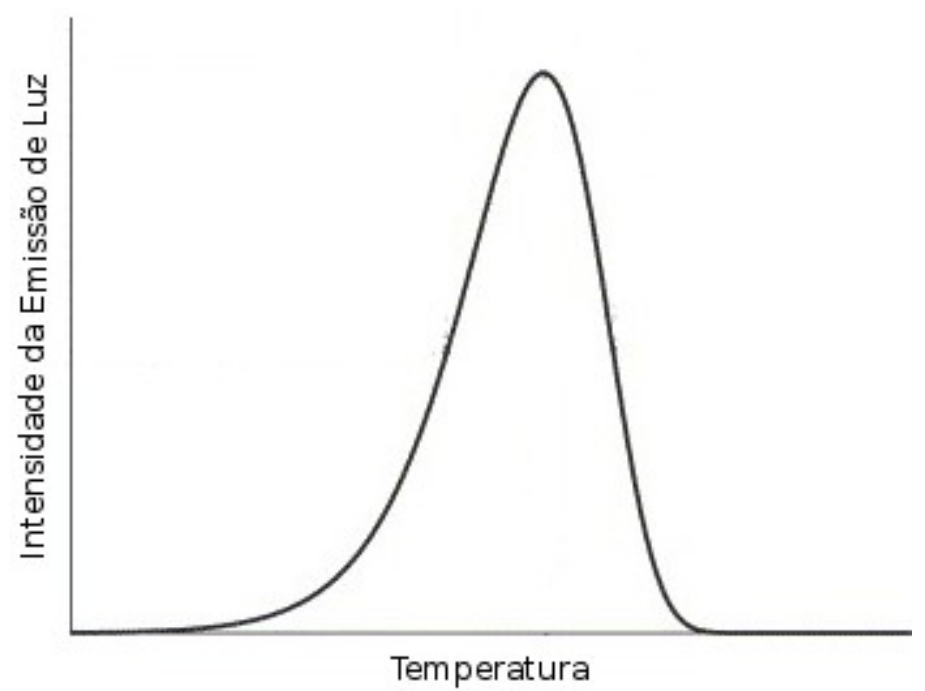

Figura 5.2. Curva de emissão de luz em função da temperatura [14].

A curva termoluminescente (TL) de cada dosímetro termoluminescente é formada por vários picos, e a seguir é apresentado os detalhes de cada tipo de TLD usado neste trabalho, bem como suas respectivas curvas TL.

\subsection{TLD 400}

O fluoreto de cálcio dopado com manganês $\left(\mathrm{CaF}_{2}: \mathrm{Mn}\right)$ é chamado pelo fabricante de TLD 400. Este dosímetro é utilizado para determinar a dose absorvida devido à radiação gama. O TLD 400 possui maior sensibilidade para radiação gama do ${ }^{60} \mathrm{Co}$ quando comparado com os TLDs 600 e 700.

A curva TL do fluoreto de cálcio é constituída de 6 picos como mostra a Figura 5.3. A região do chamado pico dosimétrico é formada pelos picos 4.5 e 6 [15]. As demais regiões constituídas pelos picos 1, 2 e 3 não aparecem na leitura de rotina dos TLDs, principalmente pela taxa de aquecimento usado nas leituras de rotina. 


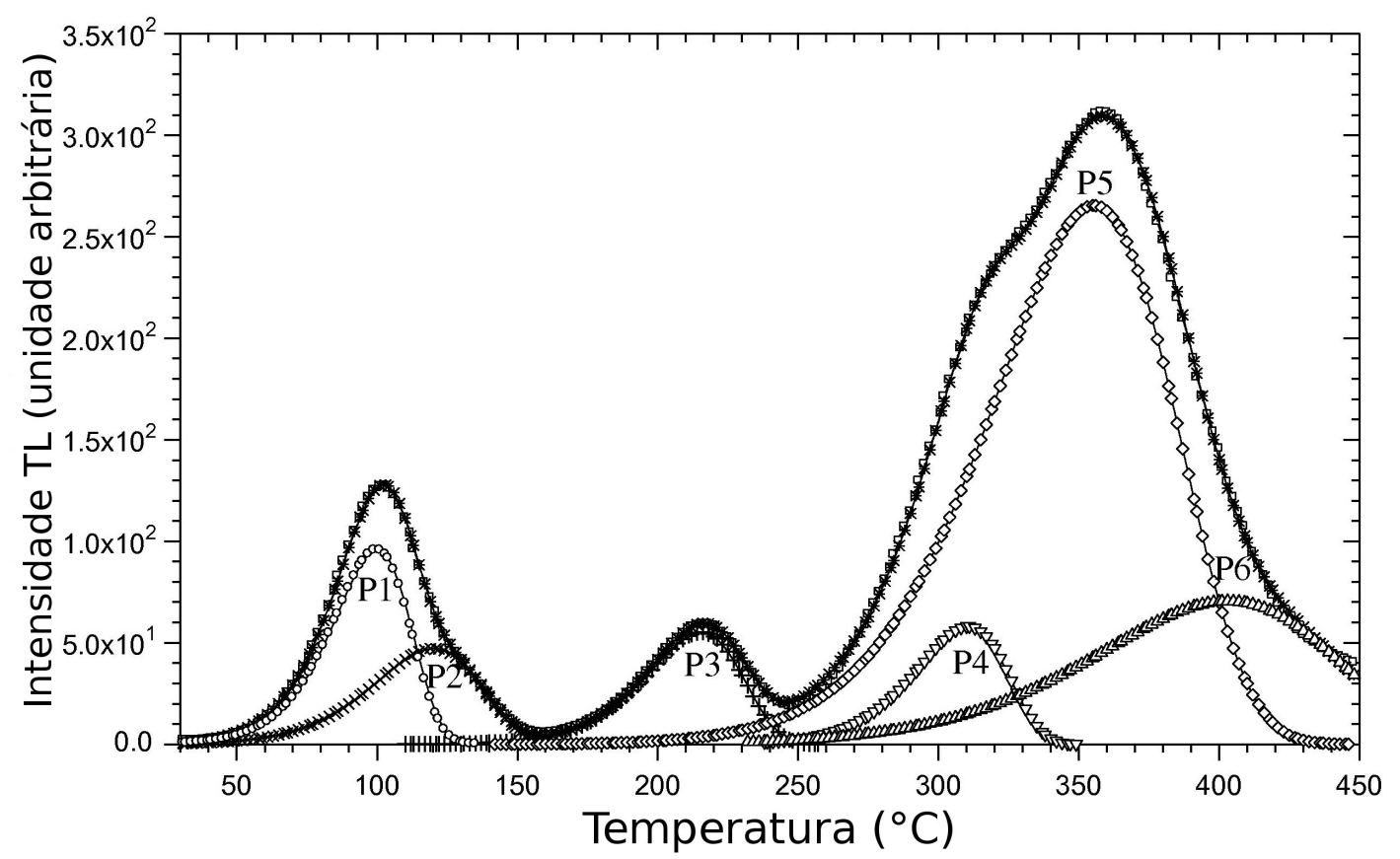

Figura 5.3. Curva TL do TLD 400 [15].

Os picos que formam a região dosimétrica tem resposta linear com a dose absorvida até 100Gy, Figura 5.4, ou seja, TLD 400 tem resposta linear até 100Gy [16].

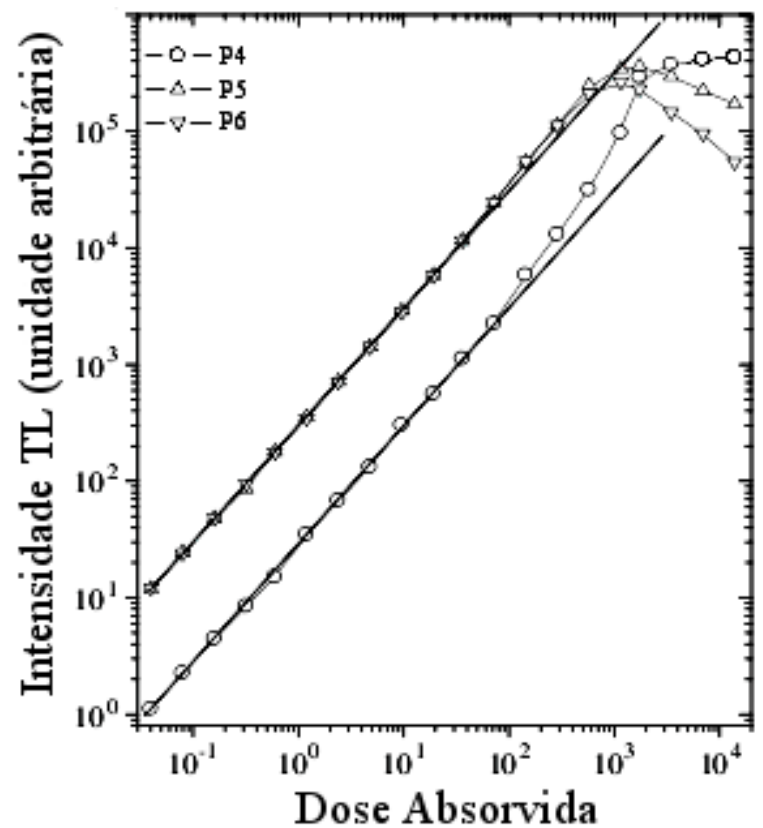

Figura 5.4. Linearidade dos picos 4, 5 e 6 até 100Gy do TLD 400 [16]. 
O conhecimento da dependência energética dos dosímetros é importante para se fazer as considerações entre o campo de radiação usado para calibração e o campo de radiação onde se realizarão as medidas.

O comportamento da dependência energética do fluoreto de cálcio e do sulfato de cálcio é mostrado na Figura 5.5. Até aproximadamente $500 \mathrm{keV}$ é grande a variação da dependência energética do TLD 400; entre $500 \mathrm{keV}$ e $15 \mathrm{MeV}$ a dependência energética é a mesma.

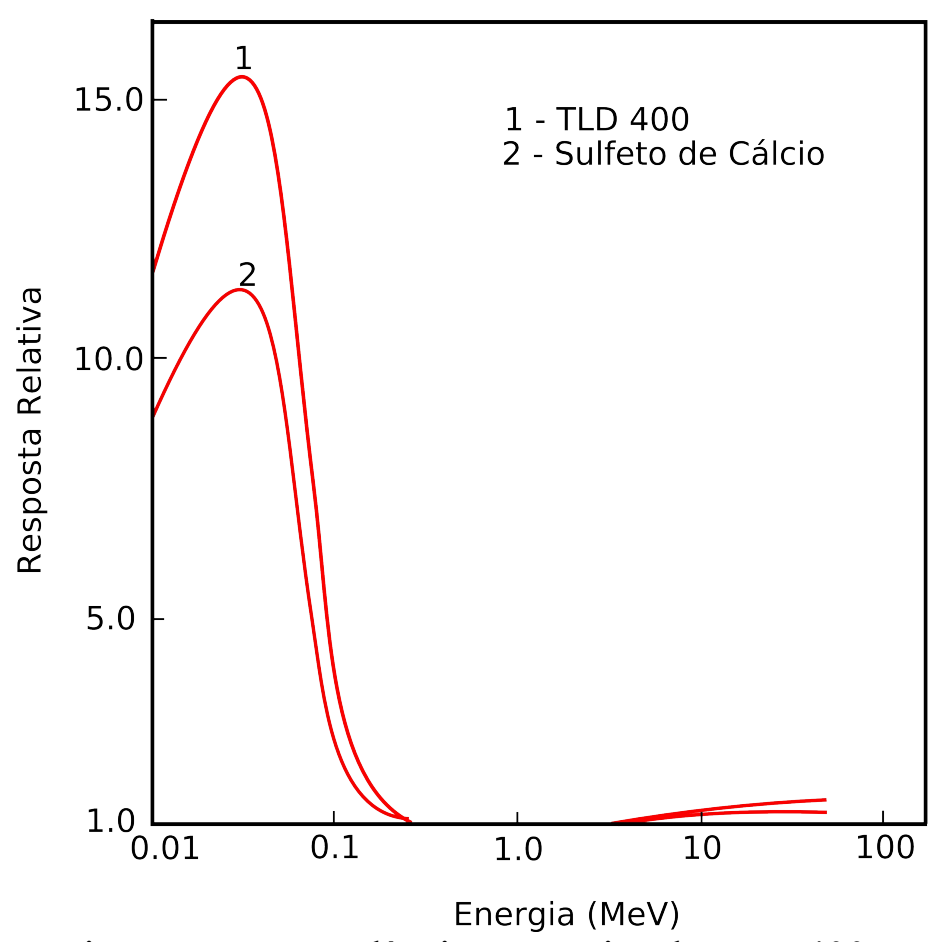

Figura 5.5. Dependência energética do TLD 400.

TLD 400 (1) e a do sulfeto de cálcio (2) [17].

\subsection{TLD 700}

O fluoreto de lítio dopado com magnésio e titânio ( ${ }^{7} \mathrm{LiF}: \mathrm{Mg}$, Ti) na concentração de $99,993 \%{ }^{7} \mathrm{Li}$ e $0,007 \%$ de ${ }^{6} \mathrm{LI}$ é identificado como TLD 700 . A principal aplicação deste TLD é como par do TLD 600 para descontar a reposta, devida a radiação gama do TLD 600 uma vez que o TLD 700 e 600 possuem curvas TL idênticas. A Figura 
5.6, mostra a resposta de três tipos de TL: 600, 700 e MCP (equivalente ao TLD 100, cuja concentração isotópica de ${ }^{6} \mathrm{Li} \mathrm{e}{ }^{7} \mathrm{Li}$ é a natural), para uma fonte de ${ }^{60} \mathrm{Co}$.

Da Figura 5.6 pode-se observar que o TLD 600 e o 700 têm a mesma eficiência, o que para cada lote de pastilhas usado tem que ser verificado.

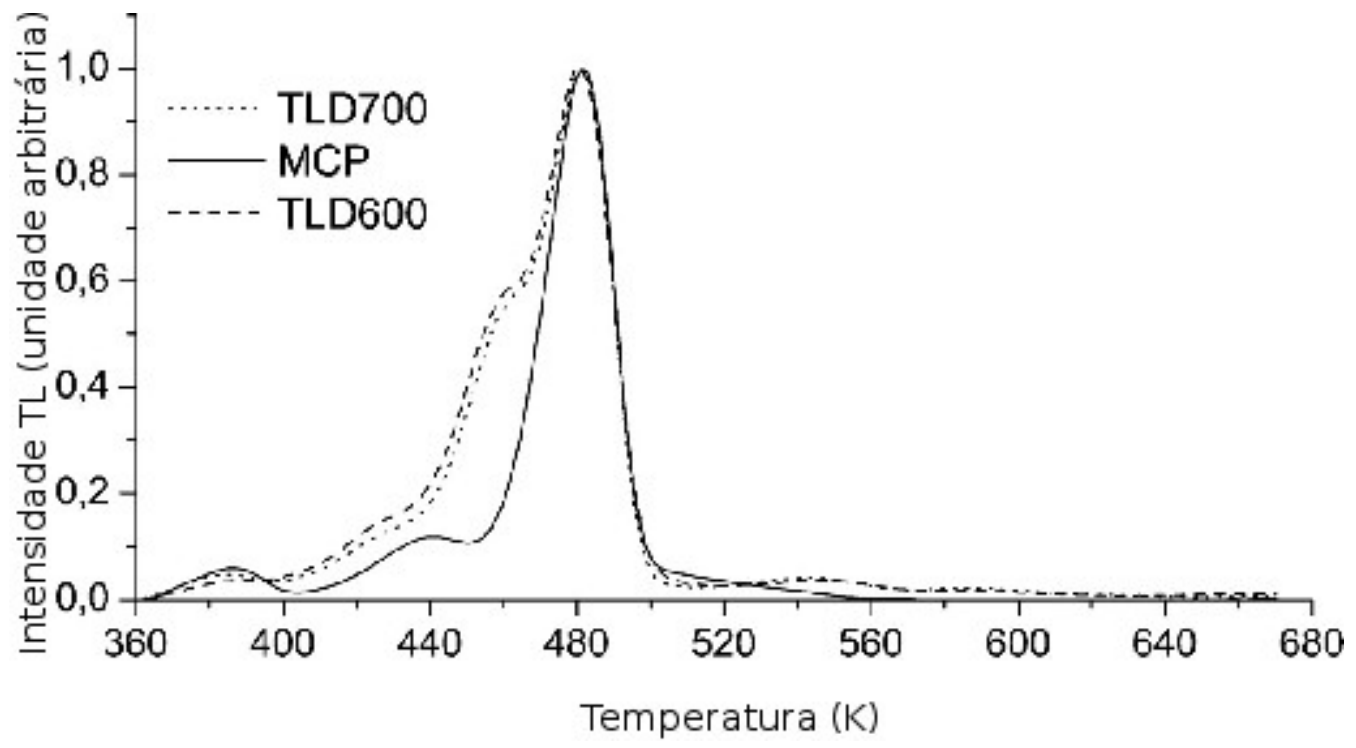

Figura 5.6. Resposta TL para fonte de Cobalto-60.

Com três tipos de TLD: 700, MCP (equivalente ao TLD 100) e 600 [18].

Devido à reduzida quantidade de ${ }^{6} \mathrm{Li}$ e à baixa seção de choque $\left(0,033\right.$ b) do ${ }^{7} \mathrm{Li}$ para nêutrons térmicos é desprezível a resposta do TLD 700 para nêutrons térmicos. A Tabela 5.2 mostra a eficiência para detecção de nêutrons térmicos do TLD 700 e 600.

Tabela 5.2 - Sensibilidade dos TLDs 600 e 700 para nêutrons térmicos.

\begin{tabular}{cc}
\hline TLD & Sensibilidade \\
\hline 600 & 1360 \\
700 & 328 \\
\hline
\end{tabular}

Fonte - OBERHOFER et al, 1979 [17]. 
Segundo o fabricante, o TLD 700 tem resposta linear para dose de radiação gama até $10 \mathrm{~Gy}$.

\subsection{TLD 600}

O fluoreto de lítio dopado com magnésio e titânio (LiF:Mg,Ti), cuja concentração isotópica é de $95,62 \%$ de ${ }^{6} \mathrm{LI}$ e $4,38 \%{ }^{7} \mathrm{Li}$ identificado pelo fabricante como TLD 600. Este dosímetro é utilizado na dosimetria de nêutrons térmicos.

A principal contribuição da termoluminescência do TLD 600 é devido a partículas alfa e trítio produzidas na reação ${ }^{6} \mathrm{Li}(\mathrm{n}, \alpha){ }^{3} \mathrm{H}$. O ${ }^{6} \mathrm{Li}$ possui uma alta seção de choque de captura para nêutrons térmicos (945 b), como mostra a Figura 5.7 [19].

As partículas $\alpha$ e ${ }^{3} \mathrm{H}$ geradas da reação têm energias de $2,07 \mathrm{MeV}$ e $2,74 \mathrm{MeV}$ respectivamente, e por se tratar de partículas carregadas elas possuem alta transferência de energia linear (LET), maior do que radiação eletromagnética. São as partículas $\alpha$ e ${ }^{3} \mathrm{H}$ que ionizarão o cristal dando origem à parte da resposta TL do TLD 600 e a outra parte é devido à radiação gama.

Segundo o fabricante o TLD 600, assim como o 700, possui resposta linear até 10Gy. 


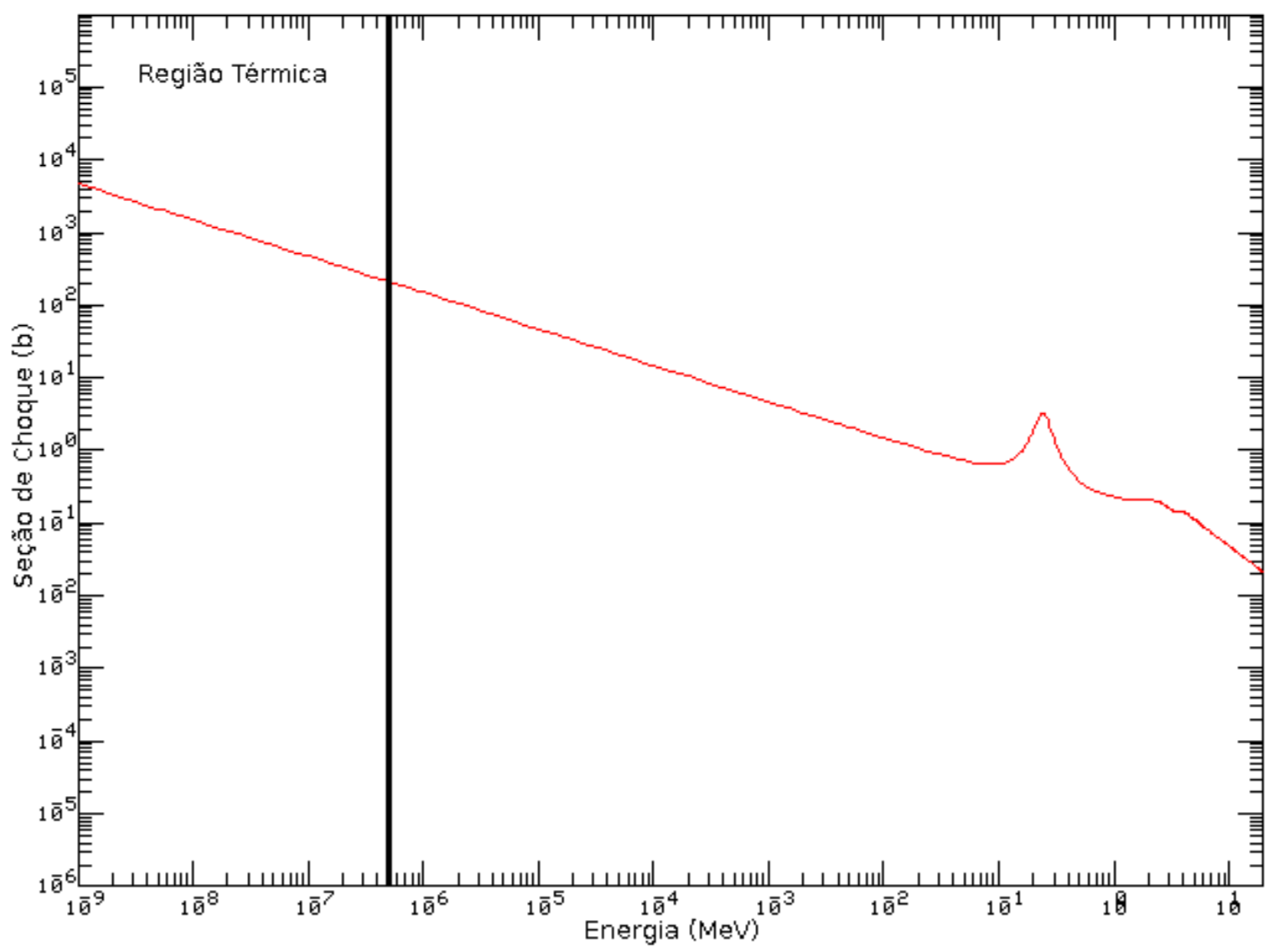

Figura 5.7. Seção de choque total de absorção do Lítio - 6 [20].

A curva TL do TLD 600 é constituída de 8 picos e dividida em duas regiões dosimétricas como mostra a Figura 5.8 [18]. 


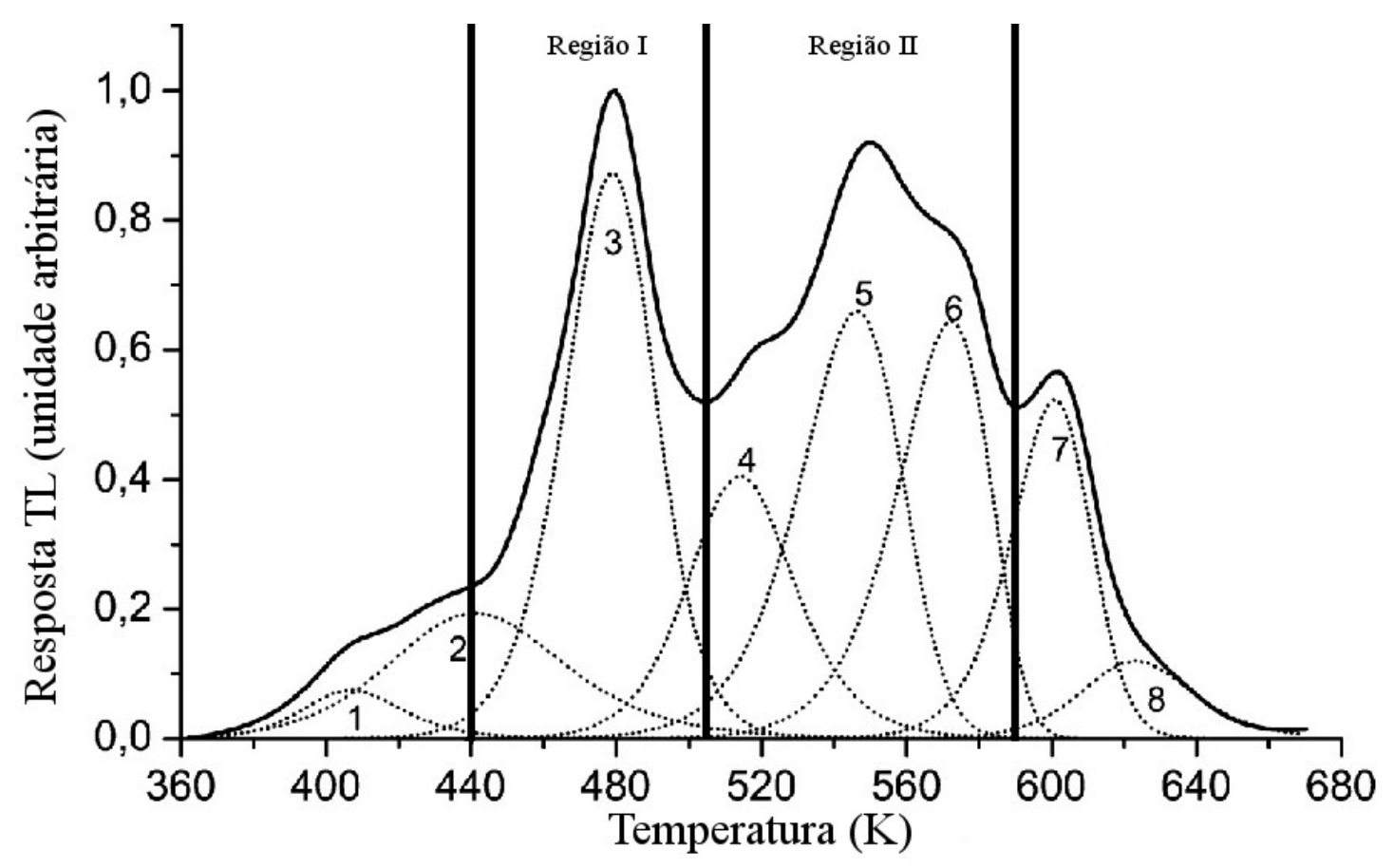

Figura 5.8. Curva TL do TLD 600 com as duas regiões dosimétricas [18].

A região I é considerada a principal região dosimétrica. Os estudos relacionados à região II buscam uma metodologia entre as duas regiões (I e II) para utilizar apenas o TLD 600 para obter informação sobre a dose de nêutrons e gama, quando o TLD 600 é irradiado em um campo misto, nêutrons e gama - como são praticamente todos os campos de radiação com nêutrons [21].

Para descontar a resposta devido a radiação gama do TLD 600, a principal técnica usada é irradiar um par de TLDs 600 e 700, e descontar da resposta do TLD 600 da resposta do TLD 700 como segue:

$$
\begin{gathered}
\mathrm{R}_{700}=\mathrm{D} \gamma \\
\mathrm{R}_{600}=\mathrm{D} \boldsymbol{\gamma}+\mathrm{D}_{\mathrm{n}} \\
\mathrm{D}_{\mathrm{n}}=\mathrm{R}_{600}-\mathrm{R}_{700},
\end{gathered}
$$


onde:

$$
\begin{array}{ll}
\mathrm{R}_{700}, & \text { é a resposta do TLD 700; } \\
\mathrm{D}_{\gamma}, & \text { resposta TL devido à radiação gama; } \\
\mathrm{R}_{600}, & \text { é a resposta do TLD } 600 \text { e } \\
\mathrm{D}_{\mathrm{n}}, & \text { resposta TL devido aos nêutrons térmicos. }
\end{array}
$$

Essa análise considera que os TLDs 600 e 700 possuem a mesma sensibilidade para a radiação gama. Porem é necessário um estudo da sensibilidade dos TLDs que se deseja utilizar, pois as sensibilidades dos TLDs variam de lote para lote e é necessário determinar a relação da sensibilidade entre eles. Uma análise mais detalhada é apresentada em materiais e métodos.

Como no Brasil a dosimetria de nêutrons é ainda muito restrita comparada com a dosimetria gama, ficando a de nêutrons praticamente em estudo nos Institutos de pesquisa, ainda não se tem uma metodologia bem estabelecida para a dosimetria de nêutrons utilizando TLDs. 


\section{CÓDIGO COMPUTACIONAL DOT 3.5}

No projeto da instalação para pesquisa em BNCT, um dos códigos que a equipe de pesquisadores, do Centro de Engenharia Nuclear (CEN) do IPEN, utilizou foi o código DOT 3.5.

O código DOT (Two Dimensional Discrete Ordinates Radiation Transport Code) usa o método de ordenadas discretas, que soluciona o problema de transporte de partículas que não estejam sob influência de um campo de forças externas em geometria bidimensionais ( $\mathrm{XY}, \mathrm{RZ}$ ou $\mathrm{R} \theta$ ), com espalhamento anisotrópico de ordem arbitrária. As fontes de partículas podem ser fixas. Este código foi desenvolvido para solucionar problemas de transporte de nêutrons e fótons ou quando há acoplamento entre eles [22].

O cálculo do DOT 3.5 foi realizado em uma estrutura multi-grupo de energia, com 22 grupos de nêutrons (de $1,0.10^{-5} \mathrm{eV}$ a 17,333MeV) e 18 grupos de gamas (de $0,01 \mathrm{eV}$ a $14 \mathrm{MeV}$ ), em um conjunto de quadratura (“biased”) de 100 ângulos de espalhamento [24]. A instalação foi modelada em geometria cilíndrica - RZ, empregando 89 intervalos (meshes) radiais e 221 intervalos axiais. A fonte para cada grupo de energia é proporcional à densidade de potência ponderada com o espectro de energia.

A biblioteca de secções de choque utilizada para todos os materiais que constituem a instalação foi a VITAMIN-C [25].

A instalação foi modelada computacionalmente com o código DOT 3.5 [23] e utilizou-se o programa ISODOSE, desenvolvido pela Área de Física de Reatores do CEN, para converter os valores de fluxo oriundos do DOT 3.5 para dose absorvida. E neste trabalho, o DOT e ISODOSE, foram usados para obter o fluxo de nêutrons e a dose absorvida ao longo do simulador antropomórfico colocado na posição de irradiação de amostra. 


\section{SIMULADOR ANTROPOMÓRFICO}

Foi construído um simulador antropomórfico de acrílico com suporte "alça" que possibilita colocar e retirar o simulador antropomórfico com o reator em operação da posição de irradiação de amostra através do sistema (trilho e garra) descrito no capítulo 2; o simulador antropomórfico foi construído com aletas laterias para acomodação na posição de irradiação. O simulador antropomórfico, Figura 7.1, possui um diâmetro externo de $10 \mathrm{~cm}$ e interno $9,1 \mathrm{~cm}$ e comprimento de $22 \mathrm{~cm}$.
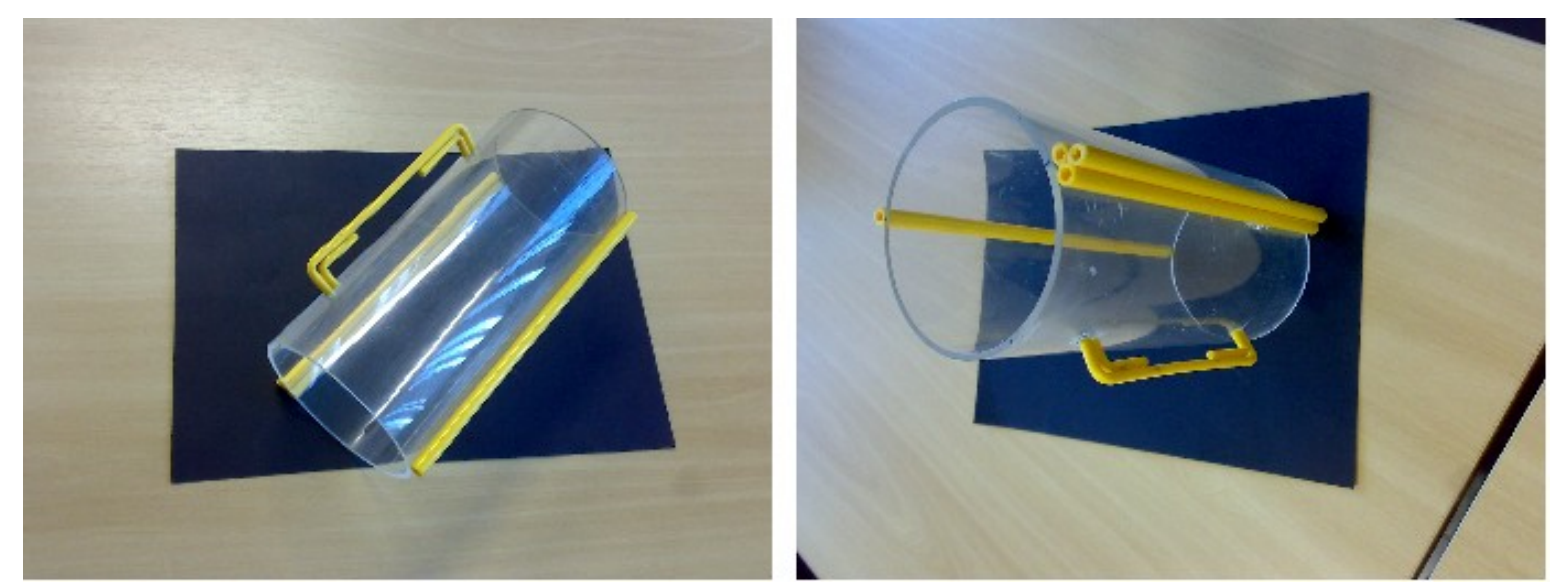

Figura 7.1. Simulador antropomórfico.

O simulador antropomórfico construído não possui o formato de nenhuma parte do corpo humano, porém ele permite que seu interior seja preenchido com compostos que simule um órgão do corpo humano (exemplo o cérebro). E então sejam realizadas pesquisas da interação da radiação com a parte do corpo humano simulada.

Foram confeccionado discos de acrílico (Figura 7.2), que preenchem o interior do simulador antropomórfico e onde foram colocados os detetores para medições. 


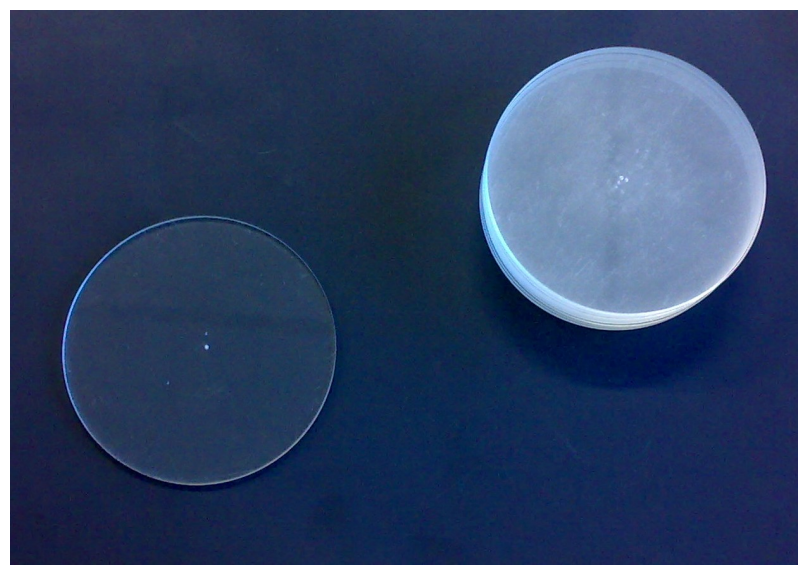

Figura 7.2. Discos de acrílico.

Uma alteração necessária no sistema de colocação de amostra da instalação foi a colocação de mais molas no sistema de garra, para que ela suporte o peso do simulador preenchido com os discos de acrílico (Figura 7.3).

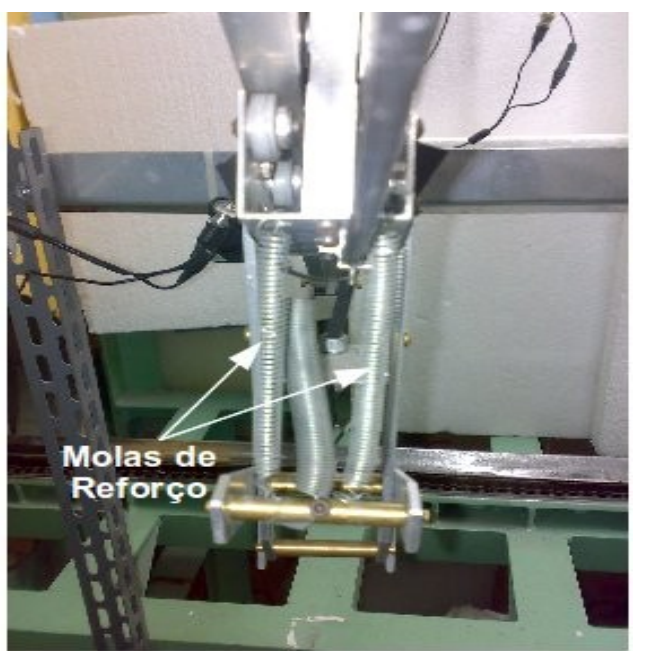

Figura 7.3. Garra com as molas de reforço para segurar o simulador antropomórfico.

Com o simulador construído para a instalação é possível desenvolver projetos que envolvam a análise de regiões do simulador, como por exemplo, a colocação de recipientes no interior do simulador com diferentes concentrações de boro. 


\section{MATERIAIS E MÉTODOS}

\subsection{Detectores de Ativação}

Os detectores de ativação usados são de ouro hiper-puro e possuem as seguintes dimensões: $10 \mathrm{~mm}$ de diâmetro e $0,13 \mathrm{~mm}$ de espessura. A Figura 8.1 mostra um par de folhas de ouro utilizada, bem como a cobertura de $\mathrm{Cd}$.

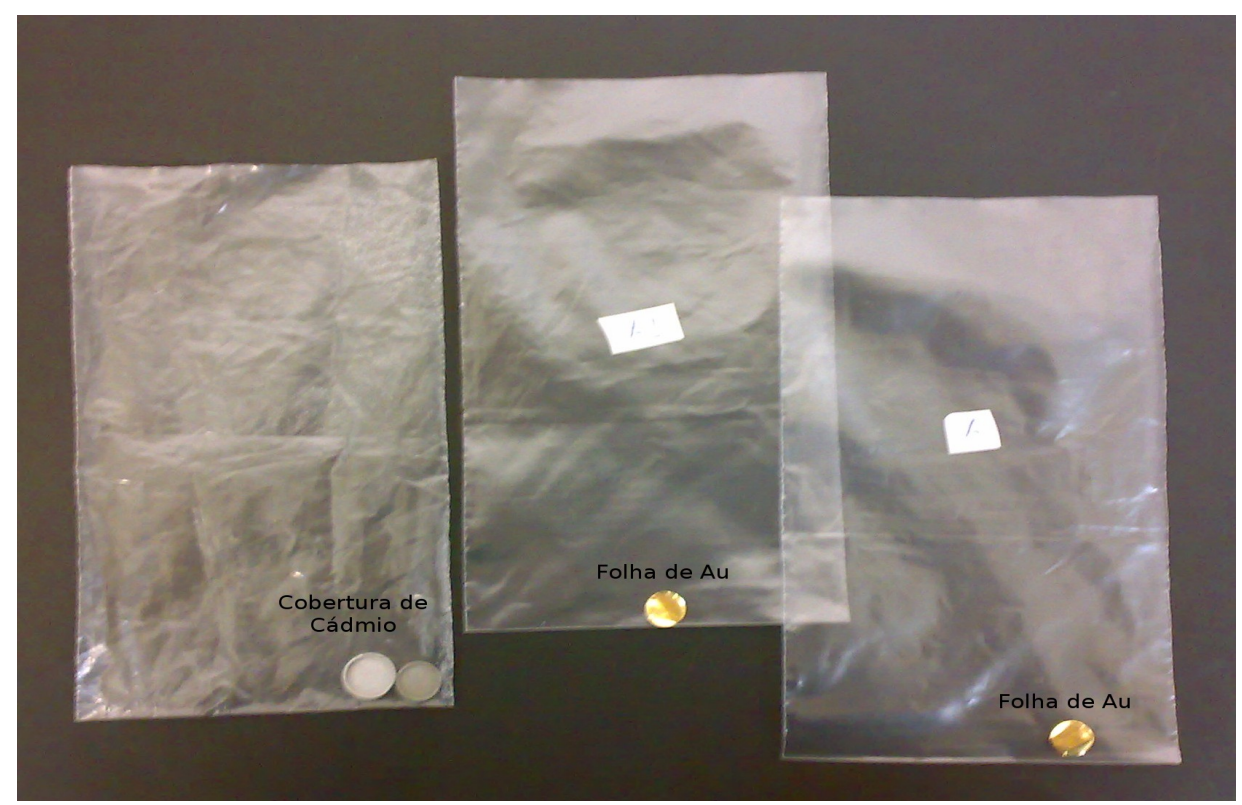

Figura 8.1. Folhas de Ouro e cobertura de Cádmio.

A espectrometria gama da folha de ativação é realizada utilizando um detector de Germânio Hiper Puro (HPGe) da ORTEC, com sua eletrônica associada (Figura 8.2) [26] [27]. O sistema possui posições fixas de distâncias chamadas de "gaveta", (Figura 8.2 (b)), onde se coloca o disco com a folha. Neste trabalho utilizou-se a terceira gaveta. 


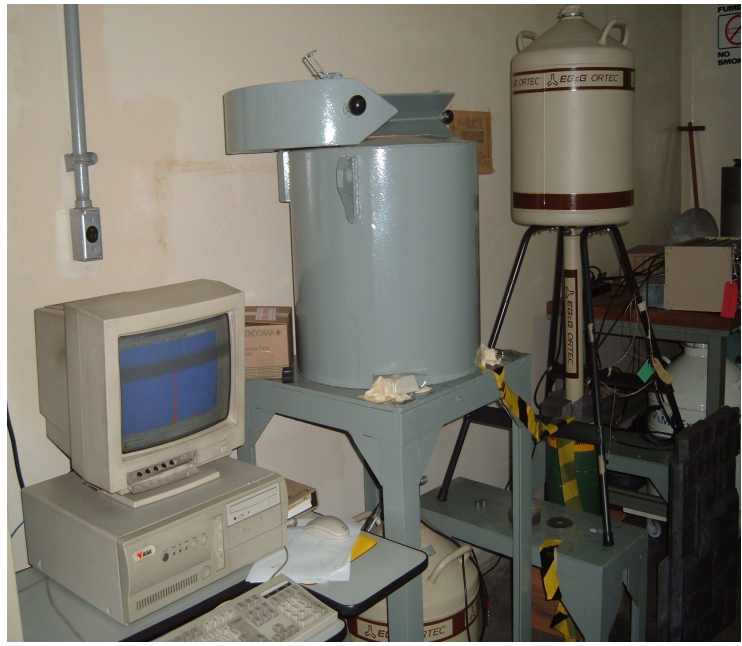

(a)

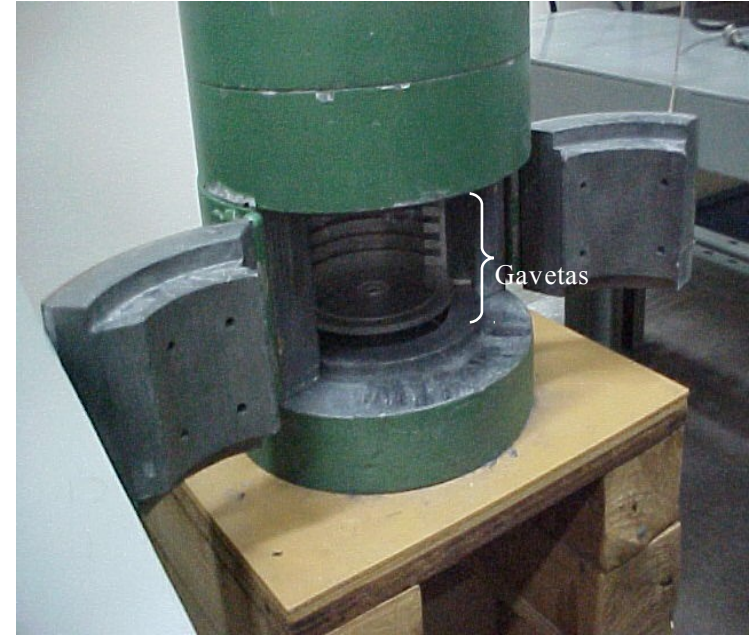

(b)

Figura 8.2. Laboratório de espectrometria gama.

(a) computador e detector HPGE. (b) detalhe das gavetas onde são colocadas as folhas para a espectrometria gama no HPGe.

A eletrônica associada ao detetor é a padrão de instrumentação nuclear e é apresentada no diagrama da Figura 8.3.

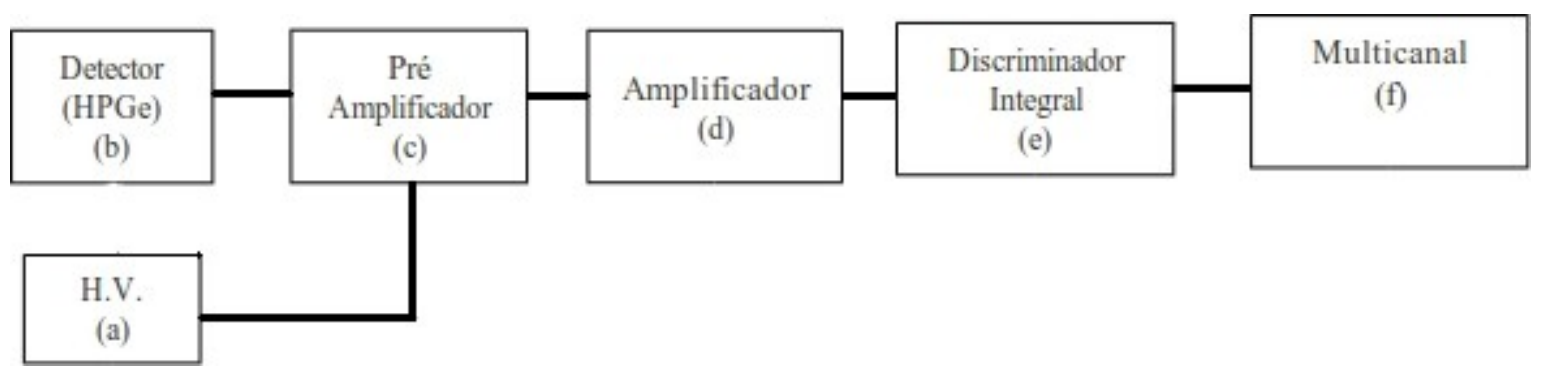

Figura 8.3. Diagrama da eletrônica utilizada para a espectrometria gama.

A função de cada dispositivo da Figura 8.3 é:

a) alta tensão (H.V.) polariza o detector reversamente aumentando a região depletada do detector,

b) detector semicondutor de Germânio Hiper Puro (HPGe), 
c) pré-amplificador que amplifica o sinal para que este possa ser transmitido pelo cabeamento sem perda na relação sinal/ruído na entrada do amplificador,

d) amplificador que amplifica o sinal que vem do pré-amplificador e formata o sinal de saída,

e) discriminador integral elimina o ruído eletrônico e

f) multicanal que registra a contagem da radiação com uma determinada energia em um mesmo canal. A contagem em canais distintos corresponde a energias diferentes.

A contagem por canal do multicanal é analisada pelo programa Maestro $3.2 \mathrm{da}$ ORTEC [28], que foi desenvolvido pelo fabricante do equipamento para análise dos espectros de contagens. $\mathrm{O}$ valor da contagem líquida onde é descontada a radiação de fundo (Net Área), de cada folha foi obtida através deste programa. Como exemplo tem-se na Figura 8.4, a tela do programa com a informação da contagem líquida. 


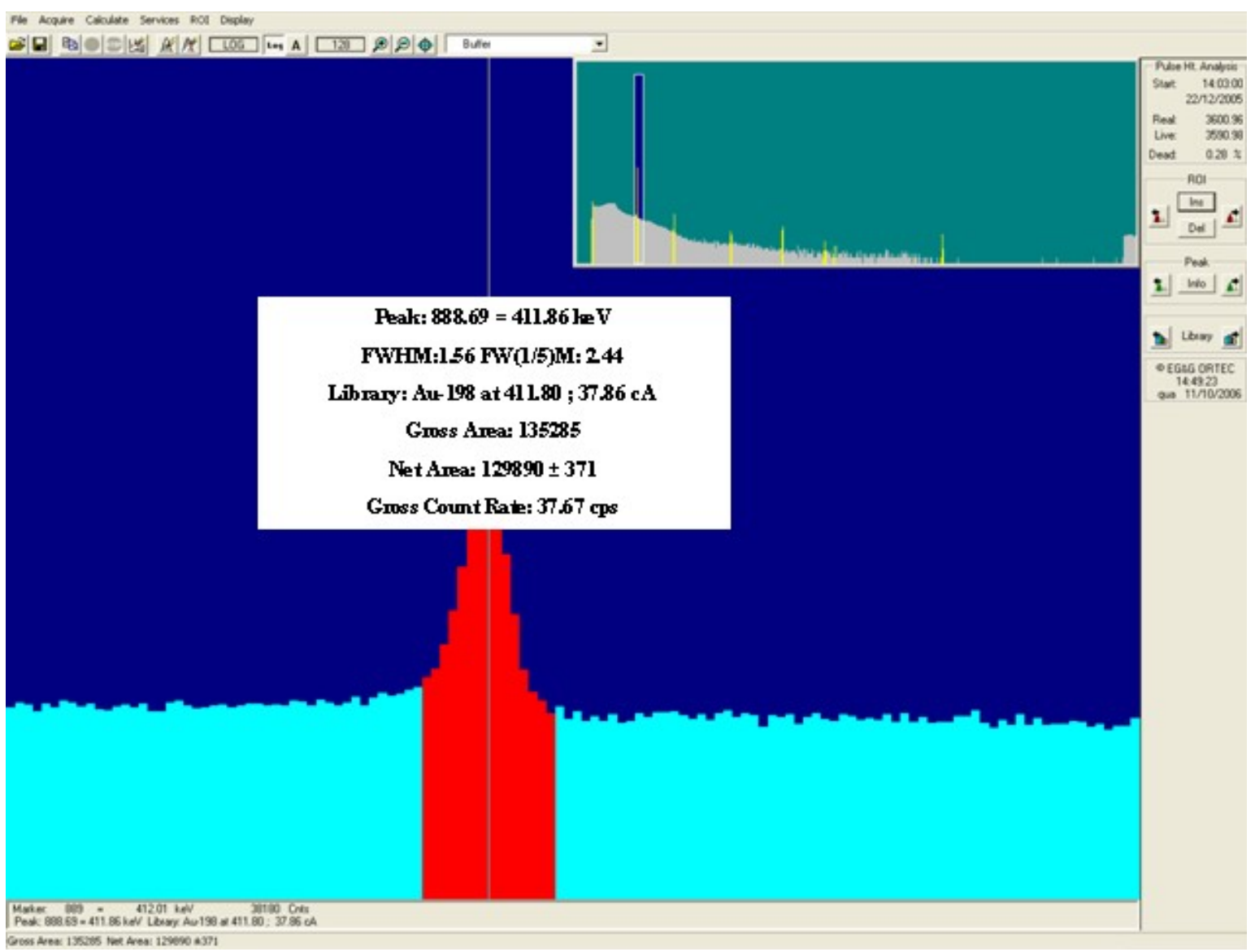

Figura 8.4. Tela do programa Maestro para a folha de Ouro irradiada.

Para realizar a espectrometria gama da folha de ativação é necessário o levantamento da eficiência global absoluta em função da energia do sistema de detecção. Foi utilizada uma fonte isotrópica de európio $\left({ }^{152} \mathrm{Eu}\right)$ com atividade de $(13,3 \pm 0,6) \mathrm{kBq}$ (em 01/03/1991) para o levantamento da eficiência.

A fonte de ${ }^{152} \mathrm{EU}$ é uma fonte apropriada para determinar a eficiência absoluta do sistema de detecção (HPGe), uma vez que ela emite fótons com energias bem distribuídas, as energias usadas para determinação da eficiência, vão desde $244,17 \mathrm{keV}$ até 1407,8keV, como mostra a Tabela 8.1. A fonte de ${ }^{152} \mathrm{Eu}$ utilizada tem o formato de um disco com as seguintes dimensões: $8 \mathrm{~mm}$ de diâmetro por $1 \mathrm{~mm}$ de espessura. 
Tabela 8.1 - Energias dos fótons emitidos pela fonte de Európio-152.

\begin{tabular}{ccc}
\hline Energia (keV) & Intensidade & ${ }^{*} \sigma_{\text {Intensidade }}$ \\
\hline 244,17 & 0,0751 & 0,0005 \\
344,62 & 0,2658 & 0,0018 \\
411,36 & 0,0223 & 0,0001 \\
444,18 & 0,0312 & 0,0002 \\
778,97 & 0,1296 & 0,0007 \\
964,05 & 0,1462 & 0,0006 \\
1112,07 & 0,1400 & 0,0006 \\
1408,01 & 0,2085 & 0,0008 \\
\hline
\end{tabular}

Fonte - Dados nucleares disponível em $<$ http://atom.kaeri.re.kr $>$

* Incerteza

Após um tempo de contagem que permita uma boa estatística, tem-se a contagem para as energias que a fonte de európio emite. Como a atividade da fonte é conhecida, sabe-se quantos fótons a fonte emitiu com cada energia durante o tempo de contagem. Empregando-se a razão entre a contagem do detector e o número de emissões da fonte obtêm-se a eficiência absoluta do sistema de detecção para as energias do európio. A Figura 8.5, mostra o ajuste da eficiência absoluta por energia. O ajuste foi realizado com o programa Origin 7.5 [29]. Este procedimento foi realizado para a terceira gaveta. 


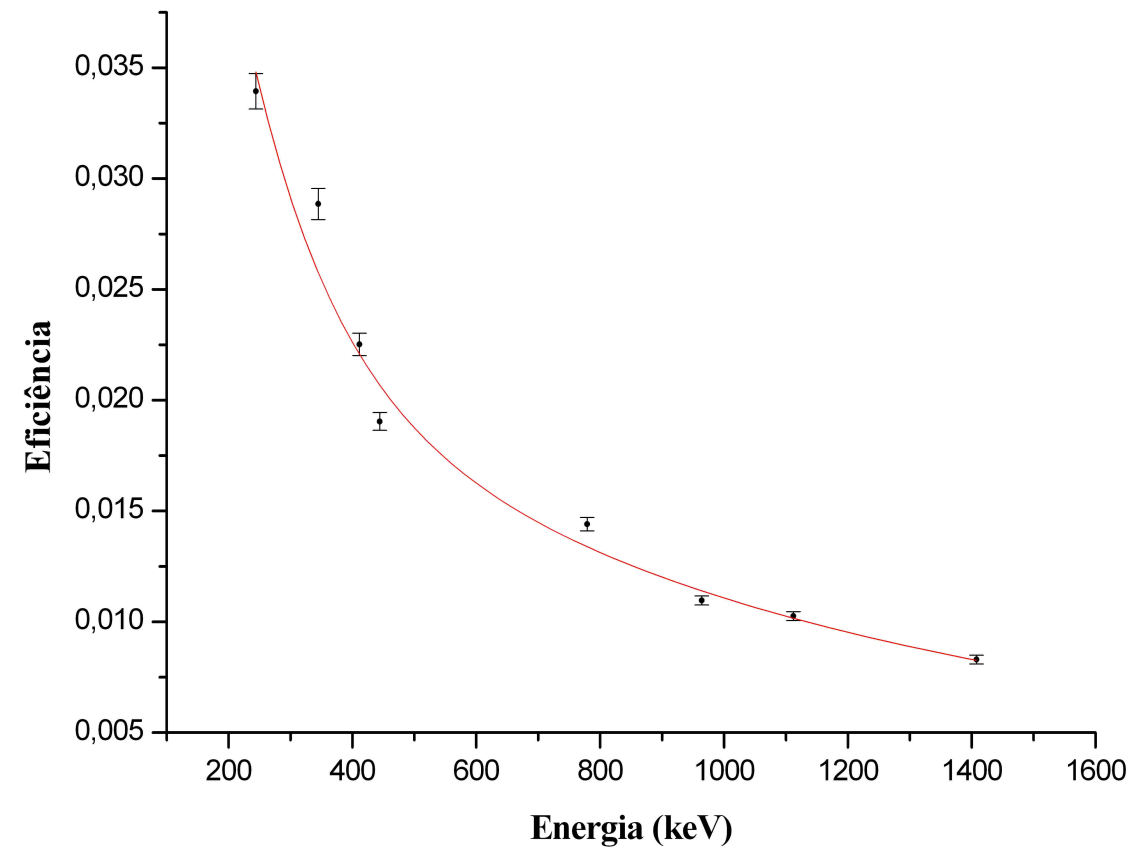

Figura 8.5. Eficiência absoluta em função da energia do fóton para a $3^{\mathrm{a}}$ gaveta.

A função utilizada para o ajuste foi:

$$
\epsilon=\varepsilon_{0}+A_{1} e^{-E_{g} / t_{1}}
$$

onde:

$\varepsilon$ é a eficiência do sistema de detecção na geometria usada (gaveta);

$\varepsilon_{0}, \mathrm{~A}_{1}$ e $\mathrm{t}_{1}$, são parâmetros ajustados pelo programa Origin e $\mathrm{E}_{\mathrm{g}}$, energia do fotópico medido.

Os valores dos parâmetros obtidos estão na Tabela 8.2. 
Tabela 8.2 - Valores dos parâmetros do ajuste de eficiência.

\begin{tabular}{cc}
\hline Parâmetro & Valor \\
\hline$\varepsilon_{0}$ & $0.0078 \pm 0.0012$ \\
$\mathrm{~A}_{1}$ & $0.048 \pm 0.010$ \\
$\mathrm{t}_{1}$ & $356 \pm 83 \mathrm{keV}$ \\
$\mathrm{R}^{2}$ & 0.96626 \\
\hline
\end{tabular}

Na Tabela 8.2 o parâmetro $R^{2}$ representa o coeficiente de determinação que é utilizado pelo programa Origin para calcular a qualidade do ajuste, quanto mais próximo do valor unitário estiver este valor melhor será considerado a qualidade do ajuste.

O ouro emite fótons de 411,80keV [20], que é praticamente de mesma energia que um dos fótons emitidos pelo európio - $152(411,36 \mathrm{keV})$, conforme apresentado na Tabela 8.1. Assim a determinação da eficiência do sistema de detecção para energia do fóton emitido pelo o ouro é mais preciso guando utiliza-se o valor numérico determinado pela espectrometria da fonte (Tabela 8.3).

Tabela 8.3 - Eficiência $(\varepsilon)$ global absoluta do HPGe em função da energia de cada fotópico emitido pela fonte de Európio - 152.

\begin{tabular}{ccc}
\hline Energia (keV) & $\boldsymbol{\varepsilon}$ & $\boldsymbol{\sigma}_{\boldsymbol{\varepsilon}}$ \\
\hline 244,17 & 0,0339 & 0,0008 \\
344,62 & 0,0289 & 0,0007 \\
411,36 & 0,0225 & 0,0005 \\
444,18 & 0,0190 & 0,0005 \\
778,97 & 0,0144 & 0,0003 \\
964,05 & 0,0110 & 0,0003 \\
1112,07 & 0,0103 & 0,0002 \\
1408,01 & 0,0083 & 0,0002 \\
\hline
\end{tabular}


As folhas, antes de serem irradiadas, tiveram suas massas medidas utilizandose uma balança Mettler H20 (Figura 8.6). E com a a equação 3.15 obtêm-se o número de núcleos alvos de cada detector de ativação.

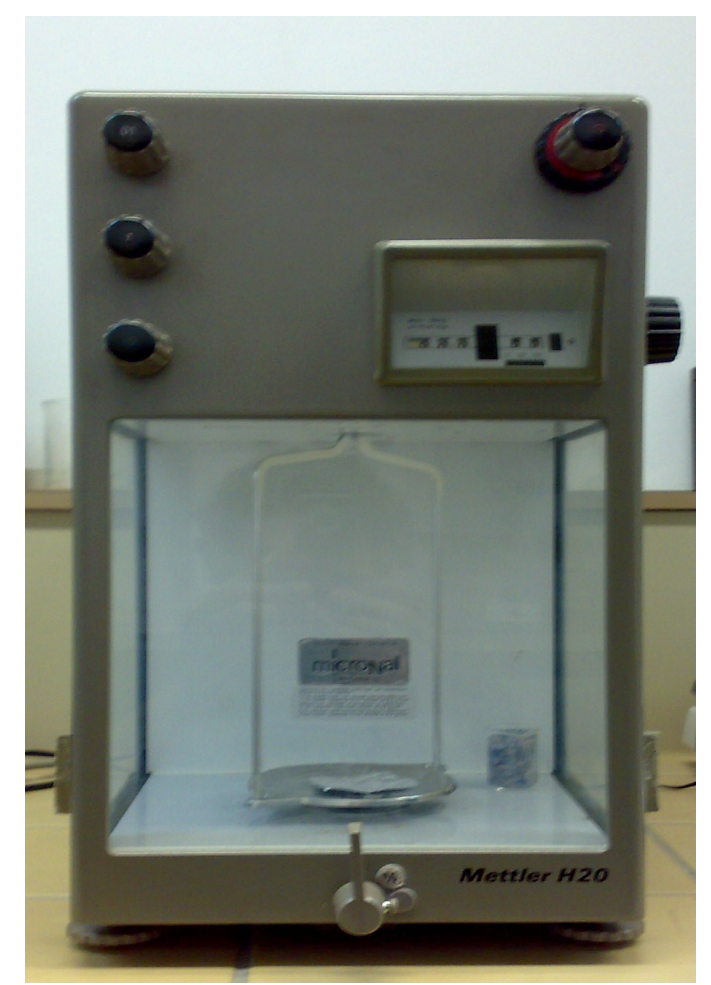

Figura 8.6. Balança Mettler H20.

As folhas foram colocadas junto com os TLDs no simulador antropomórfico e irradiadas. Após a espectrometria gama e com as equações apresentadas no capítulo 3, obtêm-se os fluxos térmicos e epitérmicos em cada posição do simulador antropomórfico.

\subsection{TLDs}

A primeira etapa na preparação do sistema de leitura dos TLDs foi ajustar os parâmetros da leitora de TLDs com os tipos de TLDs utilizados, uma vez que diferentes ajustes modificam a curva TL gerada pelo TLD. 


\subsubsection{Leitura dos TLDs}

A leitora de TLDs utilizada foi à Victoreen modelo 2800 M (Figura 8.7) [30].

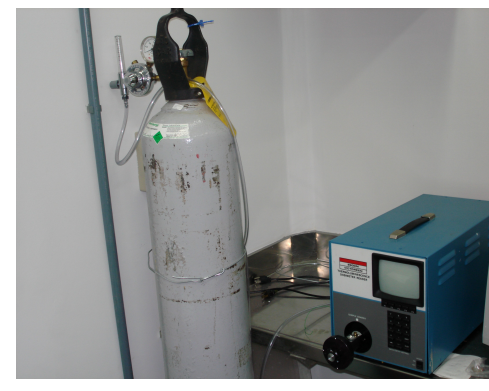

(a)

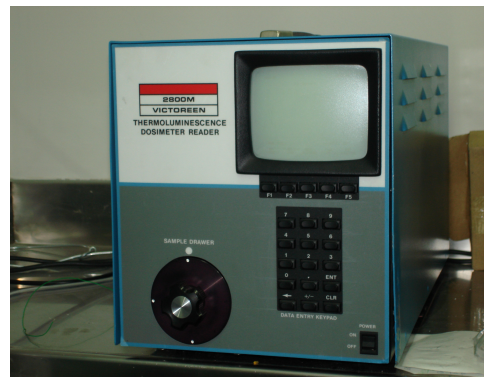

(b)

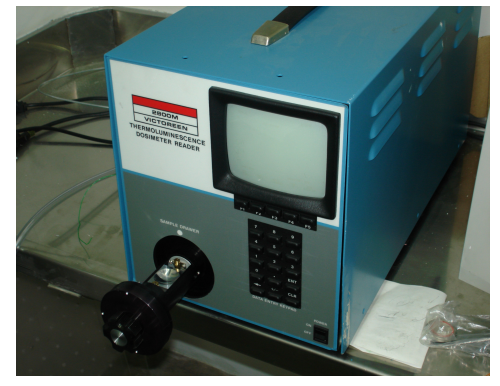

(c)

Figura 8.7. Leitora Victoreen.

(a) leitora e cilindro de nitrogênio. (b) visão da parte frontal da leitora. (c) leitora com a gaveta para colocação de TLDs aberta.

Antes de utilizar a leitora é necessário ajustar seus parâmetros para os tipos de TLDs e técnica que se deseja utilizar: temperatura de início de contagem, temperatura máxima e tempo por canal - pois as mudanças nos parâmetros modificam a curva TL gerada pela leitora [31]. Os ajustes determinados para a leitora estão na Tabela 8.4. Estes parâmetros permitem a leitura dos TLDs 400, 600 e 700 sem que seja necessário fazer alterações na leitora, uma vez que a curva TL do TLD 400 é diferente da curva TL do 600 e 700 - com este procedimento é possível fazer os teste de funcionamento da leitora sem ter que mudar os parâmetros (caso utiliza-se parâmetros diferentes para a leitura dos TLDs). 
Tabela 8.4 - Parâmetros utilizados na leitora de TLDs.

\begin{tabular}{cc}
\hline Parâmetros & Valores \\
\hline Temperatura de Inicio (pré-heat) & $60^{\circ} \mathrm{C}$ \\
Taxa de Aquecimento & $10^{\circ} \mathrm{C} / \mathrm{s}$ \\
Temperatura Máxima & $400^{\circ} \mathrm{C}$ \\
Tempo por Canal & $0,1 \mathrm{~s}$ \\
Tempo de Rampa & $45 \mathrm{~s}$ \\
\hline
\end{tabular}

A curva TL gerada na leitora é carga por canal - o canal é a relação entre os parâmetros utilizados. Para converter o valor do canal em temperatura usa-se a relação da temperatura inicial, taxa de aquecimento e tempo por canal, conforme equação 8.2, até a temperatura máxima.

$$
\mathrm{T}=\mathrm{T}_{\mathrm{e}}+\mathrm{t}_{\mathrm{a}} \cdot \mathrm{t}_{\mathrm{c}} \cdot \mathrm{C}
$$

em que:

T, temperatura no canal;

$\mathrm{T}_{\mathrm{e}}$, temperatura de inicio;

$\mathrm{t}_{\mathrm{a}}, \quad$ Taxa de aquecimento;

$\mathrm{t}_{\mathrm{c}}$, tempo por canal;

C, número do canal.

Com os ajustes da Tabela 8.4 aplicados a equação 8.2 obtêm-se a equação:

$$
\mathrm{T}=60+\mathrm{C}
$$


A equação 8.2 é válida até a temperatura de $400{ }^{\circ} \mathrm{C}$ (temperatura máxima), pois ao atingir esta temperatura a leitora mantém a temperatura máxima até terminar o tempo de rampa. Esta equação é utilizada para converter a informação do canal em temperatura.

Como exemplo têm-se as curvas TL dos dosímetros 400, 600 e 700 geradas na leitora (Figura 8.8 e 8.9). O gráfico da Figura 8.9 mostra a curva TL de um TLD 600 e um 700 irradiados na fonte panorâmica de ${ }^{60} \mathrm{Co}$ com uma dose absorvida de $0,5 \mathrm{~Gy}$. No caso do TLD 600 e 700, a forma da curva TL gerada é semelhante, porém a sensibilidade é diferente como mostra a Figura 8.9. A resposta do TLD 600 é maior do que a do 700.

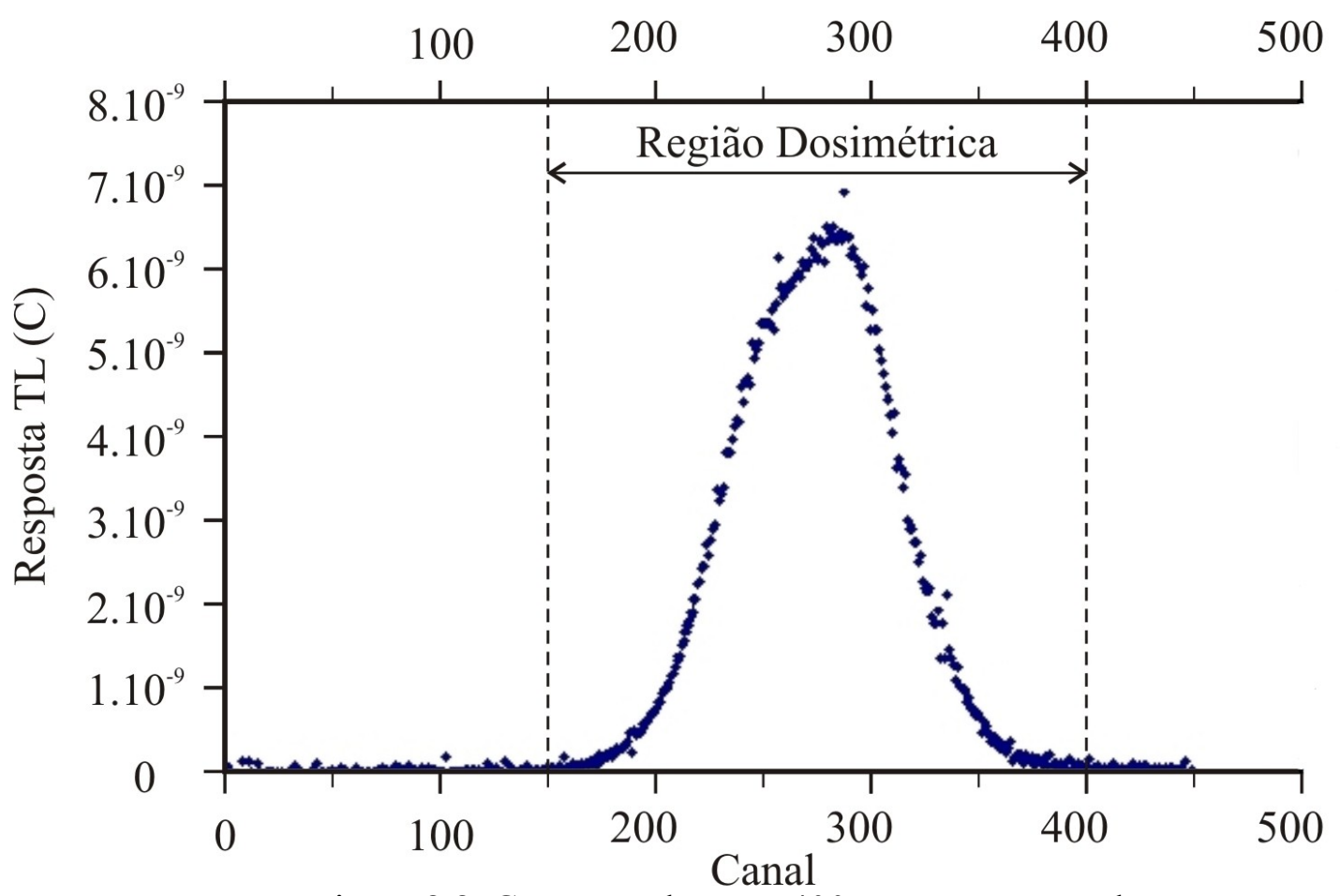

Figura 8.8. Curva TL do TLD 400 - carga por canal. 


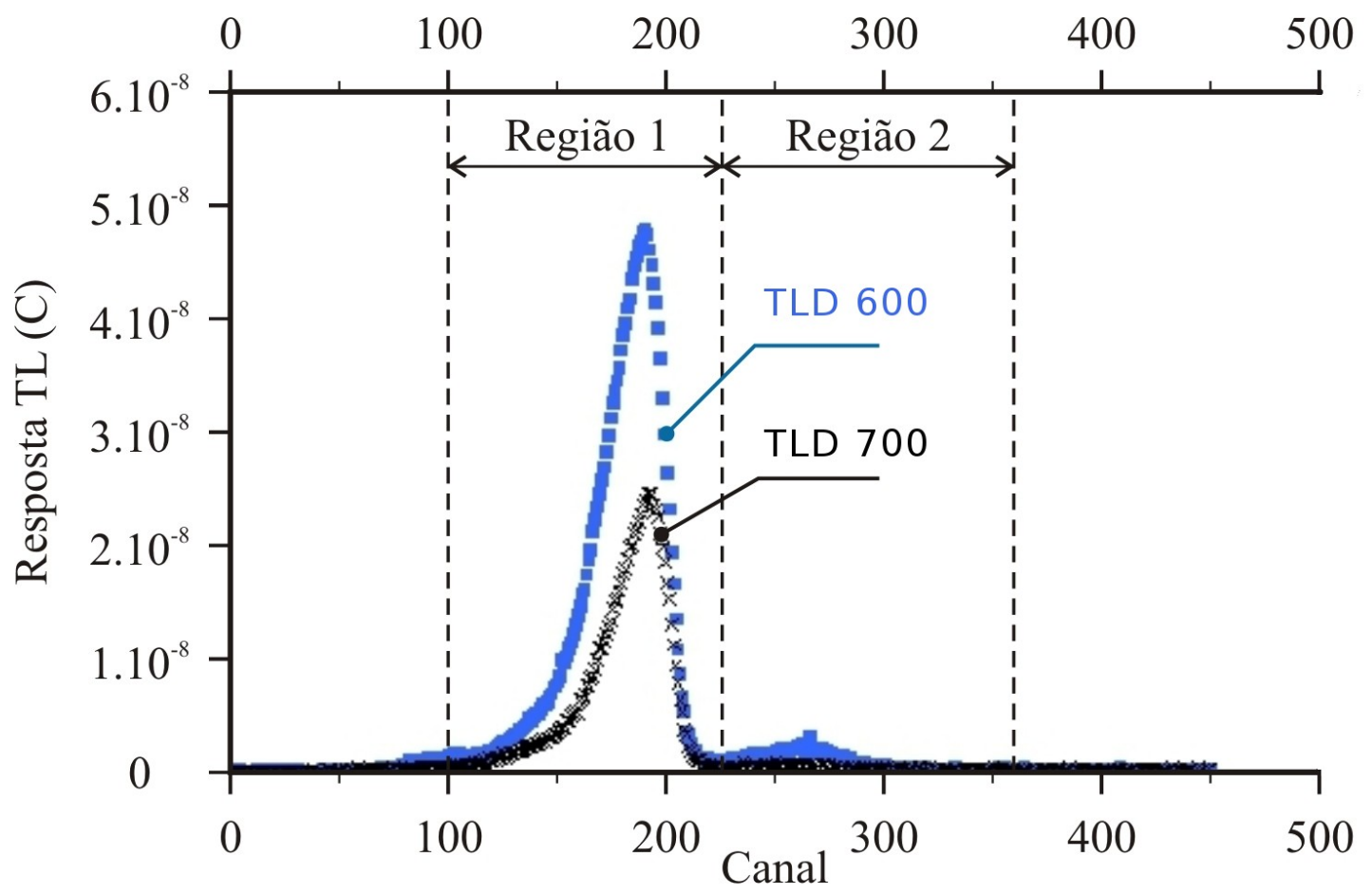

Figura 8.9. Relação entre as repostas TL do TLD 600 e 700 irradiados na fonte de cobalto-60.

A resposta TL a ser considerada é a integral da região chamada de pico dosimétrico. Após a análise das curvas TL determinou-se as regiões como sendo para o TLD 400 do canal 150 a 400 (Figura 8.8), e para os TLDs 600 e 700 do canal 100 a 220, (Figura 8.9).

\subsubsection{Tratamento Térmico}

Após a leitura dos TLDs é necessário aplicar o tratamento térmico para que os dosímetros sejam reutilizados. O tratamento térmico faz com que os elétrons que não foram desarmadilhados durante a leitura sejam liberados e assim não comprometam a resposta de uma nova irradiação com informação residual. Cada tipo de TLD tem um tratamento indicado pelo fabricante. No caso dos TLDs utilizados os tratamentos são: para os TLDs 600 e 700 uma hora à $400^{\circ} \mathrm{C}$ e duas horas à $100^{\circ} \mathrm{C}$ e para o TLD 400 uma hora à $400^{\circ} \mathrm{C}$. Na Figura 8.10 temos os fornos utilizados no tratamento térmico. 


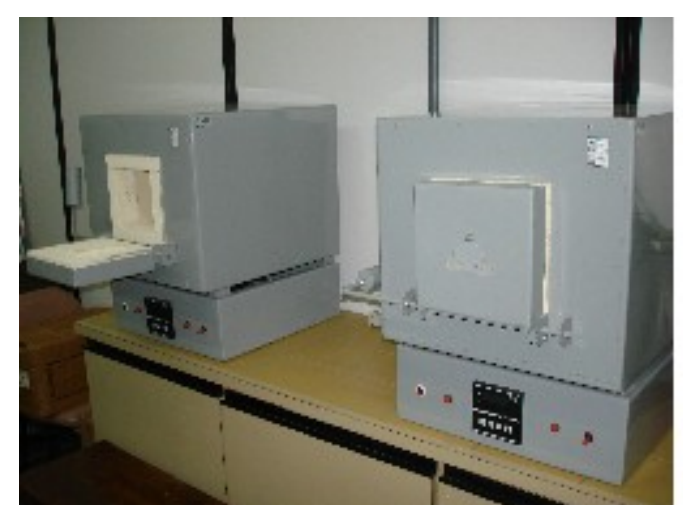

(a)

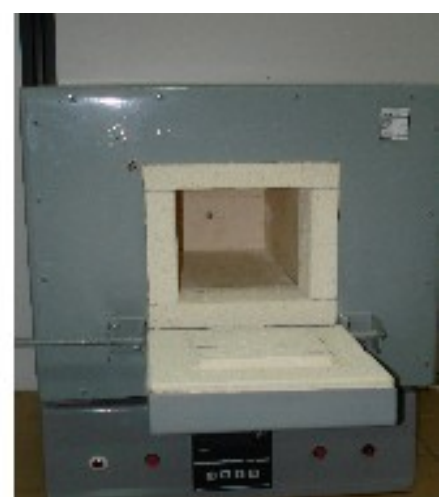

(b)

Figura 8.10. Fornos para tratamento térmico.

(a) forno da esquerda para tratamento de $400^{\circ} \mathrm{C}$ e o da direita para $100^{\circ} \mathrm{C}$ (b) visão interna do forno.

No diagrama da Figura 8.11 temos o ciclo para reutilização dos TLDs.

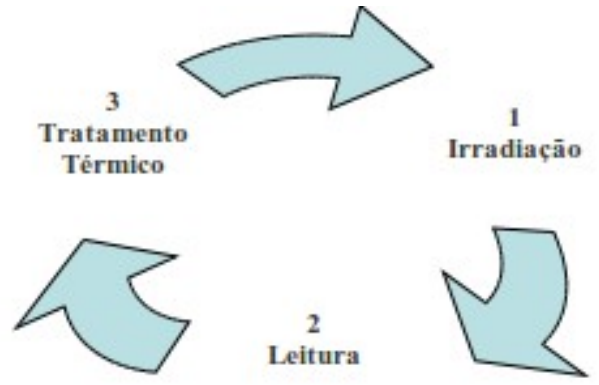

Figura 8.11. Diagrama de reutilização dos TLDs

\subsubsection{Selecionamento e Calibração}

Antes da utilização dos TLDs para determinar a Dose absorvida na instalação são necessárias duas etapas: selecionamento e curva de calibração.

O selecionamento é a etapa em que, a partir de um lote de pastilhas, selecionam-se as que possuam maior reprodutibilidade e resposta média próxima uma das outras para que possam ser utilizadas nas medições.

Para converter a reposta TL em dose é necessário que os TLDs sejam calibrados. Eles são irradiados em um campo de dose conhecida, então a resposta em carga 
da região dosimétrica é correspondente a dose aplicada, com isso, realizando irradiações para vários valores de dose, obtêm-se a curva de calibração. Cada tipo de TLD precisa ter a sua curva de calibração.

\subsubsection{Selecionamento do TLD 600}

Para o selecionamento dos TLDs 600 foi utilizada uma fonte de amerício berílio (AmBe). O amerício-241 decai para neptúnio-237, emitindo radiações alfa e gama, com meia vida de 432,2 anos. As principais energias e intensidades são apresentadas nas Tabela 8.5 e 8.6 [20].

Tabela 8.5 - Principais energias e intensidades das partículas Alfa emitida pelo Amerício-241.

\begin{tabular}{cc}
\hline Energia (keV) & Intensidade (\%) \\
\hline 5544,52 & 0,34 \\
5511,47 & 0,22 \\
5485,56 & 84,51 \\
5442,80 & 13,06 \\
5388,23 & 1,62 \\
\hline
\end{tabular}

Fonte - Dados nucleares disponível em <http://atom.kaeri.re.kr $>$

Tabela 8.6 - Principais energias dos fótons emitidos pelo Amerício-241.

\begin{tabular}{cc}
\hline Energia (keV) & Intensidade (\%) \\
\hline 26,3 & 2,5 \\
33,2 & 0,1 \\
43,4 & 0,1 \\
59,5 & 35,3 \\
\hline
\end{tabular}

Fonte - Dados nucleares disponível em $<$ http://atom.kaeri.re.kr $>$

O neptúnio-237 decai com meia-vida de 2.144.000 anos [20], portanto sua atividade é extremamente baixa e as partículas alfa e radiação gama emitidas são desprezíveis. 
As partículas alfa emitidas pelo Amerício vão induzir no Berílio a seguinte reação nuclear [32]:

$$
{ }_{2}^{4} \alpha+{ }_{4}^{9} B e \rightarrow{ }_{6}^{12} C+{ }_{0}^{1} n
$$

O espectro de energia dos nêutrons emitidos pela fonte AmBe é apresentado na Figura 8.12.

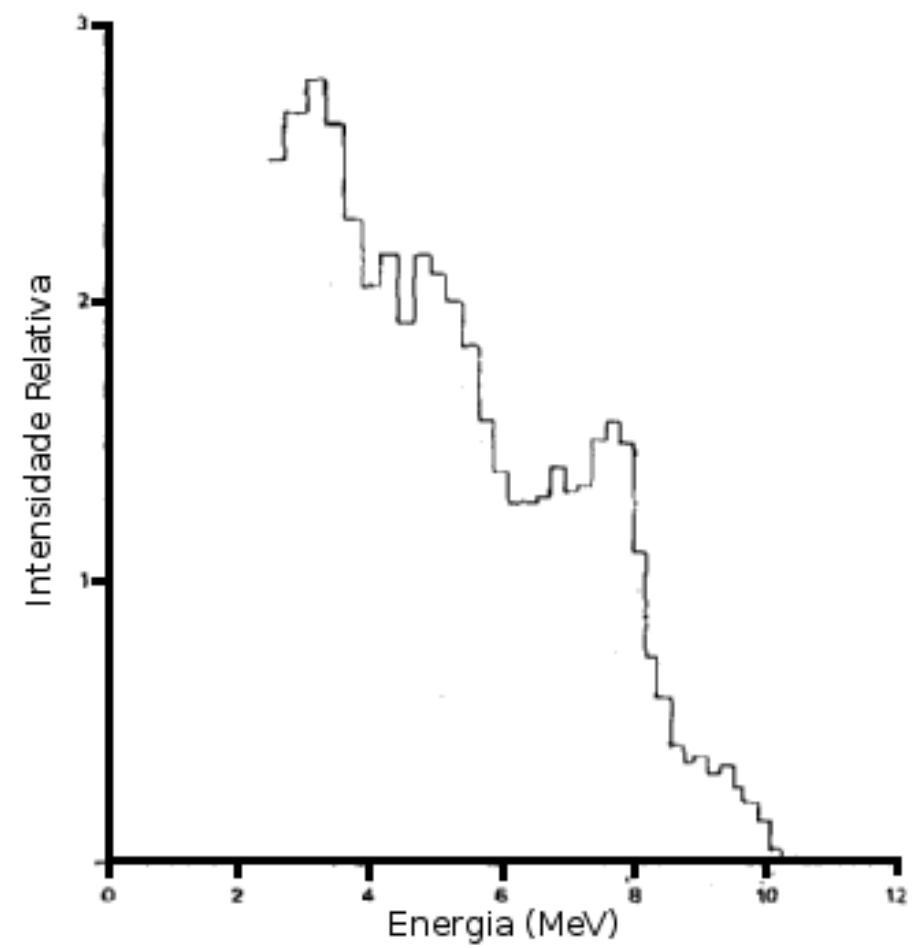

Figura 8.12. Espectro de emissão de nêutrons da fonte $\mathrm{AmBe}[33]$.

Aproximadamente $23 \%$ dos nêutrons emitidos tem energia abaixo de $1 \mathrm{MeV}$, com energia média de $400 \mathrm{keV}$ [33].

As fontes de AmBe são fontes mistas, que emitem nêutrons da reação ${ }^{9} \mathrm{~B}(\alpha, n){ }^{12} \mathrm{C}$ e gama do decaimento do ${ }^{241} \mathrm{Am}$.

A fonte de AmBe utilizada é uma fonte comercial cilíndrica produzida pela Amersham de $3 \mathrm{Ci}$ de atividade e possui as seguintes dimensões: $22,4 \mathrm{~mm}$ de diâmetro por 
48,5mm de altura. Como a fonte de $\mathrm{AmBe}$ emite, principalmente nêutrons rápidos e os TLDs 600 são sensíveis a nêutrons térmicos, têm-se que diminuir a energia dos nêutrons emitidos pela fonte (moderar os nêutrons) envolvendo-a com material moderador. $\mathrm{O}$ material utilizado neste trabalho foi a parafina. $O$ arranjo utilizado foi um disco de parafina com diâmetro de $18 \mathrm{~cm}$ total com um furo de $4 \mathrm{~cm}$ no meio onde é encaixado a fonte, (Figura 8.13). Os TLDs 600 foram colocados em volta do disco de parafina [34].

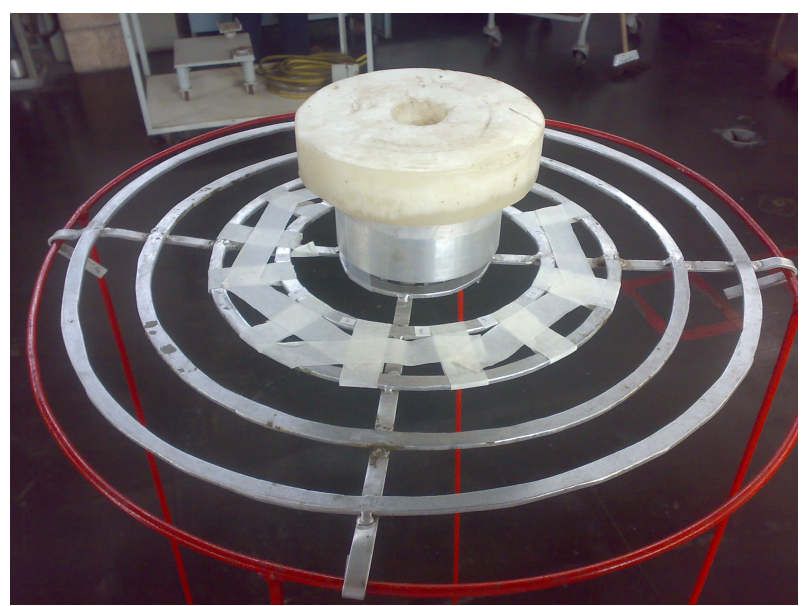

Figura 8.13. Arranjo utilizado para calibração dos TLDs 600.

Como a etapa de selecionamento busca a reprodutibilidade das pastilhas, nesta etapa utilizou-se a resposta total dos TLDs 600, sem descontar a resposta gama.

Após uma primeira etapa com seis irradiações, 12 (entre 99) pastilhas de TLD 600 foram selecionadas do lote por possuírem resposta mais próxima uma da outra e melhor reprodutibilidade. Essas pastilhas foram novamente irradiadas no arranjo por um período de 17 horas repetindo-se o procedimento três vezes. A resposta média destas três irradiações e o desvio padrão (em nano - coulomb) estão na Figura 8.14. 


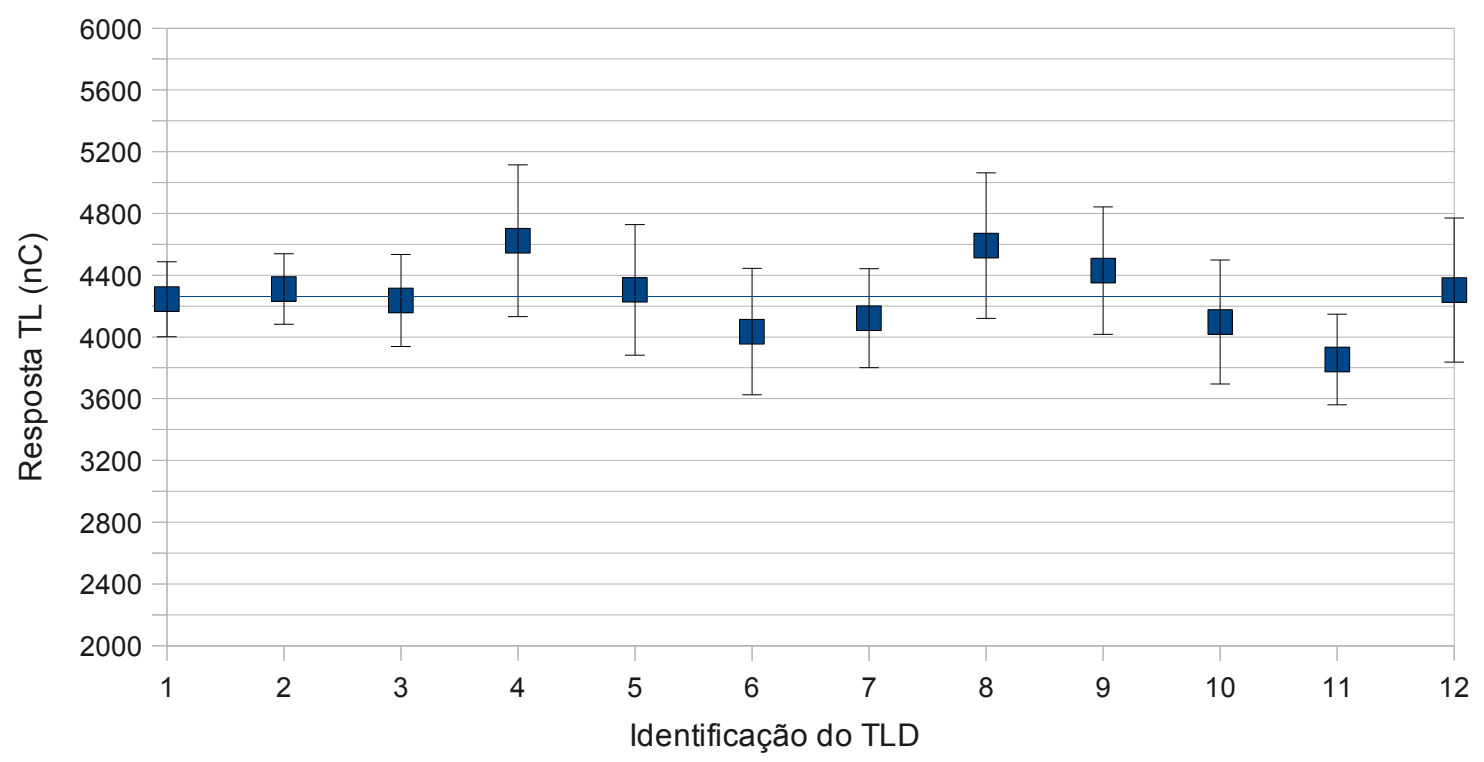

Figura 8.14. Resposta média dos TLDs 600 Selecionados.

Alguns TLDs apresentaram valores muito alto: o TLD 4 por exemplo, apresentou incerteza percentual de $10,61 \%$, estas pastilhas permitem o estabelecimento da metodologia para a utilização de TLDs para nêutrons na instalação. Por questões práticas, não foi possível diminuir a quantidade de pastilhas para melhorar o selecionamento, pois o número de irradiações necessária no simulador antropomórfico na instalação, levaria um tempo que não seria possível, devido a necessidade de compatibilizar o uso da instalação com os outros estudos em andamento.

Em seguida foi obtida, um fator individual para cada pastilha em relação ao valor médio, ou seja, dividiu-se o valor médio de reposta das 12 pastilhas, (4227 \pm 97$) \mathrm{nC}$, pela resposta de cada pastilhas, obtendo-se assim o chamado fator individual de cada pastilha. Os fatores estão apresentados na Tabela 8.7 . 
Tabela 8.7 - Fator individual de cada TLD.

\begin{tabular}{ccc}
\hline Pastilha & Fator individual & $\sigma_{\text {Fator Individual }}$ \\
\hline 1 & 1,00 & 0,06 \\
2 & 0,98 & 0,06 \\
3 & 1,00 & 0,07 \\
4 & 0,91 & 0,10 \\
5 & 0,98 & 0,10 \\
6 & 1,05 & 0,11 \\
7 & 1,03 & 0,08 \\
8 & 0,92 & 0,10 \\
9 & 0,95 & 0,09 \\
10 & 1,03 & 0,10 \\
11 & 1,10 & 0,09 \\
12 & 0,98 & 0,11 \\
\hline
\end{tabular}

Ao utilizar o fator individual a resposta da pastilha tem que ser multiplicada pelo seu respectivo fator. Na prática é difícil aplicar o fator individual, uma vez que os TLDs não poderão sair de ordem, e caso eventualmente eles saiam da ordem e não for possível identificar quais pastilhas foram trocadas, o fator individual terá que ser novamente determinado. Um método mais prático e seguro é calcular o fator de selecionamento ( $\mathrm{F}_{\text {selecionamento }}$ ), que é a média ponderada pela incerteza dos fatores individuais e pode-se aplicar em todos os TLDs. O valor do fator de selecionamento dos TLDs usados é $0,994 \pm 0,024$.

\subsubsection{Selecionamento TLDs 400 e 700}

O selecionamento dos TLDs 400 e 700 foram realizados em um trabalho anterior [35]. As pastilhas foram selecionadas utilizando fonte de ${ }^{60} \mathrm{Co}$ com um desvio padrão da média de $5 \%$. 


\subsubsection{Relação de Resposta Gama para os TLDs 600 e 700}

Como mostrado na seção 8.2.1 os TLDs 600 e 700 têm sensibilidades diferentes para radiação gama. Portanto, foi necessário medir o fator gama $\left(\mathrm{F}_{\text {gama }}\right)$, para equivalência da resposta gama do TLDs 600 com o 700 .

Para determinar o fator gama, que é a razão entre a resposta do TLD 600 e a reposta do TLD 700, todos os TLDs 600 e 700 selecionados foram irradiados na fonte panorâmica de ${ }^{60}$ Co no Centro de Tecnologia das Radiações (CTR) do IPEN, com doses absorvidas de: 5, 10 e $25 \mathrm{~Gy}$.

Na Tabela 8.8 são apresentados os valores da resposta dos TLDs e o fator gama para cada dose absorvida aplicada.

Tabela 8.8 - Fator gama para cada dose aplicada.

\begin{tabular}{cccccc}
\hline TLDs & Dose (Gy) & Resposta $(\mathbf{n C})$ & $\boldsymbol{\sigma}_{\text {Resposta }}$ & Fator Gama & $\boldsymbol{\sigma}_{\text {Fator Gama }}$ \\
\hline 600 & 5 & 121 & 6 & 1,71 & 0,17 \\
700 & 71 & 6 & & \\
\hline 600 & \multirow{2}{*}{10} & 258 & 25 & 1,70 & 0,23 \\
700 & & 152 & 14 & 1,63 & 0,17 \\
\hline 600 & \multirow{2}{*}{25} & 861 & 48 & & \\
700 & & 530 & 48 & & \\
\hline
\end{tabular}

Os valores obtidos para o fator gama mostraram uma boa reprodutibilidade considerando que a variação de dose aplicada e a incerteza é resultado da dispersão das respostas tanto dos TLD 600 quanto dos 700 .

O fator gama utilizado é a média ponderada pelas incertezas dos fatores gama para cada dose aplicada. O fator gama obtido da média ponderada foi $1,67 \pm 0,11$. 
Para subtrair a resposta gama do TLD 600 utilizando o TLD 700 é necessário multiplicar a resposta do TLD 700 pelo fator gama encontrado para equivaler à resposta gama do TLD 600 com o TLD 700.

\subsubsection{Calibração TLDs 400 e 700}

A calibração em relação à radiação gama dos TLDs 400 e 700 foi realizada utilizando a fonte panorâmica de ${ }^{60} \mathrm{Co}$ (Figura 8.15), do CTR. A taxa de dose para cada raio de irradiação ao redor da fonte é rastreada pela Agência Internacional de Energia Atômica (IAEA) através do programa IDAS (International Dose Assurance Service). Esta fonte tem uma incerteza de $1,7 \%$ do valor da dose absorvida quando aplicada aos materiais de dimensões reduzida como no caso dos TLDs.

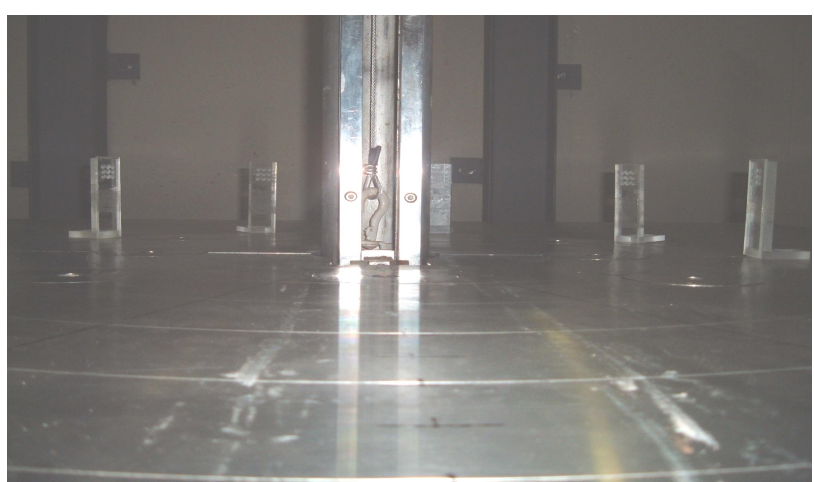

Figura 8.15. Fonte panorâmica de ${ }^{60} \mathrm{Co}$ do CTR.

a) Curva de Calibração dos TLDs 400

A curva de calibração dos TLDs 400 foi obtida utilizando-se doses absorvidas de $5,10,20,25,30,40,50,60,70$ e 80Gy. Foi aplicada uma regressão linear com o programa Origin 7.5 aos dados experimentais obtendo-se a reta apresentada na, Figura 8.16 . 


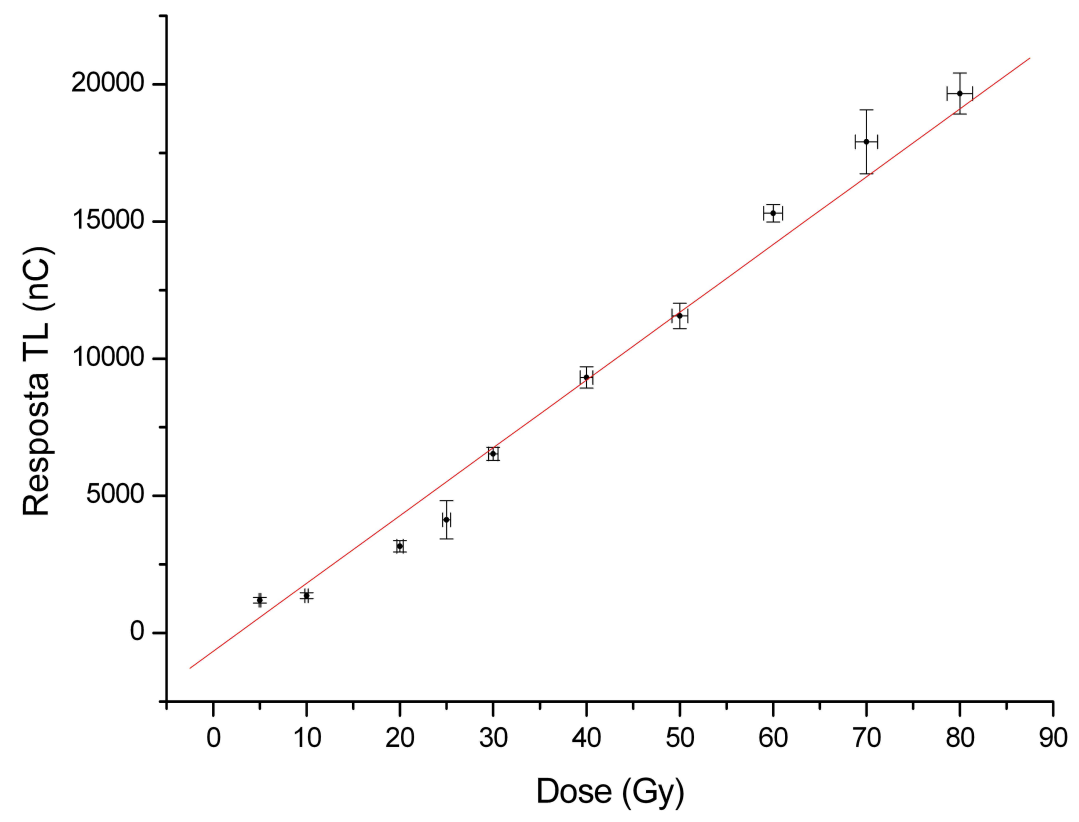

Figura 8.16. Curva de calibração para os TLDS 400.

A função ajustada foi:

$$
y=A+B \cdot x
$$

Tabela 8.9 - Valores dos parâmetros da calibração dos TLDs 400.

\begin{tabular}{cc}
\hline Parâmetro & Valor \\
\hline $\mathrm{A}$ & $(-662 \pm 89) \mathrm{nC}$ \\
$\mathrm{B}$ & $(247 \pm 4) \mathrm{nC} / \mathrm{Gy}$ \\
$\mathrm{R}^{2}$ & 0,9853 \\
\hline
\end{tabular}

Com o ajuste da curva de calibração é possível converter a resposta TL dos TLDs 400 em dose absorvida devido à radiação gama. 
b) Curva de Calibração dos TLDs 700

O TLD 700 possui uma resposta linear com a dose até 10Gy. Segundo o fabricante, acima de 10Gy o TLD apresenta um comportamento supra - linear, ou seja, os valores estão acima do que seria a continuação da reta. Na curva de calibração dos TLDs 700 foram usados 8 pontos de dose absorvida: 5, 10, 15, 20, 25, 30, 40 e 50Gy. Com os TLDs obteve-se uma resposta linear até 15Gy, Figura 8.17.

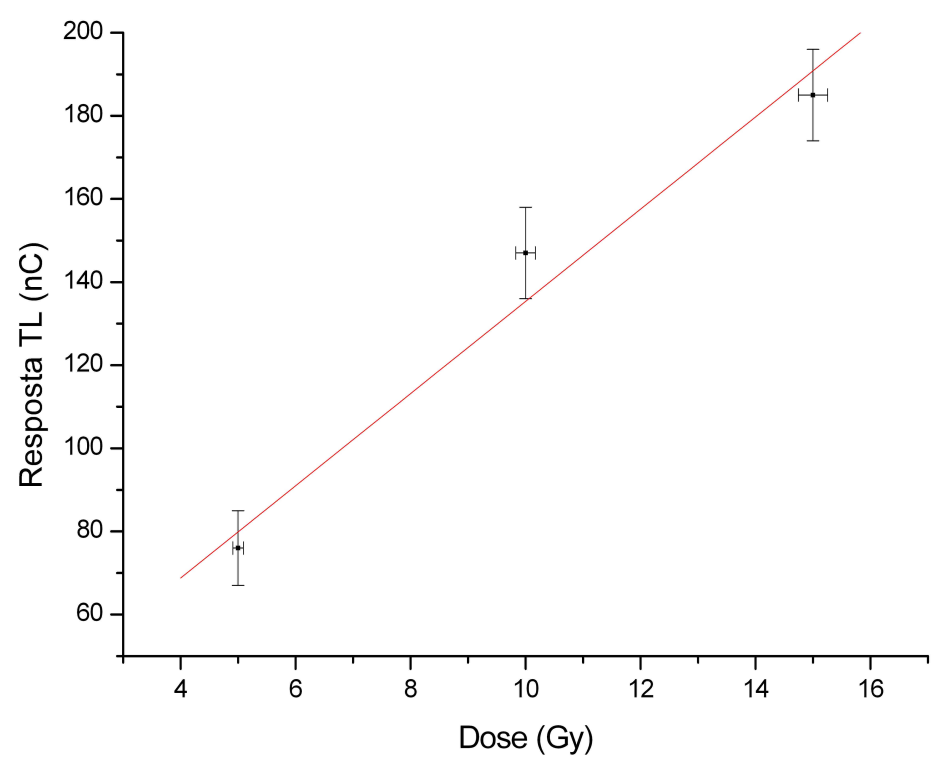

Figura 8.17. Curva de calibração dos TLDs 700 com ajuste linear.

A função ajustada foi:

$$
y=A+B \cdot x
$$

Tabela 8.10 - Valores dos parâmetros da calibração linear dos TLDs 700.

\begin{tabular}{cc}
\hline Parâmetro & Valor \\
\hline $\mathrm{A}$ & $(24 \pm 14) \mathrm{nC}$ \\
$\mathrm{B}$ & $(11,1 \pm 1,4) \mathrm{nC} / \mathrm{Gy}$ \\
$\mathrm{R}^{2}$ & 0,9870 \\
\hline
\end{tabular}


Acima desta dose tem-se a resposta supra - linear. Considerando todos os pontos foi realizado um ajuste polinomial conforme a Figura 8.18. Os dois ajustes são importantes para não limitar o uso do TLD 700 até a dose de 15Gy na instalação.

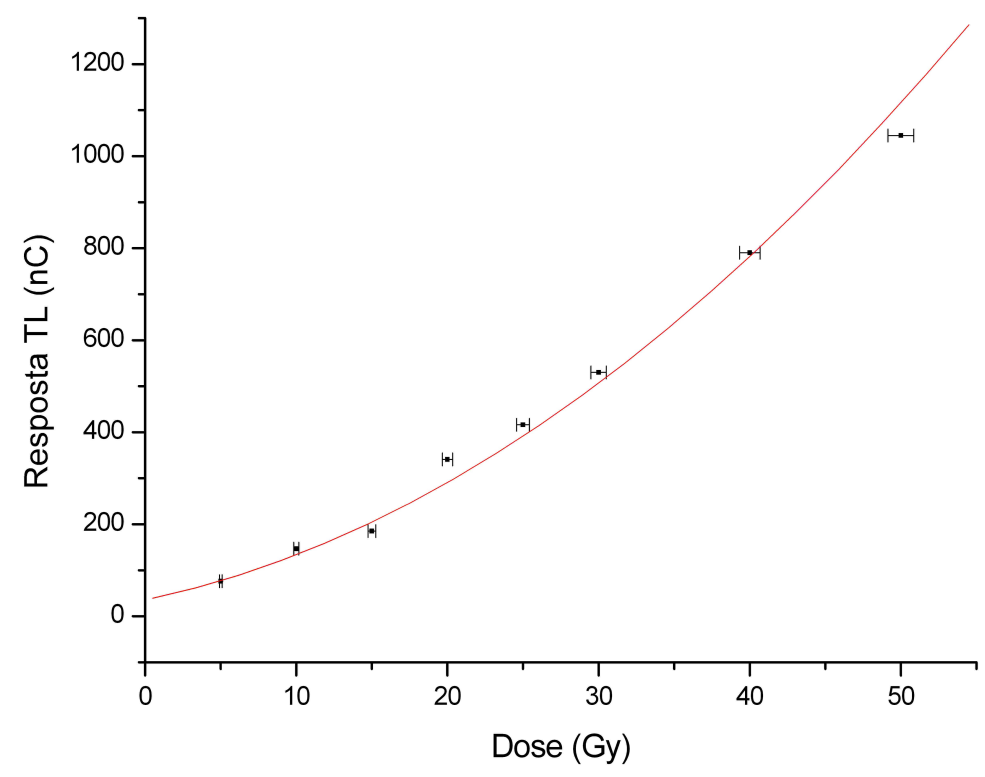

Figura 8.18. Curva de calibração dos TLDs 700 com ajuste polinomial.

A função ajustada foi:

$$
y=A+B_{1} x+B_{2} x^{2}
$$

Tabela 8.11 - Valores dos parâmetros da calibração polinomial dos TLDs 700.

\begin{tabular}{cc}
\hline Parâmetro & Valor \\
\hline $\mathrm{A}$ & $(36 \pm 17) \mathrm{nC}$ \\
$\mathrm{B}_{1}$ & $(7 \pm 2) \mathrm{nC} / \mathrm{Gy}$ \\
$\mathrm{B}_{2}$ & $(0,30 \pm 0,06) \mathrm{nC} / \mathrm{Gy}^{2}$ \\
$\mathrm{R}^{2}$ & 0,9822 \\
\hline
\end{tabular}


c) Curva de Calibração dos TLDs 600

Não é possível utilizar a fonte de AmBe na calibração do TLD 600 para aplicação na instalação, devido a sua baixa intensidade comparado com a posição de irradiação de amostra da instalação. Com a fonte de AmBe, o máximo que se obtém de dose para nêutrons térmico é alguns milésimos de Gray (mGy) com um tempo longo de exposição; enquanto na instalação, a dose é na ordem de Gray (Gy).

Portanto, para calibrar os TLDs 600 foi utilizada a própria instalação com o seguinte procedimento.

a) Antes da irradiação dos TLDs 600, eram irradiados um par de folhas de ativação e TLDs 400 durante vinte minutos e na mesma posição que seriam irradiados os TLDs 600, para monitorar o fluxo de nêutros e a dose devido a radiação gama, retirava-se o par de folhas e os TLDs 400 e eram colocados os TLDs 600 e 700 .

b) Irradiava-se os TLDs 600 simultaneamente com TLDs 700 .

c) Após a irradiação dos TLDs 600 e 700, um outro par de folhas de ativação e TLDs 400 eram novamente irradiados.

Este procedimento foi repetido para os tempos de irradiação de 30, 60, 90, 120, 180 e 240 minutos.

Com o fluxo de nêutrons térmicos avaliado com as folhas de ativação é possível determinar como apresentado no capítulo 4 a dose absorvida devido aos nêutrons térmicos que os TLDs 600 estiveram expostos. O fluxo médio durante a irradiação dos TLDs foi de $(3,52 \pm 0,04) \cdot 10^{8}\left(\mathrm{n} / \mathrm{cm}^{2} \mathrm{~s}\right)$, o fluxo térmico convertido em dose absorvida para cada tempo de irradiação está na Tabela 8.12. 
Tabela 8.12 - Dose absorvida devido a nêutrons térmicos, utilizando as folhas de Ouro.

\begin{tabular}{ccc}
\hline Tempo (minutos) & Dose Absorvida (Gy) & $\boldsymbol{\sigma}_{\text {Dose Absorvida }}$ \\
\hline 30 & 4,31 & 0,06 \\
60 & 8,61 & 0,11 \\
90 & 12,92 & 0,17 \\
120 & 17,22 & 0,22 \\
180 & 25,8 & 0,3 \\
240 & 34,4 & 0,4 \\
\hline
\end{tabular}

A resposta do TLD 600 considerando a sua reposta gama, o fator de selecionamento e o fator gama é dado por:

$$
R_{600 \mathrm{n}}=R_{600} \cdot F_{\text {selecionamento }}-R_{700} \cdot F_{\text {Gama }}
$$

onde:

$$
\begin{array}{ll}
R_{600 \mathrm{n}} & \text { resposta do TLD } 600 \text { devido a nêutrons térmicos; } \\
R_{600} & \text { resposta do TLD } 600 ; \\
F_{\text {selecionamento }} & \text { fator de selecionamento; } \\
R_{700} & \text { resposta do TLD } 700 \mathrm{e} \\
F_{\text {Gama }} & \text { fator gama. }
\end{array}
$$

Com a equação 8.7 e os valores de dose absorvida (Tabela 8.12), a reposta dos TLDs 600, devido a nêutrons térmicos, foi convertida em dose absorvida, obtendo-se a resposta dos TLDs em função da dose absorvida devido a nêutrons térmicos apresentada na Figura 8.19. 


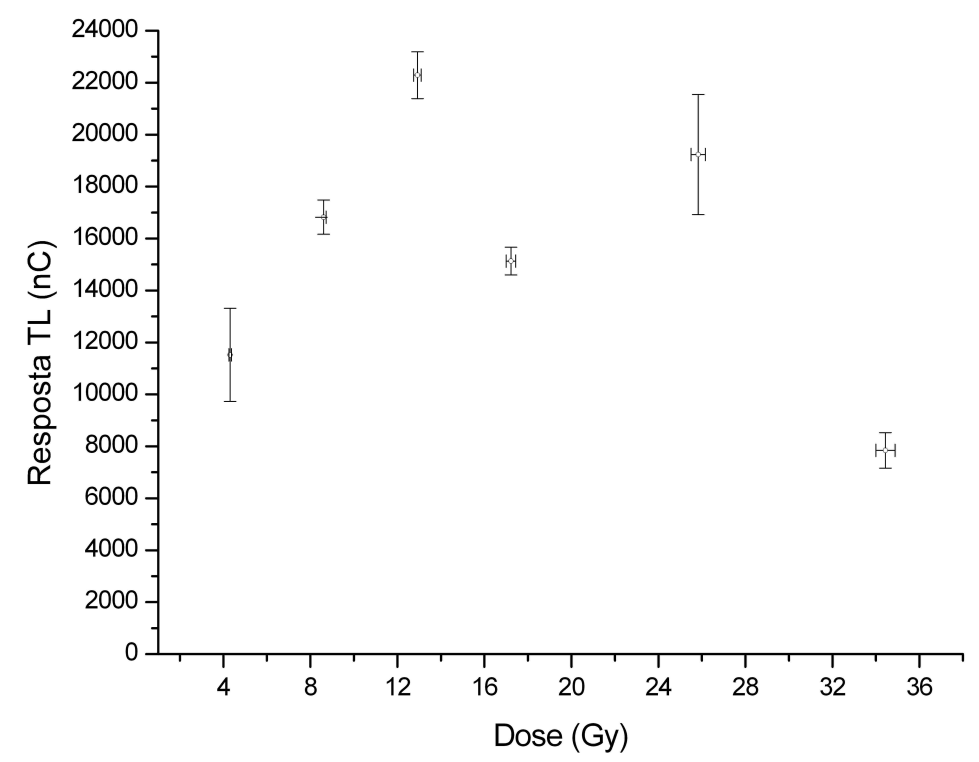

Figura 8.19. Resposta dos TLDs 600 em função da dose absorvida devido a nêutrons térmicos.

A resposta dos TLDs 600 (Figura 8.19) mostra que até a dose de 12,92Gy, que corresponde a irradiação de 90 minutos, a resposta do TLD 600 tem um comportamento linear. Para as doses acima deste valor a resposta dos TLDs diminui. O TLD 600 tem esse comportamento devido ao fato que, aumentando a dose, o pico da segunda região da curva TL também vai aumentando até chegar ao ponto em que tem a mesma altura que o da primeira região. Em noventa minutos de irradiação na instalação, o pico da segunda região atinge a altura da primeira como mostra a curva TL da Figura 8.20 de um dos TLDs 600 irradiados durante este tempo. 


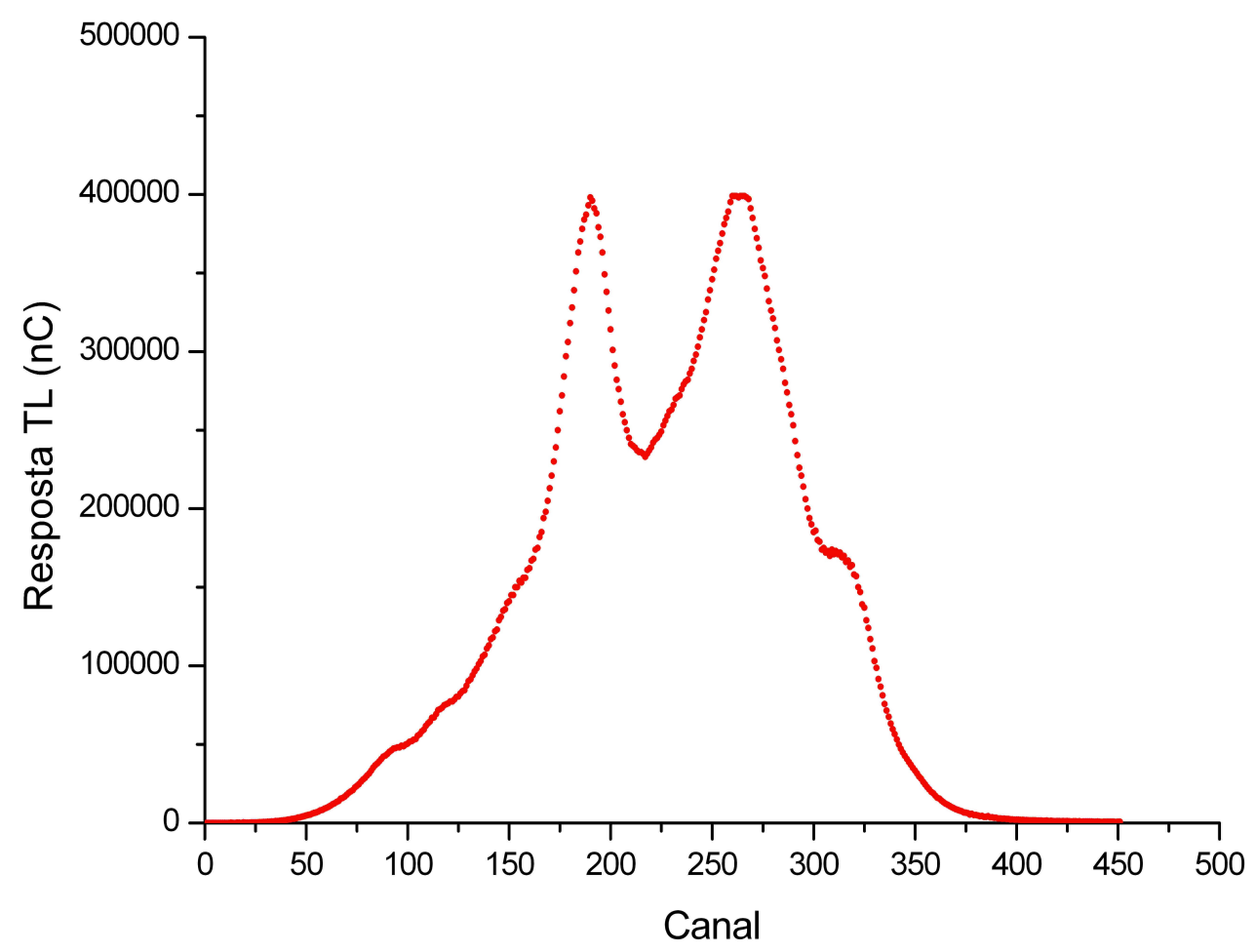

Figura 8.20. Curva TL de um dos TLDs 600 irradiados durante 90 minutos.

A partir do ponto em que o pico da segunda região atinge a altura da primeira, o TLD 600 satura, a área da segunda região aumenta e a da primeira diminui, o que ocorre acima do tempo de irradiação de noventa minutos. A Figura 8.21, explica o comportamento dos pontos da curva de calibração. Este fato impõem noventa minutos como um limite de tempo de irradiação do TLD 600 na instalação. 


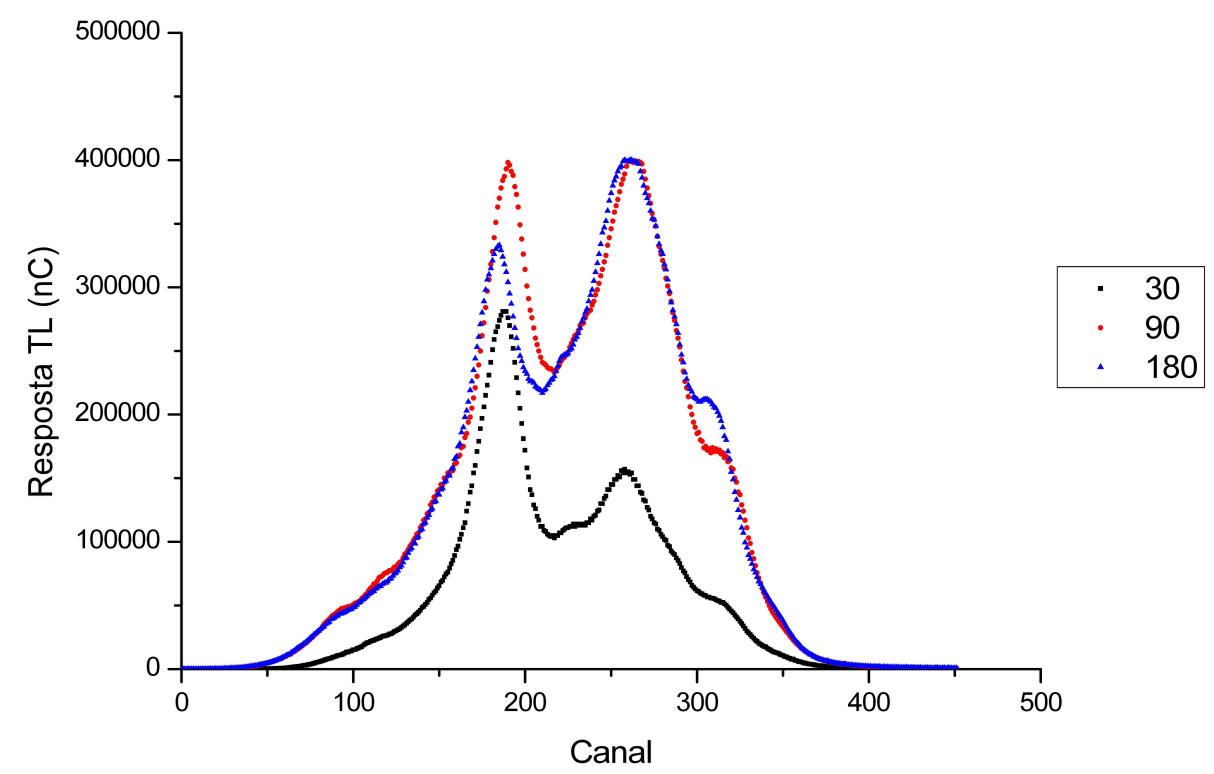

Figura 8.21. Curva TL dos TLDs 600 irradiados por 30, 90 e 180 minutos.

$\mathrm{Na}$ irradiação do simulador antropomórfico, o tempo de irradiação foi de 30 minutos, que está na região linear de resposta dos TLDs 600. Para utilizar a calibração dos TLDs 600 no simulador antropomórfico foi necessário normalizar a resposta dos TLDs, tanto na calibração, quanto na irradiação do simulador. No caso da calibração, as respostas foram normalizadas em relação ao primeiro ponto, que corresponde ao tempo de 30 minutos, pois este foi o tempo de irradiação do simulador antropomórfico. Com este procedimento a curva de calibração normalizada obtida é apresentada na Figura 8.22. 


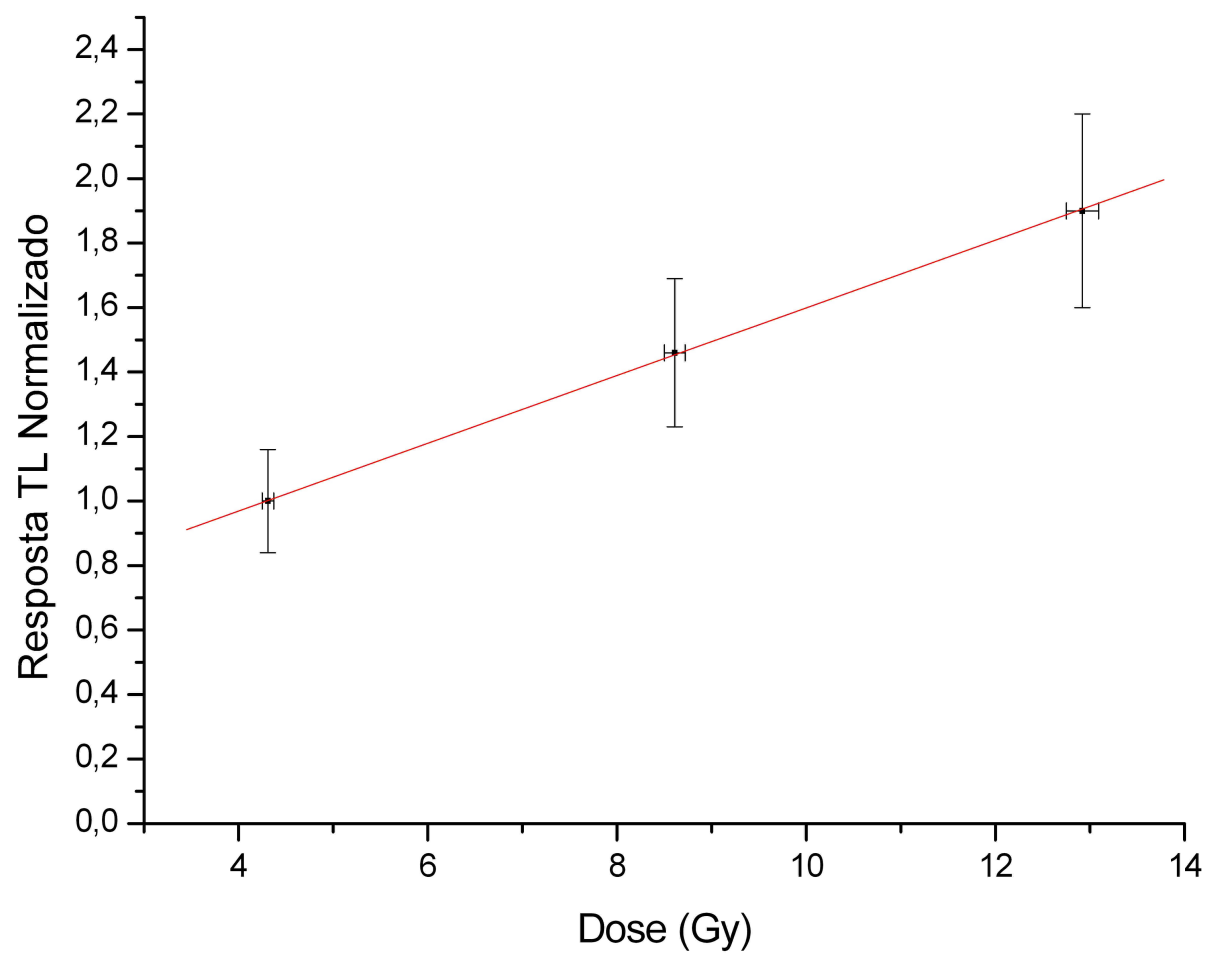

Figura 8.22. Curva de calibração normalizada dos TLDs 600.

A função ajustada foi:

$$
y=A+B \cdot x
$$

Tabela 8.13 - Valores dos parâmetros da calibração normalizada dos TLDs 600.

\begin{tabular}{cc}
\hline Parâmetro & Valor \\
\hline A & $0,55 \pm 0,28$ \\
B & $(0,11 \pm 0,04) \mathrm{Gy}^{-1}$ \\
$\mathrm{R}^{2}$ & 0,9999 \\
\hline
\end{tabular}

Com os TLDs 400, a taxa de dose absorvida devido à radiação gama verificada durante a calibração dos TLDs 600 foi de $(30,9 \pm 0,8) \mathrm{Gy} / \mathrm{h}$. 


\section{RESULTADOS E DISCUSSÃO}

O simulador antropomórfico foi preenchido com 20 discos correspondendo a $60 \mathrm{~mm}$ de acrílico. Os detectores de ativação e TLDs foram colocados nas posições correspondentes à 0 (sem acrílico na frente), 6, 12, 18, 24, 30, 36, 42 e 48 milímetros. Cada posição continha um par de folhas de ouro (com e sem cobertura de cádmio) e os TLDs 400, 600 e 700 que foram irradiados por 30 minutos. A quantidade de TLDs 600 e 700 disponíveis não permitiu a irradiação de todas as posições de uma vez, então as posições foram separadas em etapas. Na primeira etapa foram medidas as posições 0,18 e $36 \mathrm{~mm}$, na segunda etapa 6, 24 e 42mm e na terceira etapa 12, 30 e $48 \mathrm{~mm}$. Em todas às etapas o reator estava com potência de $3,5 \mathrm{MW}$.

O fluxo térmico, medido e simulado, em cada posição é apresentado na Figura 9.1. A partir do segundo ponto há uma boa concordância entre os valores medidos e calculados e nas posições finais, inclusive, os valores medidos e calculados se sobrepõem. A diferença observada entre os valores medidos e simulados esta na interface, na primeira e segunda posição. Essa diferença pode ser oriunda da mudança de meios na simulação ar para o acrílico. 


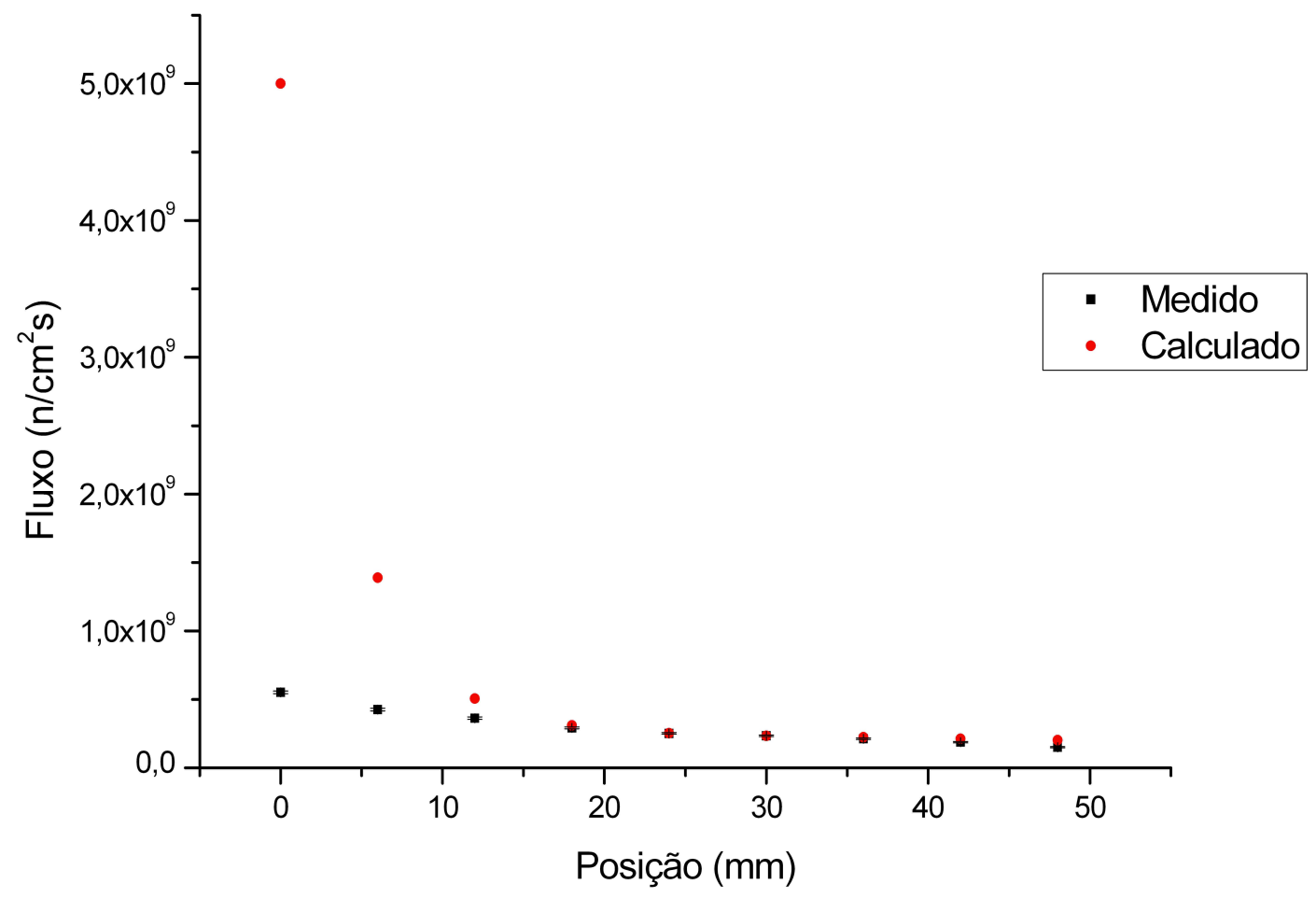

Figura 9.1. Fluxo térmico medido e calculado ao longo do simulador antropomórfico.

O fluxo epitérmico, Figura 9.2, apresenta o mesmo comportamento do fluxo térmico, com boa concordância na maioria das posições mas com discrepância nas duas primeiras posições (região de interface). 


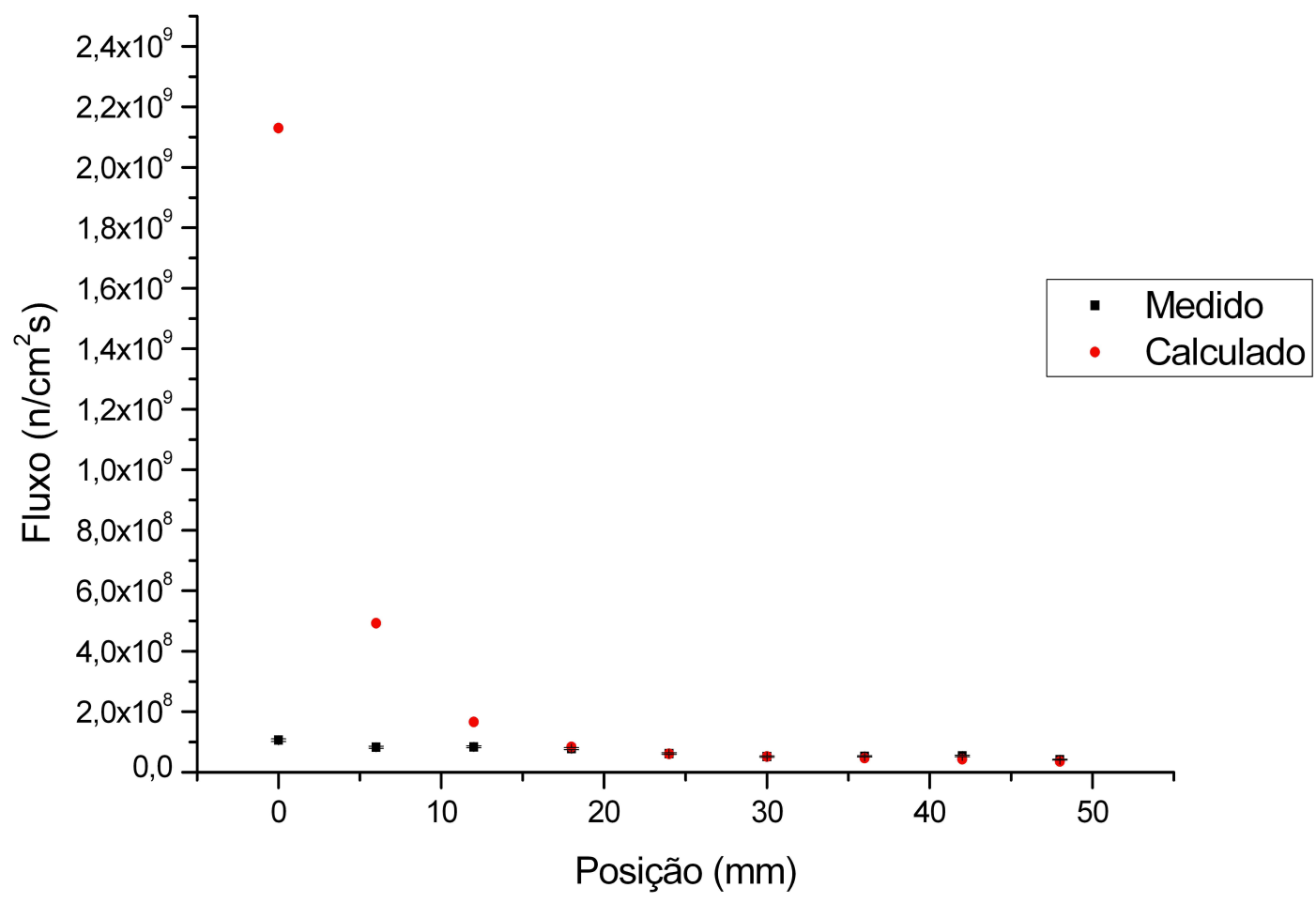

Figura 9.2. Fluxo epitérmico medido e calculado ao longo do simulador antropomórfico.

A dose absorvida devido aos nêutrons térmicos ao longo do simulador antropomórfico é apresentada na Figura 9.3. Devido às incertezas apresentadas pelos TLDs, os resultados têm uma grande variação de resposta, não permitindo observar o perfil de dose correspondente ao perfil calculado. 


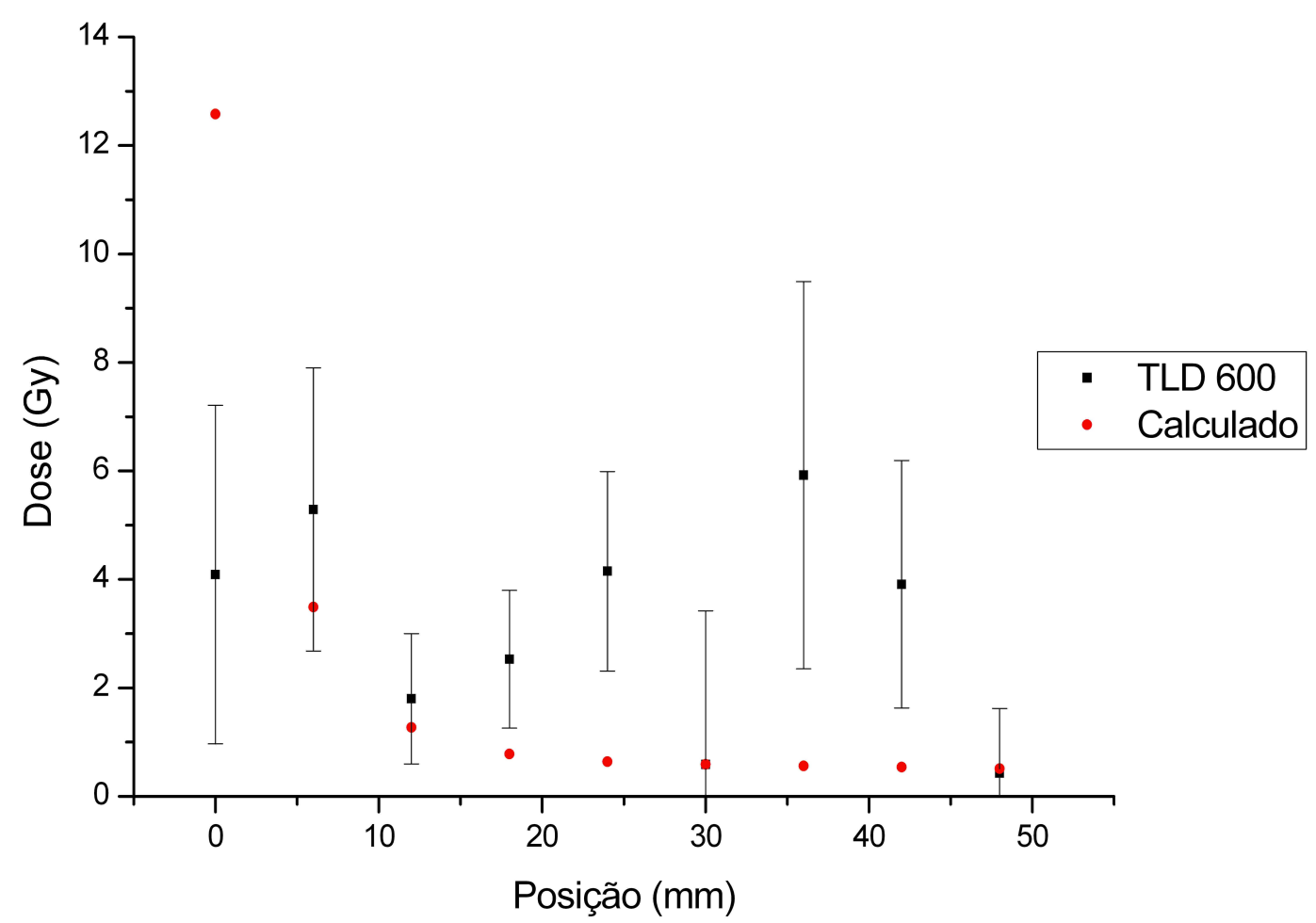

Figura 9.3. Dose absorvida devido aos nêutrons térmicos ao longo do simulador antropomórfico.

A dose absorvida devido à radiação gama ao longo do simulador antropomórfico é apresentada na Figura 9.4. As repostas dos TLDs 400 e 700 com os valores calculados mostram uma boa concordância nos valores das doses devida a radiação gama ao longo do simulador antropomórfico. Observa-se que no primeiro ponto as respostas dos TLDs 400 e 700 se sobrepõem. 


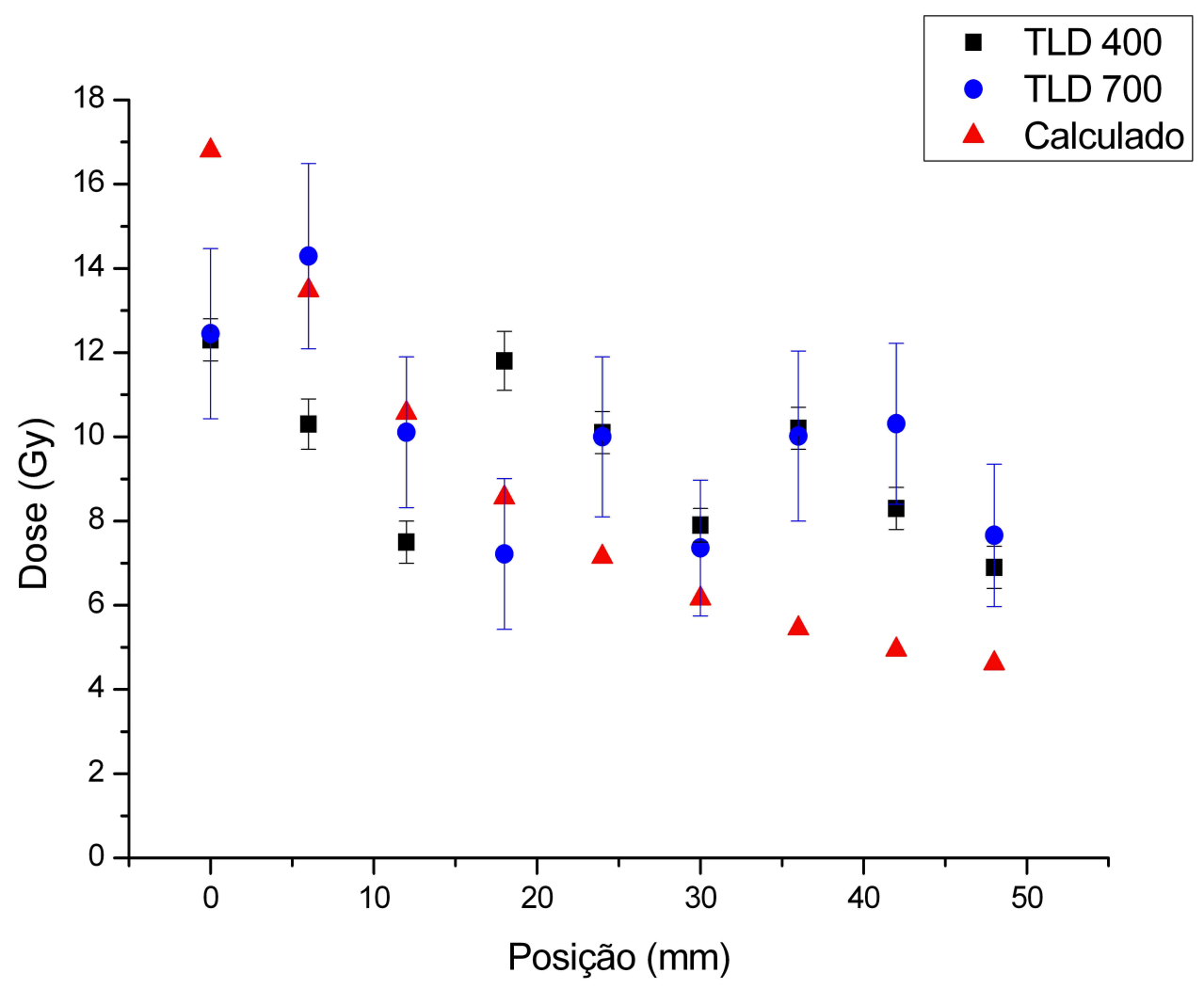

Figura 9.4. Dose absorvida devido à radiação gama ao longo do simulador antropomórfico.

A análise do comportamento das respostas dos TLDs utilizados mostra que é necessária uma melhor avaliação dos parâmetros importantes no processo de irradiação e leitura dos TLDs com a padronização destes parâmetros. Observou-se que no caso dos TLDs 600 é necessário monitorar eventuais mudanças na relação de nêutrons e gamas na composição do campo de radiação (Figura 8.21) [18].

$\mathrm{Na}$ posição correspondente a aproximadamente metade do simulador antropomórfico $(24 \mathrm{~mm})$ e para o tempo de 30 minutos de irradiação, observa-se uma boa relação entre os valores medidos e os calculados, tendo sido obtidos os seguintes valores medidos: fluxo de nêutrons térmicos $(2,52 \pm 0,06) \cdot 10^{8} \mathrm{n} / \mathrm{cm}^{2} \mathrm{~s}$, fluxo de nêutrons epitérmico $(6,17 \pm 0,26) \cdot 10^{7} \mathrm{n} / \mathrm{cm}^{2} \mathrm{~s}$, dose absorvida devido a nêutrons térmicos de $(4,2 \pm 1,8) \mathrm{Gy}$ e devido a radiação gama $(10,1 \pm 1,3) \mathrm{Gy}$. 
Os resultados obtidos mostram que, a posição de irradiação de mostra da instalação, possuí o fluxo de nêutrons térmicos apropriado para estudos em BNCT e nas áreas correlatas, e uma boa relação entre o fluxo térmico e epitérmico. Mas a dose devido a radiação gama está alta em relação a dose de nêutrons, portanto, é necessário estudos e implementação de melhorias na instalação para aprimorá-la para os estudos a serem realizados.

As discrepâncias encontradas nos valores medidos e calculados nos dois primeiros pontos dos fluxos térmicos e epitérmicos, Figura 9.1 e Figura 9.2, são objetos de estudo no momento e ainda não foi possível obter uma resposta satisfatória para reduzir esta discrepância. 


\section{CONCLUSÕES}

O objetivo deste trabalho, avaliar a adequação do campo de radiação na instalação para a realização de estudos na área de BNCT, foi atingido através das metas estabelecidas:

$1^{\mathrm{o}}$ Foi implantado, no Centro de Engenharia Nuclear do IPEN, um laboratório de dosimetria TL, com a obtenção da leitora TL e o estudo de seus parâmetros para leitura de TLDs 400, 600 e 700, e uma metodologia foi desenvolvida para trabalhar com estes TLDs em campo misto (nêutrons e gama) com altas taxas de dose. Os TLDs utilizados foram selecionados e calibrados e estão disponíveis para novos trabalhos na instalação.

$2^{\circ}$ Um simulador antropomórfico para a instalação foi desenvolvido e testado, com os atributos necessários, para ser colocado, irradiado e retirado da posição de irradiação de amostra com o reator em operação.

$3^{\circ}$ As medidas de fluxo de nêutrons térmicos e epitérmicos foram obtidas através da técnica de razão de cádmio com os detectores de ativação (folhas de ouro) utilizando-se o método apresentado neste trabalho. Este método pode ser aplicado em qualquer ponto dentro da instalação para avaliar o fluxo de nêutrons.

$4^{\mathrm{o}}$ Foram realizadas simulações computacionais para calcular perfis de fluxo e dose ao longo do simulador antropomórfico e da posição de irradiação de amostra.

Os valores obtidos mostram que os fluxos de nêutrons térmicos e epitérmicos são adequados para os estudos em BNCT, porém, a dose devido à radiação gama está elevada, indicando que a instalação deve ser aprimorada, com estudo de um novo conjunto de materiais para os filtros e moderadores.

A convergência entre os resultados medidos e calculados utilizando a técnica de detectores de ativação e a metodologia desenvolvida para os TLDs demostra que dispõem-se de ferramentas adequadas de medida e cálculo, porém para a continuidade do projeto é necessário estudos a respeito da discrepância entre os valores medidos e calculados na região de interface - entre o ar e o simulador antropomórfico. 
O desenvolvimento deste trabalho permite ao grupo de BNCT do IPEN avaliar e planejar as alterações necessárias para adequar o campo de radiação às condições necessárias para as pesquisas em BNCT e áreas correlacionadas. 


\section{SUGESTÃO DE TRABALHOS FUTUROS}

Para aprimorar os assuntos abordados neste trabalho os seguintes itens são sugeridos:

$1^{\circ}$ Avaliação do esmaecimento do TLD 400, para tempos curtos, na ordem de um dia. O esmaecimento é de $8 \%$ segundo o fabricante, o que pode inserir erros na resposta do TLD 400.

$2^{\circ}$ Estudo mais detalhado do comportamento do TLD 600 em campo misto, nêutrons e gama, e para irradiações com tempo maior que 90 minutos na instalação.

$3^{\circ}$ Realizar análise da resposta dos TLDs 600 para nêutrons epitérmicos.

$4^{\circ}$ Utilizar folhas de ouro infinitamente diluídas para evitar correção quanto aos efeitos de auto - blindagem das folhas de ouro hiper-puras.

$4^{\mathrm{o}}$ Desenvolver aplicações com o simulador antropomórfico direcionados aos estudos na área de BNCT.

$5^{\circ}$ Estudos na região de interface - ar acrílico, tanto na parte experimental quanto na de calculo, objetivando a melhoria na relação de resposta nesta região.

$6^{\circ}$ Aprimorar a instalação, tendo em vista aplicações em BNCT, com a melhoria na relação de dose devido aos nêutrons térmicos e à radiação gama, através de estudos de novos conjuntos de filtros, moderadores e blindagem. 


\section{REFERÊNCIAS BIBLIOGRÁFICAS}

1. HATANAKA, H. Boron - Neutron Capture Therapy for Tumors. Nishimura Co., Ltd., Niigata, Japan, 1986.

2. INTERNATIONAL ATOMIC ENERGY AGENCY. Current Status of Neutron Capture Therapy. IEA-TECDOC-1223, Vienna, 2001.

3. RILEY, K.J.; A New Option Against Cancer. 13 ${ }^{\text {th }}$ International Congress on Neutron Capture Therapy, 2-7 November, 2008, Florence, Italy. Proceedings, Comunicação Pessoal, 2008.

4. COELHO, P.R.P.; HERNANDES, A.C.; SIQUEIRA, P.T.D. Neutron Flux Calculation in a BNCT Research Facility Implemented in IEA-R1 Reactor. 10th International Congress on Neutron Capture Therapy, p. 8-13, 2002.

5. MESTINIK, F.J. A Distribuição Espacial do Fluxo de Nêutrons no Núcleo do Reator IEA-R1, Obtida por Meio da Ativação de Folhas. 1978. Dissertação (Mestrado) - Universidade de São Paulo, São Paulo.

6. BECKURTZ, K.H.; WIRTZ, K. Neutron Physics. New York. Berlin: Springer, 1964.

7. BITELLI, U.D'U. Medida e Cálculo da Distribuição Espacial e Energética de Nêutrons no Núcleo do Reator IEA - R1. 1988. Dissertação (Mestrado) - Instituto de Pesquisas Energéticas e Nucleares, São Paulo.

8. TAUHATA, L.; SALATI, I.P.A.; PRINZIO, R.Di.; PRINZIO, A.R.Di. Radioproteção e Dosimetria: Fundamentos. 5. revisão. Rio de Janeiro, R.J.: IRD/CNEN, 2003.

9. THE INTERNATIONAL COMMISSION ON RADIATION UNITS AND MEASUREMENTS. Determination of Operational Dose Equivalent Quantities for Neutrons. Bethesda, ICRU report nº6, v. 1, n. 3, England, 2001.

10. AMERICAN NATIONAL STANDARD. Neutron and Gamma-Ray Flux-to-DoseRate Factors, ANSI/ANS-6.1.1, 1997.

11. Thermo Electron Corporation, disponível em: $<$ www.thermo.com/rmp $>$ acesso em: maio 2010. 
12. MCKEEVER, S.W.; MOSCOVITCH, M.; TOWNSEND, P.D.; Thermoluminescence Dosimetry Materials: properties and uses. Ashford, Nuclear Techn. Pub, 1995.

13. MARIN, A.V. Desenvolvimento de um sistema dosimétrico postal para uso em programas de qualidade em radioterapia com feixes de fótons em condições de não referência. 2003. Dissertação (Mestrado) - Instituto Nacional de Câncer, Rio de Janeiro.

14. BOS, A. J. J. Theory of Thermoluminescence. Radiation Measurements. Radiation Measurements, v. 41, p. 45- 56, 2007.

15. TUGAY H.; YEGINGIL, Z.; DOGAN, T.; NUR, N.; YAZICI, N. The thermoluminescent properties of natural calcium fluoride for radiation dosimetry. Nucl. Instrum. Methods Phys. Res., v. 267, p. 3640-3651, 2009.

16. KAFADAR, E. V.; YAZICI, N. A.; YILDIRIM, G. R. The effects of heating rate on the dose response characteristics of TLD-200, TLD-300 and TLD-400. Nucl. Instrum. Methods Phys. Res., v. 267, p. 3337-3346, 2009.

17. OBERHOFER, M.; SCHARMANN, A. Applied Thermoluminescence Dosimetry. Ispra Courses, Italy:Adam Hilger Ltd, Bristol, 1979.

18. TRIOLO, A.; BRAI, M.; MARRALE M.; GENNARO G.; BARTOLOTTA A. Study of the Glow Curves of TLD Exposed to Thermal Neutrons. Radiation Protection Dosimetry, v. 126, p. 333-336, 13 May 2007. No. 1-4

19. DOUGLAS, J. A. The Applications of TL Materials in Neutron Dosimetry. 1978. Microficha (AERE-R-9196).

20. Dados Nucleares, disponível em: $<$ http://atom.kaeri.re.kr $>$ acesso em: maio 2010.

21. DELGADO, A.; MUÑIZ, J. L.; GÓMEZ J. M. R.; ROMERO, A. M.; RODRIGUES, R. On the Use of LIF TLD-600 in Neutron-Gamma Mixed Fields. Radiation Protection Dosimetry, v. 125, p. 327-330, 19 June 2007. No. 1-4.

22. OAK RIDGE NATIONAL LABORATORY. DOT 3.5 Two Dimensional Discrete ordinates Radiation Transport Code; (CCC-276), Radiation Shielding Information Center, Los Alamos, New Mexico, 1975.

23. SILVA, G.S.A.; COELHO, P.R.P.; SIQUEIRA, P.T. Shielding Desing For Research Facility in the IEA-R1 Reator. PHYSOR, p. 7-10, 2002. 
24. DAMY, M. A.; Bitelli, U. D.; MENDOnÇA, A. G.; SANTOS, A. Cálculo de Taxas de Reação em Folhas de Ativação no Interior do "Beam Hole" Número 8 do Reator IEA-R1 Utilizando o Código de Transporte de Radiação DOT-3.5. IX Encontro Nacional de Física de Reatores e Termo-Hidráulica, p. 212-217, 1993.

25. R. W. Roussin et all red. VITAMIN-C - 171 Neutron, 36 Gamma-Ray Group Cross Section on AMPX and CCC Interface Formats for Fusion and LMFBR Neutronic. DCL-41. ORNL, July 1980.

26. KNOLL, G. F. Radiation Detection and Measurement. 2.ed. New York: John Wiley \& Sons, 1989.

27. FANARO, L.C.C.B. Determinação Experimental de Índices Espectrais por Varredura Gama de Vareta Combustível no Reator IPEN/MB-01. 2009. Tese (Doutorado) - Instituto de Pesquisas Energéticas e Nucleares, São Paulo.

28. Software User's Manual. MCA Emulator for Microsoft Windows 95, 98 e NT. ORTEC Part N. 77800. A65-B32.

29. Origin V75 User's Manual, disponível em: $<$ http://www.originlab.com $>$ acesso em: setembro 2008.

30. Victorren. Installation, Operation, and Maintenance Instruction Manual. Published 1996, Victorren, INC. Printed in U.S.A.

31. BENITES, B.D.; MUNIZ, R.O.R.; COELHO, P.R.P. Caracterização de dose em campo misto de radiação utilizando dosímetros termoluminescentes na instalação para estudos em BNCT. International Nuclear Atlantic Conference, Rio de Janeiro, R.J., 2009.

32. Radiation Sources Industrial Laboratory, The Radiochemical Center, Amersham, Bucks, England. 1977/8.

33. LORCH, E. A. Int. J. Appl. Radiat. Isotopes, v. 24, p. 588-9, 1973.

34. SOUTO, E. B. Projeto, Construção e Caracterização de um Dosímetro para Radiação de Nêutrons. 2007. Dissertação (Mestrado) - Instituto de Pesquisas Energéticas e Nucleares. São Paulo.

35. JUNIOR, V.C. Caracterização do campo de nêutrons na instalação para estudo em BNCT no Reator IEA-R1. 2008. Dissertação (Mestrado) - Instituto de Pesquisas Energéticas e Nucleares. São Paulo. 